\title{
1 A catalog of associations between rare coding variants and COVID-19 outcomes
}

2 J. A. Kosmicki ${ }^{1 \dagger}$, J. E. Horowitz ${ }^{1 \dagger}$, N. Banerjee ${ }^{1}$, R. Lanche ${ }^{1}$, A. Marcketta ${ }^{1}$, E. Maxwell $^{1}$, X. Bai ${ }^{1}$,

3 D. Sun ${ }^{1}$, J. D. Backman ${ }^{1}$, D. Sharma ${ }^{1}$, H. M. Kang ${ }^{1}$, C. O’Dushlaine ${ }^{1}$, A. Yadav ${ }^{1}$, A. J. Mansfield ${ }^{1}$,

4 A. H. Li ${ }^{1}$, K. Watanabe ${ }^{1}$, L. Gurski ${ }^{1}$, S. E. McCarthy ${ }^{1}$, A. E. Locke ${ }^{1}$, S. Khalid ${ }^{1}$, S. O’Keeffe ${ }^{1}$, J.

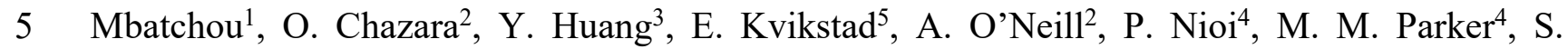

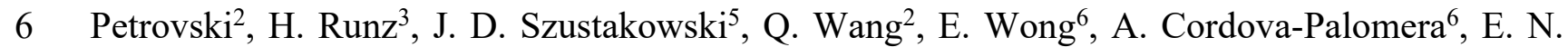

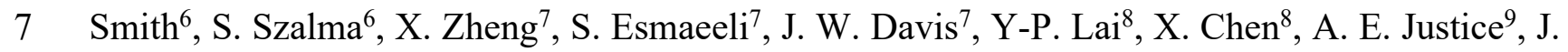

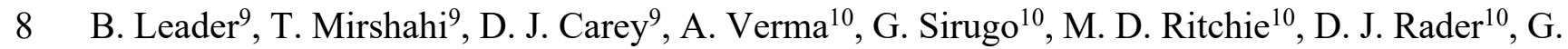

9 Povysil $^{11}$, D. B. Goldstein ${ }^{11,12}$, K. Kiryluk ${ }^{11,13}$, E. Pairo-Castineira ${ }^{14,15}$, K. Rawlik ${ }^{14}$, D. Pasko ${ }^{16}$, S.

10 Walker $^{16}$, A. Meynert ${ }^{15}$, A. Kousathanas ${ }^{16}$, L. Moutsianas ${ }^{16}$, A. Tenesa ${ }^{14,15,17}$, M. Caulfield ${ }^{16,18}$, R.

11 Scott $^{16,19}$, J. F. Wilson ${ }^{15,17}$, J. K. Baillie ${ }^{14,15,20}$, G. Butler-Laporte ${ }^{21,22}$, T. Nakanishi ${ }^{21,23-25}$, M.

12 Lathrop ${ }^{23,26}$, J.B. Richards ${ }^{21-23,27}$, Regeneron Genetics Center*, UKB Exome Sequencing

13 Consortium*, M. Jones ${ }^{1}$, S. Balasubramanian ${ }^{1}$, W. Salerno ${ }^{1}$, A. R. Shuldiner ${ }^{1}$, J. Marchini ${ }^{1}$, J. D.

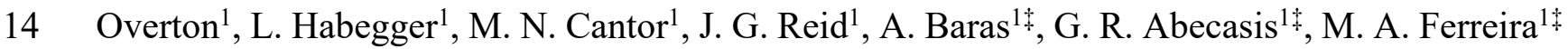

16 From:

$17{ }^{1}$ Regeneron Genetics Center, 777 Old Saw Mill River Rd., Tarrytown, NY 10591, USA

$18{ }^{2}$ Centre for Genomics Research, Discovery Sciences, BioPharmaceuticals R\&D, AstraZeneca,

19 Cambridge CB2 0AA, UK

$20 \quad{ }^{3}$ Biogen, 300 Binney St, Cambridge, MA 02142, USA

$21{ }^{4}$ Alnylam Pharmaceuticals, 675 West Kendall St, Cambridge, MA 02142, USA

$22{ }^{5}$ Bristol Myers Squibb, Route 206 and Province Line Road, Princeton, NJ 08543, USA

$23{ }^{6}$ Takeda California Inc., 9625 Towne Centre Dr, San Diego, CA 92121, USA 
$24 \quad{ }^{7}$ AbbVie, Inc., 1 N. Waukegan Rd, North Chicago, IL 60064, USA

$25{ }^{8}$ Pfizer, Inc., 1 Portland Street, Cambridge MA 02139, USA

$26{ }^{9}$ Geisinger, Danville, PA, 17822, USA

$27{ }^{10}$ Department of Genetics, Perelman School of Medicine, University of Pennsylvania,

28 Philadelphia, PA, 19104, USA

$29{ }^{11}$ Institute for Genomic Medicine, Columbia University Irving Medical Center, New York, NY

$30 \quad 10032$, USA

$31{ }^{12}$ Department of Genetics \& Development, Columbia University, New York, NY 10032, USA

$32{ }^{13}$ Division of Nephrology, Department of Medicine, Vagelos College of Physicians \& Surgeons,

33 Columbia University, New York, NY 10032, USA

$34{ }^{14}$ Roslin Institute, University of Edinburgh, Easter Bush, Edinburgh, EH25 9RG, UK

$35{ }^{15}$ MRC Human Genetics Unit, Institute of Genetics and Molecular Medicine, University of

36 Edinburgh, Western General Hospital, Crewe Road, Edinburgh, EH4 2XU, UK

$37{ }^{16}$ Genomics England, London EC1M 6BQ, UK

$38{ }^{17}$ Centre for Global Health Research, Usher Institute of Population Health Sciences and

39 Informatics, Teviot Place, Edinburgh EH8 9AG, UK

$40{ }^{18}$ William Harvey Research Institute, Barts and the London School of Medicine and Dentistry,

41 Queen Mary University of London, London EC1M 6BQ, UK

$42{ }^{19}$ Great Ormond Street Hospital for Children NHS Foundation Trust, London WC1N 3JH, UK

$43{ }^{20}$ Intensive Care Unit, Royal Infirmary of Edinburgh, 54 Little France Drive, Edinburgh, EH16

44 5SA, UK

$45 \quad{ }^{21}$ Lady Davis Institute, Jewish General Hospital, Montréal, Québec H3T 1E2, Canada

$46{ }^{22}$ Department of Epidemiology, Biostatistics and Occupational Health, McGill University,

47 Montréal, Québec H3A 0G4, Canada 
$48 \quad{ }^{23}$ Department of Human Genetics, McGill University, Montréal, Québec H3A 0G4, Canada

$49{ }^{24}$ Kyoto-McGill International Collaborative School in Genomic Medicine, Graduate School of

50 Medicine, Kyoto University, Kyoto 606-8501, Japan

$51 \quad{ }^{25}$ Research Fellow, Japan Society for the Promotion of Science

$52{ }^{26}$ Canadian Centre for Computational Genomics, McGill University, Montréal, Québec H3A

53 0G4, Canada

$54 \quad{ }^{27}$ Department of Twins Research, King's College London, London WC2R 2LS, UK

55

$56 *$ A complete list of investigators is provided in the Supplementary Appendix.

57 †. A. Kosmicki and J. E. Horowitz contributed equally to this manuscript.

$58 \ddagger$ A. Baras, G. R. Abecasis and M. A. Ferreira jointly supervised this work.

59 Correspondence to: manuel.ferreira@regeneron.com and goncalo.abecasis@regeneron.com

60 This research has been conducted using the UK Biobank Resource (Project 26041) 


\section{ABSTRACT}

62 Severe acute respiratory syndrome coronavirus-2 (SARS-CoV-2) causes coronavirus disease-19

63 (COVID-19), a respiratory illness that can result in hospitalization or death. We investigated

64 associations between rare genetic variants and seven COVID-19 outcomes in 543,213 individuals,

65 including 8,248 with COVID-19. After accounting for multiple testing, we did not identify any

66 clear associations with rare variants either exome-wide or when specifically focusing on (i) 14

67 interferon pathway genes in which rare deleterious variants have been reported in severe COVID-

6819 patients; (ii) 167 genes located in COVID-19 GWAS risk loci; or (iii) 32 additional genes of

69 immunologic relevance and/or therapeutic potential. Our analyses indicate there are no significant

70 associations with rare protein-coding variants with detectable effect sizes at our current sample

71 sizes. Analyses will be updated as additional data become available, with results publicly

72 browsable at https://rgc-covid19.regeneron.com. 
75 The severe acute respiratory syndrome coronavirus 2 (SARS-CoV-2) [1] causes coronavirus

76 disease 2019 (COVID-19) [2]. COVID-19 ranges in clinical presentation from asymptomatic

77 infection to flu-like illness with respiratory failure, hyperactive immune responses and death [3-

78 5]. It is currently estimated that SARS-CoV-2 has infected $>100$ million individuals and has been

79 attributed to $>2$ million recorded deaths worldwide. Known risk factors for severe disease include

80 male sex, older age, ancestry, obesity and underlying cardiovascular, renal, and respiratory

81 diseases [6-9], among others.

83 Since the start of the SARS-CoV-2 pandemic, host genetic analysis of common genetic variation 84 among SARS-CoV-2 patients have identified at least nine genome-wide significant loci that modulate COVID-19 susceptibility and severity, including variants in/near LZTFL1, IFNAR2, DPP9 and the HLA region [10-13]. However, to date, there has been no assessment of the contribution of rare genetic variation to COVID-19 disease susceptibility or severity through large population-based exome-wide association analyses.

To identify rare variants (RVs, minor allele frequency $[\mathrm{MAF}]<1 \%$ ) associated with COVID-19

91 susceptibility and severity, we generated exome-wide sequencing data for 543,213 individuals

92 from three studies (Geisinger Health System [GHS], Penn Medicine BioBank [PMBB] and UK

93 Biobank $[\mathrm{UKB}]$ ) and three ancestries (African, European and South Asian) (Supplementary

94 Table 1). Of these, 8,248 had COVID-19, and among those 2,085 (25.28\%) were hospitalized and

$95590(7.15 \%)$ had severe disease (i.e. requiring ventilation or resulting in death; Supplementary

96 Table 2). Using these data, we tested the association between RVs and seven COVID-19 
medRxiv preprint doi: https://doi.org/10.1101/2020.10.28.20221804; this version posted February 28, 2021. The copyright holder for this preprint (which was not certified by peer review) is the author/funder, who has granted medRxiv a license to display the preprint in perpetuity.

It is made available under a CC-BY-ND 4.0 International license .

97 outcomes: five related to disease susceptibility and two related to disease severity among COVID-

9819 cases (Supplementary Table 3). In a separate paper [13], we used these same phenotypes to

99 validate the association with common risk variants reported in previous COVID-19 GWAS[10-

100 12], thus demonstrating that our phenotypes are calibrated with those used in other studies.

101

102 For each phenotype, exome-wide association analyses were performed separately in each study

103 and ancestry using REGENIE[14], testing single RVs ( 7 million) and a burden of RVs in 18,886

104 protein-coding genes. The genomic inflation factor $\left(\lambda_{\mathrm{GC}}\right)$ for $\mathrm{RVs}$ was often $<1$ in individual

105 studies, caused by a large proportion of variants having a minor allele count (MAC) of 0 in cases

106 (Supplementary Table 4). In meta-analyses across studies and ancestries, we found no RV

107 associations at a conservative $P<9.6 \times 10^{-10}$, which corresponds to a Bonferroni correction for the

108 number of variants and traits tested. The most significant associations with RVs are listed in Table

109 1, all observed with our COVID-19 hospitalization phenotype (2,085 hospitalized cases vs.

110534,965 COVID-19 negative or unknown controls). Of these, we highlight an association with an

$111 \mathrm{RV}$ in the promoter of EEF2 (rs532051930:A, MAF=0.003\%, OR=93.9, 95\% CI 20.3-434.5,

$112 P=6.2 \times 10^{-9}$; Supplementary Figure 1A), a translation elongation factor which plays a key role in

113 viral replication[15, 16].

114

115 Despite not reaching our threshold for genome-wide significance, we highlight the association

116 with EEF2 because: (i) it was supported by two independent studies (Supplementary Figure 1B);

117 (ii) five additional RVs in the 89 bp promoter of EEF2 (out of 50 tested) had an independent and

118 directionally-consistent predisposing association with the same hospitalization phenotype

119 ( $P<0.05$; Supplementary Table 5); (iii) rs532051930 is predicted by DeepSEA [17] to be a 
120 regulatory variant and to disrupt binding of several transcription factors, including GABP, which

121 has been linked to RV-induced aberrant gene expression [18]; (iv) rs532051930 is located at the

122 peak of the transcription initiation region for EEF2 (Supplementary Figure 1C) [19], suggesting

123 that it might affect RNA polymerase II binding; and (v) among a subset of 1,988 individuals with

124 available RNA-seq data from liver tissue, the only individual who was a carrier for rs532051930:A

125 had the second highest expression of EEF2 (Supplementary Figure 1D). These results raise the 126 possibility that rs532051930 and potentially other promoter RVs increase EEF2 transcription and, 127 consequently, increase risk of hospitalization due to SARS-CoV-2 infection.

129 Given these supporting observations and the established role of EEF2 in viral replication, we

130 studied the genetic association with rs532051930 in greater detail, to understand if it was likely to

131 be a true-positive association. First, we reviewed sequencing reads for all 26 carriers of this variant,

132 to visually validate the heterozygote genotype call produced by the calling algorithm. Sequencing

133 reads were consistent with a heterozygote call for all 26 individuals. Second, we determined if the

134 association with this rare variant was robust to the association test used (Supplementary Table

135 6). A Firth test applied to a joint analysis of data across the two studies, adjusting for study specific

136 covariates as an offset, resulted in $P=5.5 \times 10^{-8}$. Similar results were obtained by: (i) an

137 approximation to this approach, which combines log-likelihood curves calculated at a grid of

138 values with the Firth penalty, applied using approximate derivatives; (ii) a $P$-value-based meta-

139 analysis, for which there is evidence of better type-I error control [20]; and (iii) the BinomiRare

140 test [21], which uses a test statistic based on allele counts in cases only, adjusts for covariates and

141 combines data across studies. We also applied tests without covariates and these uniformly led to

142 less significant associations, but this is expected since the covariates explain variation in the 
medRxiv preprint doi: https://doi.org/10.1101/2020.10.28.20221804; this version posted February 28, 2021. The copyright holder for this preprint (which was not certified by peer review) is the author/funder, who has granted medRxiv a license to display the preprint in perpetuity.

It is made available under a CC-BY-ND 4.0 International license .

143 phenotype. Third, we attempted to replicate this association by querying whether this variant was

144 present in an additional 4,341 COVID-19 cases with exome- or whole-genome sequence data

145 generated as part of the GenOMICC $(n=2,969)$ [11], Columbia University COVID-19 Biobank

$146(n=1,152)$ and Biobanque Quebec $(n=220)[22]$ studies. We found no carriers for this variant in

147 these additional COVID-19 cases (Supplementary Table 7). Given these findings, we conclude

148 that it is not certain that there is a true association between rs532051930 and COVID-19 risk,

149 illustrating the importance of replication.

151 Next, we addressed the possibility that associations with protein-coding RVs might help pinpoint

152 target genes of common risk variants identified in GWAS of COVID-19. To this end, we focused

153 on 167 genes located within $500 \mathrm{~kb}$ of the nine common variants associated with COVID-19

154 hospitalization in a separate analysis [13]. Of the 334 gene burden tests performed (167 genes x 2

155 burden tests), which considered both $\mathrm{pLoF}$ variants alone (M1 burden test) or pLoF plus

156 deleterious missense variants (M3 burden test), 17 had a nominally significant association with the

157 same COVID-19 hospitalization phenotype (Supplementary Table 6). Of these, burden tests for

158 one gene $-C H A F 1 A\left(\mathrm{OR}=25\right.$ for the M1 burden test, 95\% CI 4.9-128.5, $\left.P=1.0 \times 10^{-4}\right)-$ remained

159 borderline significant after correcting for the 334 tests performed $\left(P<0.05 / 334=1.5 \times 10^{-4}\right)$.

160 CHAF $1 A$ is located $317 \mathrm{~kb}$ from the lead common variant at locus 19p13.3 [13], is highly

161 expressed in EBV-transformed B-cells [23] and encodes a component of the chromatin assembling

162 factor complex that affects cell differentiation, including the differentiation of pre-B cells into B-

163 cells and macrophages [24]. 
165 We then examined the association with 14 genes in the interferon pathway, given recent reports

166 that deleterious RVs in these genes may be implicated in severe clinical outcomes [25, 26]. Given

167 the larger sample size in our studies, we examined whether there was any evidence for association

168 between the COVID-19 hospitalization phenotype (2,085 cases vs. 534,965 controls) and the

169 burden of rare $(\mathrm{MAF}<0.1 \%) \mathrm{pLoF}$ variants (M1 burden test) or $\mathrm{pLoF}$ plus deleterious missense

170 variants (M3 burden test) in these 14 genes, three of which are located within $500 \mathrm{~kb}$ of a COVID-

17119 GWAS risk variant (IFNAR1, IFNAR2 and TICAM1). Of the 14 genes, only two genes had a

172 nominal significant association: STAT2 and TLR7 (Table 2). However, neither remained

173 significant after correcting for the 28 tests performed (both with $P>0.05 / 28=0.0018$ ). Further, these

174 results were unchanged when testing COVID-19 severe cases $(\mathrm{N}=590)$, or when restricting the

175 burden tests to include variants with a MAF $<1 \%$ or singleton variants (Supplementary Table 7).

176 Therefore, as recently reported by others [22], we found no evidence for an association between

177 RVs in these 14 interferon signaling genes and risk of COVID-19.

178

179 Lastly, we performed the same analysis for an additional 32 genes that are involved in the etiology

180 of SARS-CoV-2 infection (ACE2, TMPRSS2), encode therapeutic targets for COVID-19 obtained

181 through ClinicalTrials.gov (e.g. IL6R, JAK1) or have been implicated in other immune or

182 infectious diseases through GWAS (e.g. IL33). After correcting for multiple testing, there were

183 also no significant associations with a burden of deleterious RVs for this group of COVID-19

184 therapeutic target genes (Supplementary Table 8).

186 In summary, we provide a catalog of RV associations with COVID-19 outcomes based on exome-

187 sequence data, capturing genetic variation not assayed by array genotyping or imputation. We did 
medRxiv preprint doi: https://doi.org/10.1101/2020.10.28.20221804; this version posted February 28, 2021. The copyright holder for this preprint (which was not certified by peer review) is the author/funder, who has granted medRxiv a license to display the preprint in perpetuity.

It is made available under a CC-BY-ND 4.0 International license .

188 not find any convincing associations with current sample sizes, but will continue to expand our

189 analyses and update results periodically at https://rgc-covid19.regeneron.com. 


\section{METHODS}

$192 \quad$ Participating Studies

193 Geisinger Health System (GHS). The GHS MyCode Community Health Initiative study has been

194 described previously [27]. Briefly, the GHS study is a health system-based cohort from central and

195 eastern Pennsylvania (USA) with ongoing recruitment since 2006. A subset of 144,182 MyCode

196 participants sequenced as part of the GHS-Regeneron Genetics Center DiscovEHR partnership

197 were included in this study. Information on COVID-19 outcomes were obtained through GHS's

198 COVID-19 registry. Patients were identified as eligible for the registry based on relevant lab results

199 and ICD-10 diagnosis codes; patient charts were then reviewed to confirm COVID-19 diagnoses.

200 The registry contains data on outcomes, comorbidities, medications, supplemental oxygen use and

$201 \quad$ ICU admissions.

202

203 Penn Medicine BioBank (PMBB) study. PMBB study participants are recruited through the

204 University of Pennsylvania Health System, which enrolls participants during hospital or clinic 205 visits. Participants donate blood or tissue and allow access to EHR information[28]. The PMBB

206 COVID-19 registry consists of patients who have positive qPCR testing for SARS-COV-2. We 207 then used electronic health records to classify COVID-19 patients into hospitalized and severe 208 (ventilation or death) categories.

210 UK Biobank (UKB) study. We studied the host genetics of SARS-CoV-2 infection in participants

211 of the UK Biobank study, which took place between 2006 and 2010 and includes approximately 212500,000 adults aged 40-69 at recruitment. In collaboration with UK health authorities, the UK 
medRxiv preprint doi: https://doi.org/10.1101/2020.10.28.20221804; this version posted February 28, 2021. The copyright holder for this preprint (which was not certified by peer review) is the author/funder, who has granted medRxiv a license to display the preprint in perpetuity.

It is made available under a CC-BY-ND 4.0 International license .

213 Biobank has made available regular updates on COVID-19 status for all participants, including

214 results from four main data types: qPCR test for SARS-CoV-2, anonymized electronic health

215 records, primary care and death registry data. We report results based on the 12 September 2020

216 data refresh and excluded from the analysis 28,547 individuals with a death registry event prior to

2172020.

218

219 COVID-19 phenotypes used for genetic association analyses

220 We grouped participants from each study into three broad COVID-19 disease categories

221 (Supplementary Table 2): (i) positive - those with a positive qPCR or serology test for SARS-

222 CoV-2, or a COVID-19-related ICD10 code (U07), hospitalization or death; (ii) negative - those

223 with only negative qPCR or serology test results for SARS-CoV-2 and no COVID-19-related

224 ICD10 code (U07), hospitalization or death; and (iii) unknown - those with no qPCR or serology

225 test results and no COVID-19-related ICD10 code (U07), hospitalization or death. We then used

226 these broad COVID-19 disease categories, in addition to hospitalization and disease severity

227 information, to create seven COVID-19-related phenotypes for genetic association analyses, as

228 detailed in Supplementary Table 3.

230 Array genotyping

231 Genotyping was performed on one of four SNP array types: Illumina OmniExpress Exome array

232 (OMNI; 59345 samples from GHS), Illumina Global Screening Array (GSA; PMBB and 82,527

233 samples from GHS), Applied Biosystems UK BiLEVE Axiom Array (49,950 samples from UKB),

234 or Applied Biosystems UK Biobank Axiom Array (438,427 samples from UKB). We retained

235 variants with a minor allele frequency (MAF) $>1 \%,<10 \%$ missingness, Hardy-Weinberg 
medRxiv preprint doi: https://doi.org/10.1101/2020.10.28.20221804; this version posted February 28, 2021. The copyright holder for this preprint (which was not certified by peer review) is the author/funder, who has granted medRxiv a license to display the preprint in perpetuity.

It is made available under a CC-BY-ND 4.0 International license .

equilibrium test $P$-value $>10^{-15}$. Array data were then used: (i) to define ancestry subsets; and (ii) carried out in REGENIE (see below).

\section{Exome sequencing}

241 Sample Preparation and Sequencing. Genomic DNA samples normalized to approximately 16

$242 \mathrm{ng} / \mathrm{ul}$ were transferred to the Regeneron Genetics Center from the UK Biobank in 0.5ml 2D matrix

243 tubes (Thermo Fisher Scientific) and stored in an automated sample biobank (LiCONiC

244 Instruments) at $-80^{\circ} \mathrm{C}$ prior to sample preparation. Exome capture was completed using a high-

245 throughput, fully-automated approach developed at the Regeneron Genetics Center. Briefly, DNA

246 libraries were created by enzymatically shearing 100ng of genomic DNA to a mean fragment size

247 of 200 base pairs using a custom NEBNext Ultra II FS DNA library prep kit (New England

248 Biolabs) and a common Y-shaped adapter (Integrated DNA Technologies [IDT]) was ligated to

249 all DNA libraries. Unique, asymmetric 10 base pair barcodes were added to the DNA fragment

250 during library amplification with KAPA HiFi polymerase (KAPA Biosystems) to facilitate

251 multiplexed exome capture and sequencing. Equal amounts of sample were pooled prior to

252 overnight exome capture, approximately 16 hours, with either (i) a slightly modified version of

253 IDT's xGen probe library (for UKB, PMBB and 81,620 samples of GHS); or (ii) NimbleGen

254 VCRome (58,856 samples of GHS). Captured fragments were bound to streptavidin-coupled

255 Dynabeads (Thermo Fisher Scientific) and non-specific DNA fragments removed through a series

256 of stringent washes using the xGen Hybridization and Wash kit according to the manufacturer's

257 recommended protocol (Integrated DNA Technologies). The captured DNA was PCR amplified

258 with KAPA HiFi and quantified by qPCR with a KAPA Library Quantification Kit (KAPA 
Biosystems). The multiplexed samples were pooled and then sequenced using: (i) for UKB samples -75 bp paired-end reads with two 10 base pair index reads on the Illumina NovaSeq 6000

261 platform using S2 or S4 flow cells; (ii) for GHS samples captured with VCRome - 75 bp paired-

262 end reads with two 8 bp index reads on the Illumina HiSeq 2500; (iii) for GHS captured with IDT

$263-$ two 8 bp index reads on the Illumina HiSeq 2500 or two 10 bp index reads on the Illumina

264 NovaSeq 6000 on S4 flow cells; (iv) for UPENN-PMBB - two 10 bp index reads on the Illumina

265 NovaSeq 6000 on S4 flow cells.

267 Variant calling and quality control. Sample read mapping and variant calling, aggregation and 268 quality control were performed via the SPB protocol described in Van Hout et al. [29]. Briefly, for 269 each sample, NovaSeq WES reads are mapped with BWA MEM to the hg38 reference genome.

270 Small variants are identified with WeCall and reported as per-sample gVCFs. These gVCFs are 271 aggregated with GLnexus into a joint-genotyped, multi-sample VCF (pVCF). SNV genotypes with 272 read depth (DP) less than seven and indel genotypes with read depth less than ten are changed to 273 no-call genotypes. After the application of the DP genotype filter, a variant-level allele balance 274 filter is applied, retaining only variants that meet either of the following criteria: (i) at least one 275 homozygous variant carrier or (ii) at least one heterozygous variant carrier with an allele balance 276 ( $\mathrm{AB})$ greater than the cutoff $(\mathrm{AB} \geq 0.15$ for $\mathrm{SNVs}$ and $\mathrm{AB} \geq 0.20$ for indels).

278 Identification of low-quality variants from exome-sequencing using machine learning. Briefly, in

279 each study, we defined a set of positive control and negative control variants based on: (i)

280 concordance in genotype calls between array and exome sequencing data; (ii) Mendelian 281 inconsistencies in the exome sequencing data; (iii) differences in allele frequencies between exome 
282 sequencing batches (UKB and GHS); (iv) variant loadings on 20 principal components derived

283 from the analysis of variants with a MAF $<1 \%$; (v) transmitted singletons. The model was then

284 trained on up to 30 available WeCall/GLnexus site quality metrics, including, for example, allele

285 balance and depth of coverage. We split the data into training (80\%) and test (20\%) sets. We

286 performed a grid search with 5-fold cross-validation on the training set to identify the

287 hyperparameters that return the highest accuracy during cross-validation, which are then applied

288 to the test set to confirm accuracy. This approach identified as low-quality a total of 7 million

289 variants in the UKB study ( $86 \%$ in the buffer region), 7.2 million across the two GHS datasets

290 (IDT and VCRome; 84\% in the buffer region) and 1.1 million in the PMBB study (88\% in the

291 buffer region). These variants were removed from analysis in the respective studies.

293 Gene burden masks. Briefly, for each gene region as defined by Ensembl [30], genotype

294 information from multiple rare coding variants was collapsed into a single burden genotype, such

295 that individuals who were: (i) homozygous reference (Ref) for all variants in that gene were

296 considered homozygous (RefRef); (ii) heterozygous for at least one variant in that gene were

297 considered heterozygous (RefAlt); (iii) and only individuals that carried two copies of the

298 alternative allele (Alt) of the same variant were considered homozygous for the alternative allele

299 (AltAlt). We did not phase rare variants; compound heterozygotes, if present, were considered

300 heterozygous (RefAlt). We did this separately for four classes of variants: (i) predicted loss of

301 function (pLoF), which we refer to as an "M1” burden mask; (ii) pLoF or missense (“M2”); (iii)

302 pLoF or missense variants predicted to be deleterious by $5 / 5$ prediction algorithms ("M3”); (iv)

303 pLoF or missense variants predicted to be deleterious by $1 / 5$ prediction algorithms ("M4").

304 Variants were annotated using SnpEff 4.3[31] and the most severe consequence for each variant 
was chosen, considering complete protein-coding transcripts for each gene. The following variants and donor sites, variants leading to stop gain, stop loss and start loss. The five missense deleterious

308 algorithms used were SIFT [32], PolyPhen2 (HDIV), PolyPhen2 (HVAR) [33], LRT [34], and

309 MutationTaster [35]. For each gene, and for each of these four groups, we considered five separate

310 burden masks, based on the frequency of the alternative allele of the variants that were screened

311 in that group: $<1 \%,<0.1 \%,<0.01 \%,<0.001 \%$ and singletons only. Each burden mask was then

312 tested for association with the same approach used for individual variants (see below).

\section{$314 \quad$ Genetic association analyses}

315 Association analyses in each study were performed using the genome-wide Firth logistic 316 regression test implemented in REGENIE [14]. In this implementation, Firth's approach is applied

317 when the p-value from standard logistic regression score test is below 0.05 . As the Firth penalty

318 (i.e. Jeffrey's invariant prior) corresponds to a data augmentation procedure where each

319 observation is split into a case and a control with different weights, it can handle variants with no

320 minor alleles among cases. With no covariates, this corresponds to adding 0.5 in every cell of a

$3212 \times 2$ table of allele counts versus case-control status.

322 We included in step 1 of REGENIE (i.e. prediction of individual trait values based on the 323 genetic data) array variants with a minor allele frequency (MAF) $>1 \%,<10 \%$ missingness, Hardy-

324 Weinberg equilibrium test $P$-value $>10^{-15}$ and linkage-disequilibrium (LD) pruning (1000 variant 325 windows, 100 variant sliding windows and $\left.r^{2}<0.9\right)$. The exception was the GHS study, for which 326 we used exome (not array) variants in step 1; we did this because two different exome capture 
to capture in step 1 of REGENIE any differences in exome sequencing performance between IDT histo-compatibility (MHC) region, or in regions of low complexity.

The association model used in step 2 of REGENIE included as covariates (i) age, age ${ }^{2}$, sex, adequately correct for fine-scale population structure [36, 37].

European (EUR) and South Asian (SAS). We determined continental ancestries by projecting each sample onto reference principle components calculated from the HapMap3 reference panel.

347 and projected each of our samples onto those PCs. To assign a continental ancestry group to each 348 non-HapMap3 sample, we trained a kernel density estimator (KDE) using the HapMap3 PCs and used the KDEs to calculate the likelihood of a given sample belonging to each of the five 
351 was assigned to that ancestry group. When two ancestry groups had a likelihood $>0.3$, we 352 arbitrarily assigned AFR over EUR, AMR over EUR, AMR over EAS, SAS over EUR, and AMR

353 over AFR. Samples were excluded from analysis if no ancestry likelihoods were $>0.3$, or if more 354 than three ancestry likelihoods were $>0.3$.

355 Results were subsequently meta-analyzed across studies and ancestries using an inverse 356 variance-weighed fixed-effects meta-analysis.

\section{Gene expression analysis in participants of the GHS study}

359 For a subset of individuals from the GHS study (n=1,988, ascertained through the Geisinger

360 Bariatric Surgery Clinic), RNA was extracted from liver biopsies conducted during bariatric

361 surgery to evaluate liver disease. Individuals had class 3 obesity (BMI $\left.>40 \mathrm{~kg} / \mathrm{m}^{2}\right)$ or class 2 obesity

362 (BMI 35-39 kg/m²) with an obesity-related co-morbidity (e.g. type-2 diabetes, hypertension, sleep

363 apnea, non-alcoholic fatty liver disease). RNA libraries were prepared using polyA-extraction and

364 then sequenced with $75 \mathrm{bp}$ paired-end reads with two $10 \mathrm{bp}$ index reads on the Illumina NovaSeq

3656000 on S4 flow cells. RNA-seq data were then analyzed using the GTEx v8 workflow[38], using

366 STAR [39] and RNASeqQC [40], except that GENCODE v32 was used in lieu of v26. Briefly: (i)

367 raw expression counts were normalized with TMM (Trimmed Mean of M-values) as implemented

368 in edgeR [40]; (ii) a rank-based inverse normal transformation was applied to the normalized

369 expression values; (iii) principal components (PCs) analysis was performed on data from 25,078

370 genes with TPM $>0.1$ in $>20 \%$ samples, to identify latent factors accounting for variation in gene

371 expression; (iv) gene expression levels were adjusted for the top 100 PCs to improve power to

372 identify cis-regulatory effects. 


\section{Frequency of $E E F 2$ rare promoter variant in COVID-19 cases from independent studies}

375 To help understand if the association between COVID-19 risk and rs532051930 in EEF2 was

376 likely to be a true-positive association, we determine its frequency in 4,341 cases from three

377 additional studies.

GenOMICC $(n=2,969)$. Individuals with severe COVID-19 were ascertained as described

379 previously[11]. DNA samples were then whole-genome sequenced on the Illumina NovaSeq 6000

380 platform, aligned to the human reference genome hg38 and variant called to GVCF stage on the

381 DRAGEN pipeline (software v01.011.269.3.2.22, hardware v01.011.269) at Genomics England. rs532051930 +/-50bp was genotyped with the GATK GenotypeGVCFs tool v4.1.8.1 and filtered

to minimum depth $8 \mathrm{X}$. Ancestry for individuals with array genotyping was inferred using ADMIXTURE[41] populations defined in 1000 Genomes[42]. When one individual had a probability $>80 \%$ of pertaining to one ancestry, then the individual was assigned to this ancestry, otherwise the individual was considered to be of admixed ancestry, as performed in the Million veteran program [43]. Somalier v0.2.12[44] was used to estimate ancestry for samples with wholegenome sequencing data. Predictions from Somalier were compared against predictions from ADMIXTURE for 1833 samples with both array genotyping and whole-genome sequencing data.

390 Of these, the ancestry assignment matched between the two approaches for 1832 samples.

391 Somalier predictions were used for the remaining 927 samples, of which 813 could be confidently

392 ( $\geq 95 \%$ probability) assigned to a population; the remaining 114 were assigned to admixed 393 ancestry.

Columbia University COVID-19 biobank $(n=1,152)$. This cohort has previously been

395 described in detail[22]. Briefly, 1,152 COVID-19 patients that were treated for COVID-19 at the

396 Columbia University Irving Medical Center were recruited to the Columbia University COVID- 
exomes were captured with the IDT xGen Exome Research Panel V1.0 and sequenced on recommendations v3.66[45]. Finally, variants were annotated with ClinEff[31] and the IGM's in-

Middle Eastern) using a neural network trained on a set of samples with known ancestry labels.

411 that did not reach $50 \%$ for any of the ancestral groups as "Admixed".

413 release $20[47]$ ) covered at $\geq 10 x$ and $\leq 3 \%$ contamination levels according to VerifyBamID[48].

414 Additionally, we removed samples with a discordance between self-declared and sequence-derived 415 gender and samples with an inferred relationship of second-degree or closer according to 416 KING[49]. All cases had at least 10x coverage at the position of rs532051930. 
420 For this study, we used results from patients with available WGS data and who were recruited at

421 the Jewish General Hospital (JGH) in Montreal. The JGH is a university affiliated hospital serving

422 a large multi-ethnic adult population and the Québec government designated the JGH as the primary

423 COVID-19 reference center early in the pandemic. In total, Biobanque Quebec contained 533

424 participants with WGS, including 62 cases of COVID-19 who required invasive ventilatory support

425 (BiPAP, high flow oxygen, or endotracheal intubation) or died, 128 COVID-19 patients who were

426 hospitalized but did not require invasive ventilatory support, 30 individuals with COVID-19 did not

427 require hospitalization, and 313 SARS-CoV-2 PCR-negative participants. Using genetic PCAs

428 derived from genome-wide genotyping, $76 \%$ of participants were of European ancestry, $9 \%$ were

429 of African ancestry, 7\% were of east Asian ancestry, and 5\% were of south Asian ancestry.

430 We performed WGS at a mean depth of 30x on all individuals using Illumina's Novaseq

4316000 platform (Illumina, San Diego, CA, USA). Sequencing results were analyzed using the

432 McGill Genome Center bioinformatics pipelines[50], in accordance with Genome Analysis

433 Toolkit (GATK) best practices recommendations[45]. Reads were aligned to the GRCh38

434 reference genome. Variant quality control was performed using the variantRecalibrator and

435 applyVQSR functions from GATK.

437 Results availability

438 All genotype-phenotype association results reported in this study are available for browsing using 439 the RGC's COVID-19 Results Browser (https://rgc-covid19.regeneron.com). Data access and use

440 is limited to research purposes in accordance with the Terms of Use (https://rgc-

441 covid19.regeneron.com/terms-of-use). The COVID-19 Results Browser provides a user-friendly

442 interface to explore genetic association results, enabling users to query summary statistics across 
443 multiple cohorts and association studies using genes, variants or phenotypes of interest. Results

444 are displayed in an interactive tabular view ordered by p-value - enabling filtering, sorting,

445 grouping and viewing additional statistics - with link outs to individual GWAS reports, including

446 interactive Manhattan and QQ plots. LocusZoom views of LD information surrounding variants

447 of interest are also available, with LD calculated using the respective source genetic datasets.

448 The data resource supporting the COVID-19 Results Browser was built using a processed

449 version of the raw association analysis outputs. Using the RGC's data engineering toolkit based in

450 Apache Spark and Project Glow (https://projectglow.io/), association results were annotated,

451 enriched and partitioned into a distributed, columnar data store using Apache Parquet. Processed

452 Parquet files were registered with AWS Athena, which enables efficient, scalable queries on

453 unfiltered association result datasets. Additionally, "filtered" views of associations significant at a

454 threshold of p-value $<0.001$ were stored in AWS RDS Aurora databases for low latency queries

455 to service primary views of top associations. APIs into RDS and Athena are managed behind the 456 scenes such that results with a p-value $>0.001$ are pulled from Athena as needed.

\section{Competing interests}

459 J.E.H., J.A.K., A.D., D.S., N.B, A.Y., A.M., R.L., E.M., X.B., D.S., F.S.P.K., J.D.B., C.O’D., 460 A.J.M., D.A.T., A.H.L., J.M., K.W., L.G., S.E.M, H.M.K., L.D., E.S., M.J., S.B., K.S.M, W.J.S., 461 A.R.S., A.E.L., J.M., J.O., L.H., M.N.C., J.G.R., A.B., G.R.A., and M.A.F. are current employees 462 and/or stockholders of Regeneron Genetics Center or Regeneron Pharmaceuticals. X.Z., S.E., 463 J.W.D. are employees of AbbVie and may hold stock in AbbVie. Financial support for this 464 research was provided by AbbVie through the UKB Exome Sequencing Consortium. AbbVie 465 participated in the interpretation of data, review, and approval of the publication. P.N. and M.M.P 
medRxiv preprint doi: https://doi.org/10.1101/2020.10.28.20221804; this version posted February 28, 2021. The copyright holder for this preprint (which was not certified by peer review) is the author/funder, who has granted medRxiv a license to display the preprint in perpetuity.

It is made available under a CC-BY-ND 4.0 International license .

466

467

468

469

470

471

472

473

474

475

476

477

478

479

480

481

482

483

484

485

486

487

488

are employees and stockholders of Alnylam Pharmaceuticals. J.B.R. has served as an advisor to GlaxoSmithKline and Deerfield Capital and these agencies had no role in the design, implementation or interpretation of this study. S.S., E.W., A.C.P., and E.N.S. are employed by Takeda. S.S. holds shares in Takeda and Janssen. The other authors declare no competing interests.

\section{Acknowledgements}

This research has been conducted using the UK Biobank Resource (Project 26041). The Penn

Medicine BioBank is funded by a gift from the Smilow family, the National Center for

Advancing Translational Sciences of the National Institutes of Health under CTSA Award

Number UL1TR001878, and the Perelman School of Medicine at the University of

Pennsylvania. Whole genome sequencing of the Biobanque Québec Covid-19 cohort was funded

by the CanCOGeN HostSeq project. The Richards research group is supported by the Canadian

Institutes of Health Research (CIHR), the Lady Davis Institute of the Jewish General Hospital, the Canadian Foundation for Innovation, the NIH Foundation, Cancer Research UK and the

Fonds de Recherche Québec Santé (FRQS). G.B.L. is supported by a joint research fellowship

from Quebec's ministry of health and social services, and the FRQS. T.N. is supported by

Research Fellowships of Japan Society for the Promotion of Science (JSPS) for Young Scientists and JSPS Overseas Challenge Program for Young Researchers. J.B.R. is supported by a FRQS

Clinical Research Scholarship. The Columbia University Biobank was supported by Columbia University and the National Center for Advancing Translational Sciences, NIH, through Grant Number UL1TR001873. Columbia University COVID-19 Biobank members that additionally contributed to this work include Muredach P. Reilly, Wendy Chung, Eldad Hod, Soumitra Sengupta, Danielle Pendrick, Nitin Bhardwaj, Ning Shang, Atlas Khan, Chen Wang, Sheila M. 
O’Byrne, Renu Nandakumar, Amritha Menon, Yat S. So, Richard Mayeux, Ali G. Gharavi, Iuliana Ionita-Laza, Andrea Califano, Christine K. Garcia, Peter Sims, and Anne-Catrin

491 Uhlemann. The content is solely the responsibility of the authors and does not necessarily

492 represent the official views of the NIH or Columbia University. GenOMICC was funded by

493 Sepsis Research (the Fiona Elizabeth Agnew Trust), the Intensive Care Society, a Wellcome-Beit

494 Prize award to J. K. Baillie (Wellcome Trust 103258/Z/13/A), a BBSRC Institute Program

495 Support Grant to the Roslin Institute (BBS/E/D/20002172, BBS/E/D/10002070 and

496 BBS/E/D/30002275), the Medical Research Council [grant MC_PC_19059]. Research

497 performed at the Human Genetics Unit was funded by the MRC (MC_UU_00007/10,

498 MC_UU_00007/15). Whole-genome sequencing was done in partnership with Genomics

499 England and was funded by UK Department of Health and Social Care, UKRI and LifeArc.

500 Genomics England and the 100,000 Genomes Project was funded by the National Institute for

501 Health Research, the Wellcome Trust, the Medical Research Council, Cancer Research UK, the

502 Department of Health and Social Care and NHS England. M Caulfield is an NIHR Senior

503 Investigator. This work is part of the portfolio of translational research at the NIHR Biomedical

504 Research Centre at Barts and Cambridge. LK was supported by an RCUK Innovation Fellowship

505 from the National Productivity Investment Fund (MR/R026408/1). We acknowledge support

506 from the MRC Human Genetics Unit programme grant, "Quantitative traits in health and

507 disease" (U. MC_UU_00007/10). A. Tenesa acknowledges funding from MRC research grant

508 MR/P015514/1, and HDR-UK award HDR-9004 and HDR-9003. Recruitment to GenOMICC

509 was enabled by the National Institute of Healthcare Research Clinical Research Network (NIHR

$510 \mathrm{CRN}$ ) and the Chief Scientist Office (Scotland), who facilitate recruitment into research studies

511 in NHS hospitals, and to the global ISARIC and InFACT consortia. We thank the patients and 
medRxiv preprint doi: https://doi.org/10.1101/2020.10.28.20221804; this version posted February 28, 2021. The copyright holder for this preprint (which was not certified by peer review) is the author/funder, who has granted medRxiv a license to display the preprint in perpetuity.

It is made available under a CC-BY-ND 4.0 International license .

512 their loved ones who volunteered to contribute to this study at one of the most difficult times in

513 their lives, and the research staff in every intensive care unit who recruited patients at personal

514 risk during the most extreme conditions we have ever witnessed in UK hospitals. 


\section{Supplementary Figures}

A.

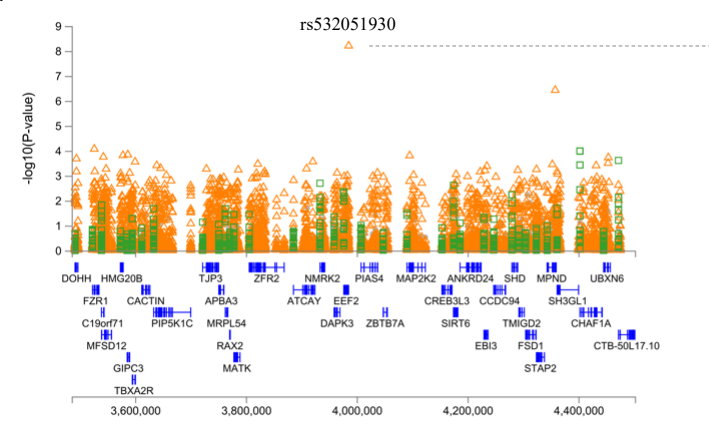

B.

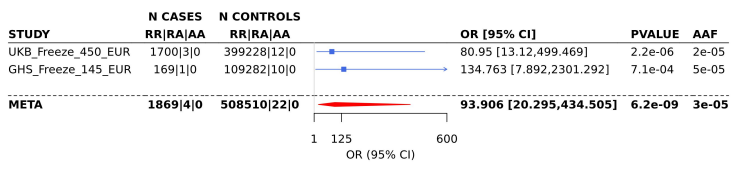

C.

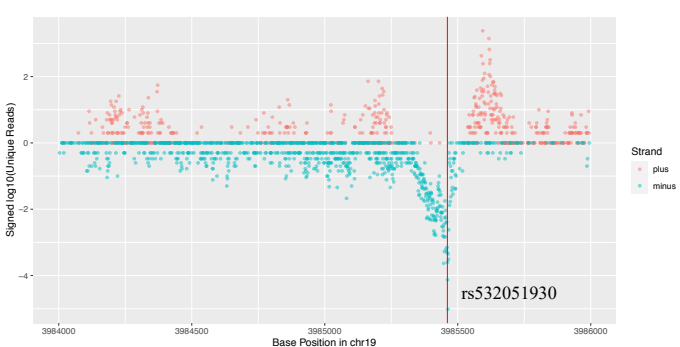

D.

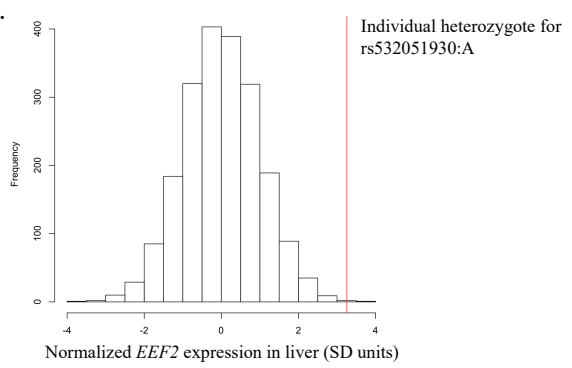

518 Supplementary Figure 1. Association between a rare promoter variant in EEF2 centered on rs532051930. Orange triangles: individual rare variants ( $\mathrm{MAF}<0.5 \%$ ). Green squares:

523 from a population-scale PROcap (Precision Run-On 5' cap sequencing) study [19], which profiles

525 (vertical red line) is located 2 bp away from the peak of transcription initiation. (D) Distribution

526 of EEF2 expression among 1,918 individuals from the GHS study with available RNA-seq data

527 from liver tissue. Vertical red line indicates expression levels for the only individual who was

528 heterozygote for the rare promoter variant rs532051930. 
medRxiv preprint doi: https://doi.org/10.1101/2020.10.28.20221804; this version posted February 28, 2021. The copyright holder for this preprint (which was not certified by peer review) is the author/funder, who has granted medRxiv a license to display the preprint in perpetuity.

It is made available under a CC-BY-ND 4.0 International license.

\section{TABLES}

530

531 Table 1. Top rare variant associations identified in this study $\left(P<10^{-8}\right)$, all observed with the

532 phenotype COVID-19 positive and hospitalized (cases) vs. COVID-19 negative or unknown

533 (controls).

\begin{tabular}{|c|c|c|c|c|c|c|c|c|}
\hline Variant & $\begin{array}{c}\text { Effect } \\
\text { allele }\end{array}$ & $\begin{array}{c}\text { Odds Ratio } \\
{[\mathbf{9 5} \% \mathbf{C I}]}\end{array}$ & P-value & $\begin{array}{c}\text { N cases with } \\
\mathbf{0 | 1} \mathbf{1} \text { copies of } \\
\text { effect allele }\end{array}$ & $\begin{array}{c}\text { N controls with } \\
\mathbf{0}|\mathbf{1}| \mathbf{2} \text { copies of } \\
\text { effect allele }\end{array}$ & $\begin{array}{c}\text { Effect } \\
\text { allele } \\
\text { frequency }\end{array}$ & $\begin{array}{c}\text { Gene } \\
\text { Variant } \\
\text { effect }\end{array}$ \\
\hline rs374698271 & $\mathrm{T}$ & $\begin{array}{c}81.60 \\
{[18.71,355.81]}\end{array}$ & $4.65 \mathrm{E}-09$ & $1698|5| 0$ & $399222|18| 0$ & 0.00003 & $R F X 2$ & Intronic \\
\hline rs532051930 & $\mathrm{A}$ & $\begin{array}{c}93.90 \\
{[20.29,434.50]}\end{array}$ & $6.17 \mathrm{E}-09$ & $1869|4| 0$ & $508510|22| 0$ & 0.00003 & $E E F 2$ & 5 prime UTR \\
\hline rs751932982 & $\mathrm{A}$ & $\begin{array}{c}22.68 \\
{[7.89,65.23]}\end{array}$ & $6.92 \mathrm{E}-09$ & $1869|2| 2$ & $508247|44| 8$ & 0.00006 & $F A M 9 B$ & Intronic \\
\hline
\end{tabular}

534 
medRxiv preprint doi: https://doi.org/10.1101/2020.10.28.20221804; this version posted February 28, 2021. The copyright holder for this preprint (which was not certified by peer review) is the author/funder, who has granted medRxiv a license to display the preprint in perpetuity.

It is made available under a CC-BY-ND 4.0 International license .

535 Table 2. Association between the phenotype COVID-19 positive and hospitalized (cases) vs

536 COVID-19 negative or unknown (controls) and 14 genes related to interferon signaling that were

537 recently reported to contain rare $(\mathrm{MAF}<0.1 \%)$, deleterious variants in patients with severe

538 COVID-19 [14, 23].

\begin{tabular}{|c|c|c|c|c|c|c|}
\hline $\begin{array}{l}\text { Variants } \\
\text { included in } \\
\text { burden test }\end{array}$ & Gene & $\begin{array}{c}\text { Odds Ratio } \\
\text { (95\% CI) }\end{array}$ & P-value & $\begin{array}{c}\text { N cases with } \\
\text { RR|RA|AA } \\
\text { genotype* }\end{array}$ & $\begin{array}{c}\text { N controls with } \\
\text { RR|RA|AA } \\
\text { genotype* }\end{array}$ & $\mathbf{A A F}$ \\
\hline \multirow{14}{*}{$\begin{array}{c}\mathrm{pLoF}, \\
\mathrm{MAF}<0.1 \%\end{array}$} & IFNARI & $0.805[0.146 ; 4.438]$ & $8.00 \mathrm{E}-01$ & $2019|1| 0$ & $525406|359| 0$ & 0.00034 \\
\hline & IFNAR2 & $2.077[0.620 ; 6.961]$ & $2.40 \mathrm{E}-01$ & $2082|3| 0$ & $534277|688| 0$ & 0.00064 \\
\hline & $I K B K G$ & $0.491[0.005 ; 50.219]$ & $7.60 \mathrm{E}-01$ & $1873|0| 0$ & $508491|31| 10$ & 0.00005 \\
\hline & $I R F 3$ & $0.956[0.251 ; 3.643]$ & $9.50 \mathrm{E}-01$ & $2083|2| 0$ & $534559|406| 0$ & 0.00038 \\
\hline & IRF7 & $1.165[0.426 ; 3.185]$ & $7.70 \mathrm{E}-01$ & $2082|3| 0$ & $534124|841| 0$ & 0.00079 \\
\hline & IRF9 & $0.371[0.003 ; 53.766]$ & $7.00 \mathrm{E}-01$ & $1873|0| 0$ & $508479|53| 0$ & 0.00005 \\
\hline & STAT1 & $0.365[0.001 ; 126.712]$ & 7.40E-01 & $1873|0| 0$ & $508490|42| 0$ & 0.00004 \\
\hline & STAT2 & $0.355[0.028 ; 4.438]$ & $4.20 \mathrm{E}-01$ & $1873|0| 0$ & $508405|127| 0$ & 0.00012 \\
\hline & $T B K 1$ & $0.365[0.011 ; 11.964]$ & $5.70 \mathrm{E}-01$ & $1873|0| 0$ & $508445|87| 0$ & 0.00009 \\
\hline & TICAMI & $3.730[0.189 ; 73.610]$ & $3.90 \mathrm{E}-01$ & $1872|1| 0$ & $508368|164| 0$ & 0.00016 \\
\hline & $T L R 3$ & $1.128[0.144 ; 8.834]$ & $9.10 \mathrm{E}-01$ & $2084|1| 0$ & $534674|291| 0$ & 0.00027 \\
\hline & $T L R 7$ & $7.627[1.872 ; 31.075]$ & $4.60 \mathrm{E}-03$ & $1872|0| 1$ & $508503|25| 4$ & 0.00003 \\
\hline & $T R A F 3$ & $0.368[0.000 ; 733.638]$ & $8.00 \mathrm{E}-01$ & $1873|0| 0$ & $508504|28| 0$ & 0.00003 \\
\hline & UNC93B1 & $1.302[0.272 ; 6.238]$ & $7.40 \mathrm{E}-01$ & $1938|2| 0$ & $516861|409| 0$ & 0.0004 \\
\hline \multirow{14}{*}{$\begin{array}{c}\text { pLoF or missense } \\
\text { predicted } \\
\text { deleterious, } \\
\text { MAF }<0.1 \%\end{array}$} & IFNARI & $0.756[0.234 ; 2.444]$ & $6.40 \mathrm{E}-01$ & $2083|2| 0$ & $534219|746| 0$ & 0.0007 \\
\hline & IFNAR2 & $1.968[0.598 ; 6.469]$ & $2.70 \mathrm{E}-01$ & $2082|3| 0$ & $534253|712| 0$ & 0.00067 \\
\hline & $I K B K G$ & $0.446[0.010 ; 19.737]$ & $6.80 \mathrm{E}-01$ & $1873|0| 0$ & $508452|70| 10$ & 0.00009 \\
\hline & $I R F 3$ & $0.786[0.238 ; 2.592]$ & $6.90 \mathrm{E}-01$ & $2083|2| 0$ & $534413|552| 0$ & 0.00052 \\
\hline & IRF7 & $1.137[0.519 ; 2.492]$ & $7.50 \mathrm{E}-01$ & $2080|5| 0$ & $533486|1479| 0$ & 0.00138 \\
\hline & IRF9 & $0.371[0.003 ; 53.766]$ & $7.00 \mathrm{E}-01$ & $1873|0| 0$ & $508479|53| 0$ & 0.00005 \\
\hline & STAT1 & $0.365[0.038 ; 3.488]$ & $3.80 \mathrm{E}-01$ & $2018|0| 0$ & $526009|218| 0$ & 0.00021 \\
\hline & STAT2 & $2.600[1.272 ; 5.314]$ & $8.80 \mathrm{E}-03$ & $2073|12| 0$ & $533405|1559| 1$ & 0.00146 \\
\hline & $T B K 1$ & $1.114[0.445 ; 2.790]$ & $8.20 \mathrm{E}-01$ & $2081|4| 0$ & $533861|1103| 1$ & 0.00103 \\
\hline & TICAMI & $3.657[0.188 ; 71.218]$ & $3.90 \mathrm{E}-01$ & $1872|1| 0$ & $508365|167| 0$ & 0.00016 \\
\hline & TLR3 & $0.805[0.435 ; 1.493]$ & $4.90 \mathrm{E}-01$ & $2077|8| 0$ & $532355|2609| 1$ & 0.00244 \\
\hline & $T L R 7$ & $1.580[0.627 ; 3.979]$ & $3.30 \mathrm{E}-01$ & $2001|3| 1$ & $525830|477| 163$ & 0.00076 \\
\hline & $T R A F 3$ & $3.013[0.527 ; 17.217]$ & $2.10 \mathrm{E}-01$ & $2019|1| 0$ & $525523|242| 0$ & 0.00023 \\
\hline & UNC93B1 & $1.665[0.774 ; 3.582]$ & $1.90 \mathrm{E}-01$ & $2075|10| 0$ & $533331|1634| 0$ & 0.00153 \\
\hline
\end{tabular}


544 Supplementary Table 1. Demographics and clinical characteristics of study participants.

Supplementary Table 2. Breakdown of COVID-19 status across the four studies included in the

547 analysis.

Supplementary Table 3. Definitions used for the seven COVID-19 phenotypes analyzed.

551 Supplementary Table 4. Genomic inflation factor $\left(\lambda_{\mathrm{GC}}\right)$ observed in the analysis of exome

552 sequence variants for each of the eight phenotypes tested.

Supplementary Table 5. Association between the COVID-19 hospitalization phenotype and 50 rare variants in the promoter of EEF2.

557 Supplementary Table 6. Evidence for association between the COVID-19 hospitalization 558 phenotype and rs532051930 across different association tests.

560 Supplementary Table 7. No carriers of the rare variant rs532051930 in the promoter of EEF2

561 were observed in an additional 4,122 individuals with COVID-19. 
563 Supplementary Table 8. Results from burden association tests for 167 genes located in eight loci 564 described in Horowitz et al. [13].

565

566 Supplementary Table 9. Results from burden association tests for 14 genes related to interferon 567 signaling and recently reported to contain rare $(\mathrm{MAF}<0.1 \%)$, deleterious variants in patients with 568 severe COVID-19.

570 Supplementary Table 10. Results from burden association tests for an additional 32 genes that 571 are involved in the etiology of SARS-CoV-2, encode therapeutic targets or have been implicated 572 in other immune or infectious diseases through GWAS. 


\section{References}

574

575

576

577

578

579

580

581

582

583

584

585

586

587

588

589

590

591

592

593

594

595

596

597

598

599

600

601

602

603

604

605

606

607

608

609

610

611

612

613

614
1. Zhu, N., et al., A Novel Coronavirus from Patients with Pneumonia in China, 2019. New England Journal of Medicine, 2020. 382(8): p. 727-733.

2. Coronaviridae Study Group of the International Committee on Taxonomy of, V., The species Severe acute respiratory syndrome-related coronavirus: classifying 2019-nCoV and naming it SARS-CoV-2. Nat Microbiol, 2020. 5(4): p. 536-544.

3. Guan, W.J., et al., Clinical Characteristics of Coronavirus Disease 2019 in China. N Engl J Med, 2020. 382(18): p. 1708-1720.

4. Kimball, A., et al., Asymptomatic and Presymptomatic SARS-CoV-2 Infections in Residents of a Long-Term Care Skilled Nursing Facility - King County, Washington, March 2020. MMWR Morb Mortal Wkly Rep, 2020. 69(13): p. 377-381.

5. Bai, Y., et al., Presumed Asymptomatic Carrier Transmission of COVID-19. JAMA, 2020. 323(14): p. 1406-1407.

6. Richardson, S., et al., Presenting Characteristics, Comorbidities, and Outcomes Among 5700 Patients Hospitalized With COVID-19 in the New York City Area. Jama, 2020. 323(20): p. 2052-2059.

7. Atkins, J.L., et al., PREEXISTING COMORBIDITIES PREDICTING SEVERE COVID-19 IN OLDER ADULTS IN THE UK BIOBANK COMMUNITY COHORT. medRxiv, 2020: p. 2020.05.06.20092700.

8. Zhou, F., et al., Clinical course and risk factors for mortality of adult inpatients with COVID-19 in Wuhan, China: a retrospective cohort study. Lancet, 2020. 395(10229): p. 1054-1062.

9. Cummings, M.J., et al., Epidemiology, clinical course, and outcomes of critically ill adults with COVID-19 in New York City: a prospective cohort study. Lancet, 2020. 395(10239): p. 1763-1770.

10. Shelton, J.F., et al., Trans-ethnic analysis reveals genetic and non-genetic associations with COVID-19 susceptibility and severity. medRxiv, 2020: p. 2020.09.04.20188318.

11. Pairo-Castineira, E., et al., Genetic mechanisms of critical illness in Covid-19. Nature, 2020.

12. Ellinghaus, D., et al., Genomewide Association Study of Severe Covid-19 with Respiratory Failure. New England Journal of Medicine, 2020.

13. Horowitz, J.E., Kosmicki, J. A., et al. , Common genetic variants identify therapeutic targets for COVID-19 and individuals at high risk of severe disease. medRxiv, 2020.

\subsubsection{6.}

14. Mbatchou, J., et al., Computationally efficient whole genome regression for quantitative and binary traits. bioRxiv, 2020: p. 2020.06.19.162354.

15. Valiente-Echeverria, F., et al., eEF2 and Ras-GAP SH3 domain-binding protein (G3BP1) modulate stress granule assembly during HIV-1 infection. Nat Commun, 2014. 5: p. 4819.

16. Fernandez, I.S., et al., Initiation of translation by cricket paralysis virus IRES requires its translocation in the ribosome. Cell, 2014. 157(4): p. 823-31.

17. Zhou, J. and O.G. Troyanskaya, Predicting effects of noncoding variants with deep learning-based sequence model. Nat Methods, 2015. 12(10): p. 931-4. 
615 18. Ferraro, N.M., et al., Transcriptomic signatures across human tissues identify functional

616 rare genetic variation. Science, 2020. 369(6509).

19. Kristjansdottir, K., et al., Population-scale study of eRNA transcription reveals bipartite functional enhancer architecture. Nat Commun, 2020. 11(1): p. 5963.

20. Ma, C., et al., Recommended joint and meta-analysis strategies for case-control association testing of single low-count variants. Genet Epidemiol, 2013. 37(6): p. 539-50.

21. Sofer, T., BinomiRare: A robust test of the association of a rare variant with a disease for pooled analysis and meta-analysis, with application to the HCHS/SOL. Genet Epidemiol, 2017. 41(5): p. 388-395.

22. Povysil, G., et al., Failure to replicate the association of rare loss-of-function variants in type I IFN immunity genes with severe COVID-19. medRxiv, 2020: $p$. 2020.12.18.20248226.

23. Consortium, G.T., The GTEx Consortium atlas of genetic regulatory effects across human tissues. Science, 2020. 369(6509): p. 1318-1330.

24. Cheloufi, S., et al., The histone chaperone CAF-1 safeguards somatic cell identity. Nature, 2015. 528(7581): p. 218-24.

25. van der Made, C.I., et al., Presence of Genetic Variants Among Young Men With Severe COVID-19. JAMA, 2020.

26. Zhang, S.Y., et al., Severe COVID-19 in the young and healthy: monogenic inborn errors of immunity? Nat Rev Immunol, 2020. 20(8): p. 455-456.

27. Dewey, F.E., et al., Distribution and clinical impact of functional variants in 50,726 whole-exome sequences from the DiscovEHR study. Science, 2016. 354(6319).

28. Park, J., et al., A genome-first approach to aggregating rare genetic variants in LMNA for association with electronic health record phenotypes. Genet Med, 2020. 22(1): p. 102111.

29. Van Hout, C.V., et al., Exome sequencing and characterization of 49,960 individuals in the UK Biobank. Nature, 2020.

30. Zerbino, D.R., et al., Ensembl 2018. Nucleic Acids Research, 2017. 46(D1): p. D754-D761.

31. Cingolani, P., et al., A program for annotating and predicting the effects of single nucleotide polymorphisms, SnpEff: SNPs in the genome of Drosophila melanogaster strain w1118; iso-2; iso-3. Fly (Austin), 2012. 6(2): p. 80-92.

32. Vaser, R., et al., SIFT missense predictions for genomes. Nat Protoc, 2016. 11(1): p. 1-9.

33. Adzhubei, I., D.M. Jordan, and S.R. Sunyaev, Predicting functional effect of human missense mutations using PolyPhen-2. Curr Protoc Hum Genet, 2013. 7(1): p. 7.20.17.20.41.

34. Chun, S. and J.C. Fay, Identification of deleterious mutations within three human genomes. Genome research, 2009. 19(9): p. 1553-1561.

35. Schwarz, J.M., et al., MutationTaster evaluates disease-causing potential of sequence alterations. Nat Methods, 2010. 7(8): p. 575-6.

36. Mathieson, I. and G. McVean, Differential confounding of rare and common variants in spatially structured populations. Nature Genetics, 2012. 44(3): p. 243-246.

37. Zaidi, A.A. and I. Mathieson, Demographic history impacts stratification in polygenic scores. bioRxiv, 2020: p. 2020.07.20.212530. 
658 38. Consortium, G.T., The Genotype-Tissue Expression (GTEx) project. Nat Genet, 2013. 45(6): p. 580-5.

660 39. Dobin, A., et al., STAR: ultrafast universal RNA-seq aligner. Bioinformatics, 2013. 29(1):

$661 \quad$ p. $15-21$

662 40. Robinson, M.D. and A. Oshlack, A scaling normalization method for differential

663 expression analysis of RNA-seq data. Genome Biol, 2010. 11(3): p. R25.

664 41. Alexander, D.H. and K. Lange, Enhancements to the ADMIXTURE algorithm for individual ancestry estimation. BMC Bioinformatics, 2011. 12: p. 246.

666 42. Auton, A., et al., A global reference for human genetic variation. Nature, 2015.

$667 \quad$ 526(7571): p. 68-74.

668 43. Gaziano, J.M., et al., Million Veteran Program: A mega-biobank to study genetic

669 influences on health and disease. J Clin Epidemiol, 2016. 70: p. 214-23.

670 44. Pedersen, B.S., et al., Somalier: rapid relatedness estimation for cancer and germline studies using efficient genome sketches. Genome Med, 2020. 12(1): p. 62.

45. Van der Auwera, G.A., et al., From FastQ data to high confidence variant calls: the Genome Analysis Toolkit best practices pipeline. Curr Protoc Bioinformatics, 2013. 43(1110): p. 11.10.1-11.10.33.

46. Ren, Z., G. Povysil, and D.B. Goldstein, ATAV: a comprehensive platform for populationscale genomic analyses. bioRxiv, 2020(p. 2020.06.08.136507.).

47. Pruitt, K.D., et al., The consensus coding sequence (CCDS) project: Identifying a common protein-coding gene set for the human and mouse genomes. Genome Res, 2009. 19(7): p. 1316-23.

48. Jun, G., et al., Detecting and estimating contamination of human DNA samples in sequencing and array-based genotype data. Am J Hum Genet, 2012. 91(5): p. 839-48.

682

683

49. Manichaikul, A., et al., Robust relationship inference in genome-wide association studies. Bioinformatics, 2010. 26(22): p. 2867-73. genomic analyses. Gigascience, 2019. 8(6). 
SUPPLEMENTARY TEXT

Regeneron Genetics Center (RGC) Research Team and Contribution Statements

690 All authors/contributors are listed in alphabetical order.

\section{$\underline{\text { RGC Management and Leadership Team }}$}

693 Goncalo Abecasis, Ph.D., Aris Baras, M.D., Michael Cantor, M.D., Giovanni Coppola, M.D.,

694 Aris Economides, Ph.D., Luca A. Lotta, M.D., Ph.D., John D. Overton, Ph.D., Jeffrey G. Reid, 695 Ph.D., Alan Shuldiner, M.D.

696 Contribution: All authors contributed to securing funding, study design and oversight. All

697 authors reviewed the final version of the manuscript.

698

\section{Sequencing and Lab Operations}

700 Christina Beechert, Caitlin Forsythe, M.S., Erin D. Fuller, Zhenhua Gu, M.S., Michael Lattari,

701 Alexander Lopez, M.S., John D. Overton, Ph.D., Thomas D. Schleicher, M.S., Maria

702 Sotiropoulos Padilla, M.S., Louis Widom, Sarah E. Wolf, M.S., Manasi Pradhan, M.S., Kia

703 Manoochehri, Ricardo H. Ulloa.

704 Contribution: C.B., C.F., A.L., and J.D.O. performed and are responsible for sample genotyping.

705 C.B, C.F., E.D.F., M.L., M.S.P., L.W., S.E.W., A.L., and J.D.O. performed and are responsible

706 for exome sequencing. T.D.S., Z.G., A.L., and J.D.O. conceived and are responsible for

707 laboratory automation. M.P., K.M., R.U., and J.D.O are responsible for sample tracking and the 708 library information management system. 


\section{Clinical Informatics}

711 Nilanjana Banerjee, Ph.D., Michael Cantor, M.D. M.A., Dadong Li, Ph.D., Deepika Sharma,

712 MHI

713 Contribution: All authors contributed to the development and validation of clinical phenotypes

714 used to identify study subjects and (when applicable) controls.

\section{Genome Informatics}

717 Xiaodong Bai, Ph.D., Suganthi Balasubramanian, Ph.D., Andrew Blumenfeld, Gisu Eom, Lukas

718 Habegger, Ph.D., Alicia Hawes, B.S., Shareef Khalid, Jeffrey G. Reid, Ph.D., Evan K. Maxwell,

719 Ph.D., William Salerno, Ph.D., Jeffrey C. Staples, Ph.D.

720 Contribution: X.B., A.H., W.S. and J.G.R. performed and are responsible for analysis needed to

721 produce exome and genotype data. G.E. and J.G.R. provided compute infrastructure

722 development and operational support. S.B., and J.G.R. provide variant and gene annotations and 723 their functional interpretation of variants. E.M., J.S., A.B., L.H., J.G.R. conceived and are

724 responsible for creating, developing, and deploying analysis platforms and computational

725 methods for analyzing genomic data.

\section{$727 \quad$ Analytical Genetics}

728 Gonçalo R. Abecasis, Ph.D., Joshua Backman, Ph.D., Manuel A. Ferreira, Ph.D., Lauren Gurski,

729 Jack A. Kosmicki, Ph.D., Alexander H. Li, Ph.D., Adam E. Locke, Ph.D., Anthony Marcketta, 730 Jonathan Marchini, Ph.D., Joelle Mbatchou, Ph.D., Shane McCarthy, Ph.D., Colm O’Dushlaine, 731 Ph.D., Dylan Sun, Kyoko Watanabe, Ph.D. 
732 Contribution: J.A.K. and M.A.F. performed association analyses and led manuscript writing

733 group. J.B. identified low-quality variants in exome sequence data using machine learning. L.G.

734 and K.W. helped with visualization of association results. A.H.L., A.E.L., A.M. and D.S.

735 prepared the analytical pipelines to perform association analyses. J.M. and J.M. developed and

736 helped deploy REGENIE. S.M. and C.O’D. helped defined COVID-19 phenotypes. G.R.A.

737 supervised all analyses. All authors contributed to and reviewed the final version of the

738 manuscript.

Immune, Respiratory, and Infectious Disease Therapeutic Area Genetics

741 Julie E. Horowitz, PhD.

742 Contribution: J.E.H. helped defined COVID-19 phenotypes, interpret association results and led

743 the manuscript writing group.

\section{$\underline{\text { Research Program Management }}$}

746 Marcus B. Jones, Ph.D., Michelle LeBlanc, Ph.D., Jason Mighty, Ph.D., Lyndon J. Mitnaul, 747 Ph.D.

748 Contribution: All authors contributed to the management and coordination of all research

749 activities, planning and execution. All authors contributed to the review process for the final 750 version of the manuscript. 
752 UK Biobank Exome Sequencing Consortium Research Team

753

$754 \quad{ }^{1}$ Bristol Myers Squibb

755 Oleg Moiseyenko, Carlos Rios, Saurabh Saha

756

$757 \quad{ }^{2}$ Regeneron Pharmaceuticals Inc.

758 Listed in pages 38 to 40.

759

$760 \quad{ }^{3}$ Biogen Inc.

761 Sally John, Chia-Yen Chen, David Sexton, Paola G. Bronson, Christopher D. Whelan, Varant

762 Kupelian, Eric Marshall, Timothy Swan, Susan Eaton, Jimmy Z. Liu, Stephanie Loomis, Megan

763 Jensen, Saranya Duraisamy, Ellen A. Tsai, Heiko Runz

764

$765 \quad{ }^{4}$ Alnylam Pharmaceuticals

766 Aimee M. Deaton, Margaret M. Parker, Lucas D. Ward, Alexander O. Flynn-Carroll, Greg

767 Hinkle, Paul Nioi

768

$769 \quad{ }^{\mathbf{5}}$ AstraZeneca

770 Olympe Chazara, Sri VV. Deevi, Xiao Jiang, Amanda O’Neill, Slavé Petrovski, Katherine

771 Smith, Quanli Wang

772

$773 \quad{ }^{6}$ Takeda California Inc 
774 Jason Tetrault, Dorothee Diogo, Aldo Cordova Palomera, Emily Wong, Rajesh Mikkilineni,

775 David Merberg, Sunita Badola, Erin N. Smith, Sandor Szalma

776

$777 \quad{ }^{7}$ Pfizer, Inc

778 Yi-Pin Lai, Xing Chen, Xinli Hu, Melissa R. Miller

$780 \quad{ }^{8}$ Abbvie

781 Xiuwen Zheng, Bridget Riley-Gillis, Jason Grundstad, Sahar Esmaeeli, Jeff Waring, J. Wade

782 Davis

$784{ }^{1}$ Bristol Myers Squibb, Route 206 and Province Line Road, Princeton, NJ 08543, USA

$785{ }^{2}$ Regeneron Pharmaceuticals Inc., 777 Old Saw Mill River Road, Tarrytown, New York 10591,

786 USA

787 B3iogen Inc., 225 Binney Street, Cambridge, MA 02139, USA

788 4Alnylam Pharmaceuticals, 675 West Kendall St, Cambridge, MA 02142, USA

$789{ }^{5}$ AstraZeneca Centre for Genomics Research, Discovery Sciences, BioPharmaceuticals R\&D,

790 Cambridge, UK

$791{ }^{6}$ Takeda California Inc., 9625 Towne Centre Dr, San Diego, CA 92121, USA

7927 Pfizer, Inc., 1 Portland Street, Cambridge MA 02139, USA

$793{ }^{8}$ AbbVie, Inc., 1 N. Waukegan Rd, North Chicago, IL 60064, USA 


\section{GenOMICC Consortium}

797 Sara Clohisey ${ }^{1}$, Fiona Griffiths ${ }^{1}$, James Furniss ${ }^{1}$, James Furniss ${ }^{1}$, Trevor Paterson ${ }^{1}$, Tony

798 Wackett $^{1}$, Ruth Armstrong ${ }^{1}$, Wilna Oosthuyzen ${ }^{1}$, Nick Parkinson ${ }^{1}$, Max Head Fourman ${ }^{1}$, Andrew

799 Law $^{1}$, Veronique Vitart ${ }^{2}$, Lucija Klaric ${ }^{2}$, Anne Richmond ${ }^{2}$, Chris P. Ponting ${ }^{2}$, Andrew D.

800 Bretherick $^{2}$, Charles Hinds ${ }^{3}$, Timothy Walsh ${ }^{4}$, Sean Keating ${ }^{4}$, Clark D Russell ${ }^{1,5}$, Malcolm G.

801 Semple $^{6,7}$, Kathy Rowan ${ }^{8}$, Elvina Gountouna ${ }^{9}$, Nicola Wrobel ${ }^{10}$, Lee Murphy ${ }^{10}$, Angie Fawkes ${ }^{10}$,

802 Richard Clark ${ }^{10}$, Audrey Coutts ${ }^{10}$, Lorna Donnelly ${ }^{10}$, Tammy Gilchrist ${ }^{10}$, Katarzyna Hafezi ${ }^{10}$,

803 Louise Macgillivray $^{10}$, Alan Maclean ${ }^{10}$, Sarah McCafferty ${ }^{10}$, Kirstie Morrice ${ }^{10}$, , Angie Fawkes ${ }^{10}$,

804 Julian Knight $^{11}$, Charlotte Summers ${ }^{12}$, Manu Shankar-Hari ${ }^{13,14}$, Peter Horby ${ }^{15}$, Alistair

805 Nichol $^{16,17,18}$, David Maslove ${ }^{19}$, Lowell Ling ${ }^{20}$, Danny McAuley ${ }^{21,22}$, Hugh Montgomery ${ }^{23}$, Peter

806 J.M. Openshaw ${ }^{24,25}$.

$807{ }^{1}$ Roslin Institute, University of Edinburgh, Easter Bush, Edinburgh, EH25 9RG, UK

$808{ }^{2}$ MRC Human Genetics Unit, Institute of Genetics and Molecular Medicine, University of

809 Edinburgh, Western General Hospital, Crewe Road, Edinburgh, EH4 2XU, UK

$810{ }^{3}$ William Harvey Research Institute, Barts and the London School of Medicine and Dentistry,

811 Queen Mary University of London, London EC1M 6BQ, UK

$812{ }^{4}$ Intensive Care Unit, Royal Infirmary of Edinburgh, 54 Little France Drive, Edinburgh, EH16

813 5SA, UK

$814{ }^{5}$ Centre for Inflammation Research, The Queen's Medical Research Institute, University of

815 Edinburgh, 47 Little France Crescent, Edinburgh, UK

$816{ }^{6}$ NIHR Health Protection Research Unit for Emerging and Zoonotic Infections, Institute of

817 Infection, Veterinary and Ecological Sciences University of Liverpool, Liverpool, L69 7BE, UK

$818{ }^{7}$ Respiratory Medicine, Alder Hey Children's Hospital, Institute in The Park, University of

819 Liverpool, Alder Hey Children's Hospital, Liverpool, UK

$820 \quad{ }^{8}$ Intensive Care National Audit \& Research Centre, London, UK

$821{ }^{9}$ Centre for Genomic and Experimental Medicine, Institute of Genetics and Molecular Medicine,

822 University of Edinburgh, Western General Hospital, Crewe Road, Edinburgh, EH4 2XU, UK

$823{ }^{10}$ Edinburgh Clinical Research Facility, Western General Hospital, University of Edinburgh, 
EH4 2XU, UK

$825{ }^{11}$ Wellcome Centre for Human Genetics, University of Oxford, Oxford, UK

$826 \quad{ }^{12}$ Department of Medicine, University of Cambridge, Cambridge, UK

$827{ }^{13}$ Department of Intensive Care Medicine, Guy's and St. Thomas NHS Foundation Trust,

828 London, UK

$829 \quad{ }^{14}$ School of Immunology and Microbial Sciences, King’s College London, UK

$830{ }^{15}$ Centre for Tropical Medicine and Global Health, Nuffield Department of Medicine, University

831 of Oxford, Old Road Campus, Roosevelt Drive, Oxford, OX3 7FZ, UK

$832{ }^{16}$ Clinical Research Centre at St Vincent's University Hospital, University College Dublin,

833 Dublin, Ireland

$834{ }^{17}$ Australian and New Zealand Intensive Care Research Centre, Monash University, Melbourne,

835 Australia

$836 \quad{ }^{18}$ Intensive Care Unit, Alfred Hospital, Melbourne, Australia

$837{ }^{19}$ Department of Critical Care Medicine, Queen's University and Kingston Health Sciences

838 Centre, Kingston, ON, Canada

$839{ }^{20}$ Department of Anaesthesia and Intensive Care, The Chinese University of Hong Kong, Prince

840 of Wales Hospital, Hong Kong, China

$841{ }^{21}$ Wellcome-Wolfson Institute for Experimental Medicine, Queen's University Belfast, Belfast,

842 Northern Ireland, UK

$843{ }^{22}$ Department of Intensive Care Medicine, Royal Victoria Hospital, Belfast, Northern Ireland, $844 \quad \mathrm{UK}$

$845 \quad{ }^{23}$ UCL Centre for Human Health and Performance, London, W1T 7HA, UK

$846 \quad{ }^{24}$ National Heart and Lung Institute, Imperial College London, London, UK 
medRxiv preprint doi: https://doi.org/10.1101/2020.10.28.20221804; this version posted February 28, 2021. The copyright holder for this preprint (which was not certified by peer review) is the author/funder, who has granted medRxiv a license to display the preprint in perpetuity.

It is made available under a CC-BY-ND 4.0 International license.

$847 \quad{ }^{25}$ Imperial College Healthcare NHS Trust: London, London, UK

848 


\section{SUPPLEMENTARY FIGURES}


A.

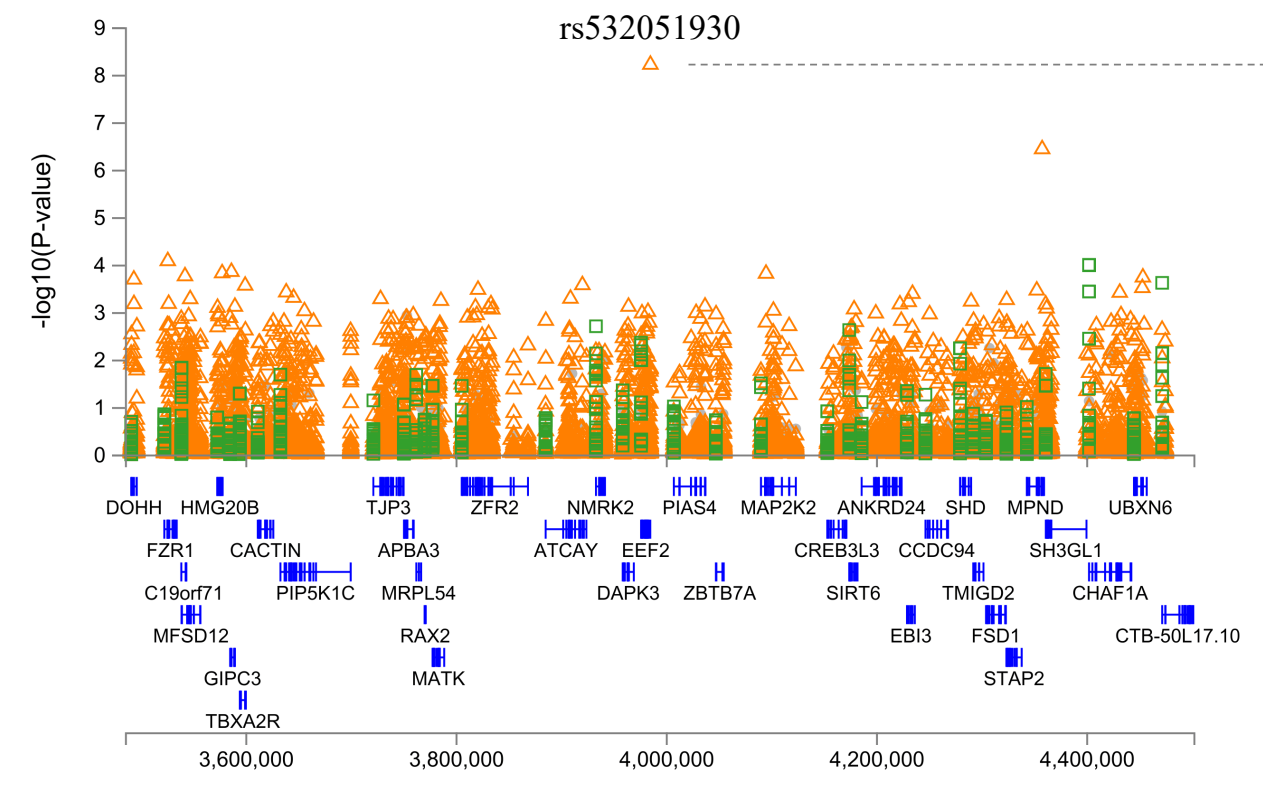

Supplementary Figure 1. Association between a rare promoter variant in $E E F$

(rs532051930:A) and the COVID-19 hospitalization phenotype. (A) Regional association plot centered on rs532051930. Orange triangles: individual rare variants $(\mathrm{MAF}<0.5 \%)$. Green squares: burden tests. Grey circles: individual common variants (MAF $>0.5 \%$ ). (B) Forest plot showing association in the two individual datasets included in the meta-analysis of this

variant. (C) Results from a population-scale PROcap (Precision Run-On 5' cap sequencing) study [19], which profiles transcription start sites of nascent RNAs attached to RNA

polymerase. The variant rs532051930 (vertical red line) is located 2 bp away from the peak of transcription initiation. (D) Distribution of EEF2 expression among 1,918 individuals from the GHS study with available RNA-seq data from liver tissue. Vertical red line indicates

expression levels for the only individual who was heterozygote for the rare promoter variant rs532051930.
B.

\begin{tabular}{lccclll} 
STUDY & RR|RA|AAA & RR|RA|AA & & OR [95\% Cl] & PVALUE & AAF \\
\hline UKB_Freeze_450_EUR & $1700|3| 0$ & $399228|12| 0$ & & $80.95[13.12,499.469]$ & $2.2 \mathrm{e}-06$ & $2 \mathrm{e}-05$ \\
GHS_Freez__45_EUR & $169|1| 0$ & $109282|10| 0$ & & $134.763[7.892,2301.292]$ & $7.1 \mathrm{e}-04$ & $5 \mathrm{e}-05$
\end{tabular}

META

$1869|4| 0 \quad 508510|22| 0$

93.906 [20.295,434.505] $6.2 \mathrm{e}-09 \quad 3 \mathrm{e}-05$

$1 \quad 125$

600

C.

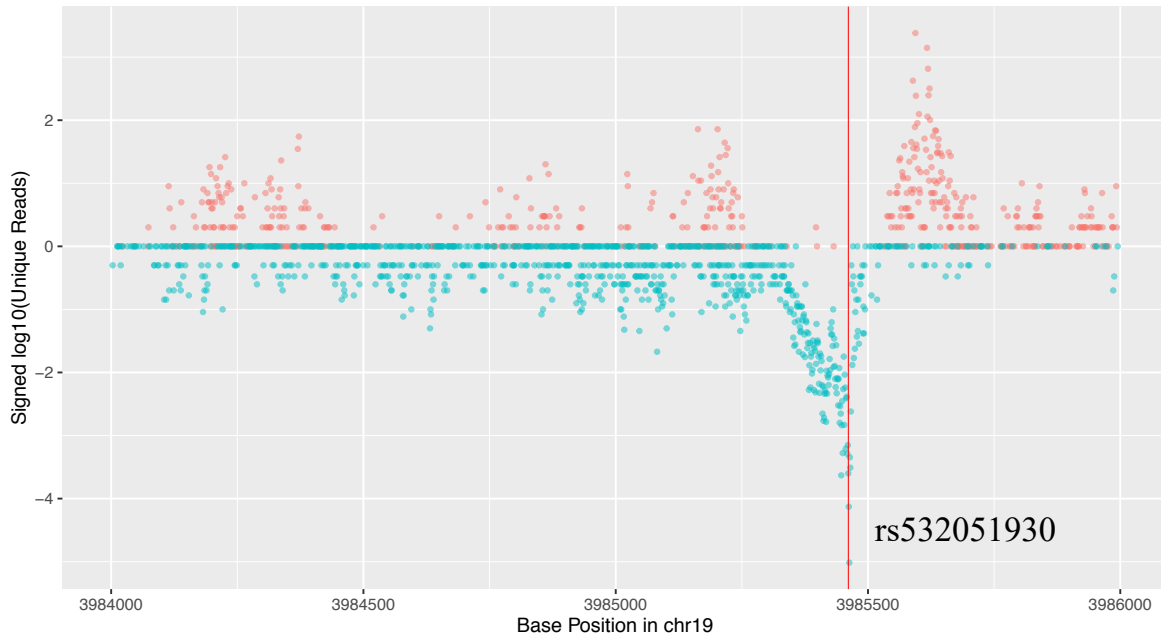

Strand
D.

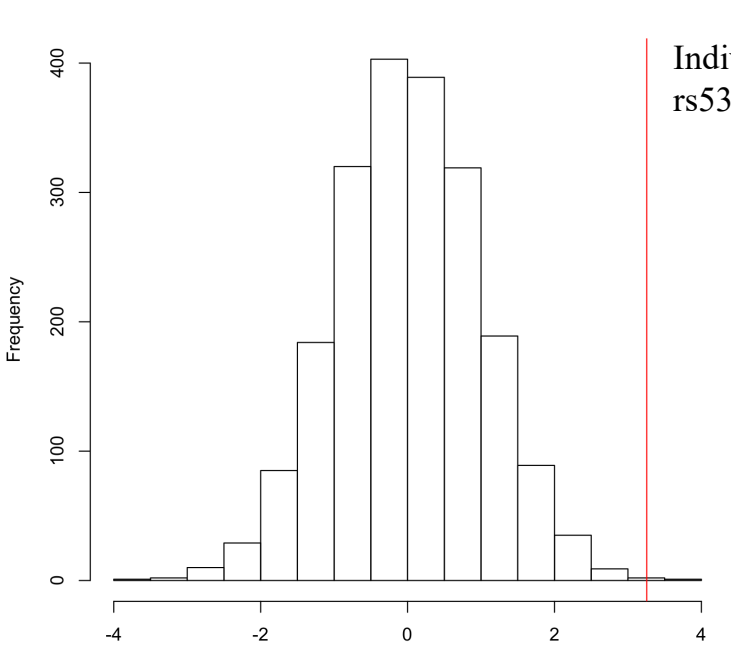

Normalized $E E F 2$ expression in liver (SD units) ividual heterozygote for 532051930:A 


\section{SUPPLEMENTARY TABLES}


Supplementary Table 1. Demographics and clinical characteristics of study participants.

\begin{tabular}{|c|c|c|c|}
\hline \multirow{2}{*}{ Demographics } & \multicolumn{2}{|c|}{ COVID-19 Positive } & \multirow{2}{*}{$\begin{array}{l}\text { Covid-19 Negative or } \\
\text { Unknown }\end{array}$} \\
\hline & Hospitalized & Not Hospitalized & \\
\hline \multicolumn{4}{|c|}{ UK Biobank } \\
\hline Total $\mathbf{N}$ & 1848 & 5400 & 416935 \\
\hline AFR ancestry, n (\%) & $80(3.8)$ & $134(2.2)$ & $8495(1.8)$ \\
\hline EUR ancestry, n (\%) & $1703(81.9)$ & $5030(83.2)$ & $399240(85.7)$ \\
\hline SAS ancestry, n (\%) & $65(3.1)$ & $236(3.9)$ & $9200(1.9)$ \\
\hline Average Age, y $(\%>60 y)$ & $59.7(57)$ & $52.6(22)$ & $56.2(36)$ \\
\hline Female, n (\%) & $737(39.8)$ & $2896(53.6)$ & $229572(55.1)$ \\
\hline Hypertension, n (\%) & $884(47.8)$ & $1214(22.5)$ & $96851(23.2)$ \\
\hline Cardiovascular Disease, n (\%) & $265(14.3)$ & $330(6.1)$ & $24859(5.8)$ \\
\hline Type 2 Diabetes, n (\%) & $342(18.5)$ & $378(7)$ & $25335(6.1)$ \\
\hline Chronic kidney disease, n (\%) & $134(7.3)$ & $112(2.1)$ & $8096(1.9)$ \\
\hline Asthma, n (\%) & $343(18.5$ & $886(16.4)$ & $59229(14.2)$ \\
\hline COPD, n (\%) & $208(11.2)$ & $164(3)$ & $10117(2.4)$ \\
\hline \multicolumn{4}{|c|}{ GHS } \\
\hline Total N & 170 & 664 & 109292 \\
\hline EUR ancestry, n (\%) & $170(100)$ & $664(100)$ & $109292(100)$ \\
\hline Average Age, y $(\%>60 y)$ & $67.81(76.47)$ & $54.74(39.0)$ & $55.75(44.14)$ \\
\hline Female, n (\%) & $90(52.94)$ & $435(65.51)$ & $68226(62.42)$ \\
\hline Hypertension, n (\%) & $138(81.17)$ & $343(51.65)$ & $53658(49.09)$ \\
\hline Cardiovascular Disease, n (\%) & $77(45.29)$ & $108(16.26)$ & $17269(15.80)$ \\
\hline Type 2 Diabetes, n (\%) & $73(42.94)$ & $158(23.79)$ & $23290(21.30)$ \\
\hline Chronic kidney disease, n (\%) & $64(37.64)$ & $94(14.15)$ & $14246(13.03)$ \\
\hline Asthma, n (\%) & $15(8.82)$ & $47(7.07)$ & $6975(6.38)$ \\
\hline COPD, n (\%) & $47(27.64)$ & $67(10.09)$ & $10822(9.90)$ \\
\hline \multicolumn{4}{|c|}{ PMBB } \\
\hline Total N & 67 & 99 & 959 \\
\hline AFR ancestry, $n(\%)$ & $67(100)$ & $99(100)$ & $959(100)$ \\
\hline Average Age, y $(\%>60 y)$ & $62.58(61.19)$ & $47.64(19.19)$ & $56.24(43.27)$ \\
\hline Female, n (\%) & $38(56.7)$ & $72(72.7)$ & $641(66.8)$ \\
\hline Hypertension, n (\%) & $59(88.1)$ & $52(52.5)$ & $704(73.4)$ \\
\hline Cardiovascular Disease, n (\%) & $40(59.7)$ & $17(17.2)$ & $359(37.4)$ \\
\hline Type 2 Diabetes, n (\%) & $50(74.6)$ & $31(31.3)$ & $440(45.9)$ \\
\hline Chronic kidney disease, n (\%) & $42(62.7)$ & $13(13.1)$ & $300(31.3)$ \\
\hline Asthma, n (\%) & $18(26.9)$ & $23(23.2)$ & $294(30.7)$ \\
\hline COPD, n (\%) & $20(29.9)$ & $8(8.1)$ & $145(15.1)$ \\
\hline
\end{tabular}


Supplementary Table 2. Breakdown of COVID-19 status across the four studies included in the analysis.

\begin{tabular}{|c|c|c|c|c|c|c|c|c|}
\hline \multirow{2}{*}{$\begin{array}{l}\text { COVID-19 } \\
\text { status }\end{array}$} & \multirow{2}{*}{$\begin{array}{c}\text { Positive } \\
\text { qPCR or } \\
\text { serology for } \\
\text { SARS-CoV-2 }\end{array}$} & \multirow{2}{*}{$\begin{array}{c}\text { ICD10 U07 } \\
\text { diagnosis or } \\
\text { hospitalization }\end{array}$} & \multirow{2}{*}{$\begin{array}{c}\text { Severe COVID-19 } \\
\text { (ventilation or } \\
\text { death) }\end{array}$} & \multirow{2}{*}{$\begin{array}{l}\text { Negative qPCR } \\
\text { or serology test } \\
\text { for SARS-CoV-2 }\end{array}$} & & & & \\
\hline & & & & & UK Biobank & GHS & РMBB & Total \\
\hline \multirow{11}{*}{ Positive } & Yes & Yes & Yes & Yes or No or NA & 382 & 49 & 27 & 458 \\
\hline & Yes & Yes & No or NA & Yes or No or NA & 1119 & 121 & 40 & 1,280 \\
\hline & Yes & No or NA & Yes & Yes or No or NA & 0 & 0 & 0 & 0 \\
\hline & Yes & No or NA & No or NA & Yes or No or NA & 5400 & 664 & 99 & 6,163 \\
\hline & No or NA & Yes & Yes & No or NA & 122 & 0 & 0 & 122 \\
\hline & No or NA & Yes & No or NA & No or NA & 77 & 0 & 0 & 77 \\
\hline & No or NA & No or NA & Yes & No or NA & 0 & 0 & 0 & 0 \\
\hline & No or NA & Yes & Yes & Yes & 37 & 0 & 0 & 37 \\
\hline & No or NA & Yes & No or NA & Yes & 111 & 0 & 0 & 111 \\
\hline & No or NA & No or NA & Yes & Yes & 0 & 0 & 0 & 0 \\
\hline & & & & & Total $=7248$ & Total $=834$ & Total $=166$ & Total $=8248$ \\
\hline Negative & No or NA & No or NA & No or NA & Yes & 32,867 & 15,574 & 959 & 49,400 \\
\hline Unknown & NA & No or NA & No or NA & NA & 384,068 & 93,718 & 7,779 & 485,565 \\
\hline \multicolumn{5}{|c|}{ Total } & 424,183 & 110,126 & 8,904 & 543,213 \\
\hline
\end{tabular}


Supplementary Table 3. Definitions used for the seven COVID-19 phenotypes analyzed.

\begin{tabular}{|c|c|c|c|c|c|c|c|c|c|}
\hline \multirow{2}{*}{$\begin{array}{l}\text { Broad phenotype } \\
\text { category }\end{array}$} & \multirow{2}{*}{ Phenotype } & \multirow{2}{*}{$\begin{array}{c}\text { Case/control } \\
\text { group }\end{array}$} & \multicolumn{3}{|c|}{ Definition } & \multicolumn{4}{|c|}{ Sample size with genetic data } \\
\hline & & & COVID-19 status & Hospitalized & Severe disease & UK Biobank & GHS & PMBB & Total \\
\hline \multirow{10}{*}{ Risk of infection } & \multirow{2}{*}{$\begin{array}{c}\text { COVID-19 positive } \\
\text { vs. } \\
\text { COVID-19 negative or unknown }\end{array}$} & Cases & Positive & Yes, No or NA & Yes, No or NA & 7,248 & 834 & 166 & 8,248 \\
\hline & & Controls & Negative or unknown & No or NA & No or NA & 416,935 & 109,292 & 8,738 & 534,965 \\
\hline & \multirow{2}{*}{$\begin{array}{l}\text { COVID-19 positive } \\
\text { vs. } \\
\text { COVID-19 negative }\end{array}$} & Cases & Positive & Yes, No or NA & Yes, No or NA & 7,248 & 834 & 166 & 8,248 \\
\hline & & Controls & Negative & No or NA & No or NA & 32,867 & 15,574 & 959 & 49,400 \\
\hline & \multirow{2}{*}{$\begin{array}{c}\text { COVID-19 positive and not hospitalized } \\
\text { vs. } \\
\text { COVID-19 negative or unknown } \\
\end{array}$} & Cases & Positive & No & No & 5,400 & 664 & 99 & 6,163 \\
\hline & & Controls & Negative or unknown & No or NA & No or NA & 416,935 & 109,292 & 8,738 & 534,965 \\
\hline & \multirow{2}{*}{$\begin{array}{l}\text { COVID-19 positive and hospitalized } \\
\text { vs. } \\
\text { COVID-19 negative or unknown }\end{array}$} & Cases & Positive & Yes (or death) & Yes, No or NA & 1,848 & 170 & 67 & 2,085 \\
\hline & & Controls & Negative or unknown & No or NA & No or NA & 416,935 & 109,292 & 8,738 & 534,965 \\
\hline & \multirow{2}{*}{$\begin{array}{c}\text { COVID-19 positive and severe } \\
\text { vs. } \\
\text { COVID-19 negative or unknown }\end{array}$} & Cases & Positive & Yes, No or NA & Yes & 541 & 49 & NA & 590 \\
\hline & & Controls & Negative or unknown & No or NA & No or NA & 416,935 & 109,292 & NA & 526,227 \\
\hline \multirow{4}{*}{$\begin{array}{l}\text { Risk of adverse outcomes } \\
\text { amongst infected } \\
\text { individuals }\end{array}$} & \multirow{2}{*}{$\begin{array}{l}\text { COVID-19 positive and hospitalized } \\
\text { vs. } \\
\text { COVID-19 positive and not hospitalized }\end{array}$} & Cases & Positive & Yes (or death) & Yes, No or NA & 1,703 & 170 & 67 & 1,940 \\
\hline & & Controls & Positive & No & No & 5,030 & 664 & 99 & 5,793 \\
\hline & \multirow{2}{*}{$\begin{array}{c}\text { COVID-19 positive and severe } \\
\text { vs. } \\
\text { COVID-19 positive and not hospitalized }\end{array}$} & Cases & Positive & Yes, No or NA & Yes & 523 & 49 & NA & 572 \\
\hline & & Controls & Positive & No & No & 5,164 & 664 & NA & 5,828 \\
\hline
\end{tabular}


Supplementary Table 4. Genomic inflation factor (lambda GC) observed in the analysis of exome sequence variants for each of the seven phenotypes tested.

\begin{tabular}{|c|c|c|c|c|c|c|c|c|c|c|c|c|c|}
\hline \multirow[b]{2}{*}{ Phenotype } & \multirow[b]{2}{*}{ Study } & \multirow[b]{2}{*}{ Ancestry } & \multirow[b]{2}{*}{$\mathrm{N}$ cases } & \multirow[b]{2}{*}{$\mathrm{N}$ controls } & \multicolumn{3}{|c|}{$\begin{array}{c}\text { Exome-sequencing variants with MAF }<0.5 \% \text { \& } \\
\text { MAC }>=5\end{array}$} & \multicolumn{3}{|c|}{$\begin{array}{l}\text { Exome-sequencing variants with MAF }<0.5 \% \text { \& } \\
\text { MAC }>25\end{array}$} & \multicolumn{3}{|c|}{ Exome-sequencing variants with MAF>0.5\% } \\
\hline & & & & & $\mathrm{N}$ variants & $\begin{array}{l}\text { Proportion of } \\
\text { variants with } \\
\text { MAC=0 in cases }\end{array}$ & $\begin{array}{c}\text { Lambda } \\
\text { GC }\end{array}$ & $\mathrm{N}$ variants & $\begin{array}{l}\text { Proportion of } \\
\text { variants with } \\
\text { MAC=0 in cases }\end{array}$ & $\begin{array}{l}\text { Lambda } \\
\text { GC }\end{array}$ & $\mathrm{N}$ variants & $\begin{array}{c}\text { Proportion of } \\
\text { variants with } \\
\text { MAC=0 in cases }\end{array}$ & $\begin{array}{c}\text { Lambda } \\
\text { GC }\end{array}$ \\
\hline \multirow{4}{*}{ COVID19_positive_hospitalized_vs_COVID19_negative_or_unknown_combined } & UKB Freeze 450 & SAS & 65 & 9200 & 798145 & 0.873 & 0.202 & 222553 & 0.719 & 0.774 & 227664 & 0.193 & 1.254 \\
\hline & $\begin{array}{l}\text { UPENN-PMBB Freze One } \\
\text { UKB Freze } 450\end{array}$ & $\begin{array}{lll}\mathrm{AFR} \\
\mathrm{AFR}\end{array}$ & 67 & $\frac{8738}{8495}$ & $\frac{890983}{81251}$ & $\frac{0.857}{0.830}$ & $\frac{0.215}{0.268}$ & 279379 & 0.708 & $\frac{0.748}{0.038}$ & $\frac{486699}{380222}$ & $\frac{0.132}{0.120}$ & $\frac{1.099}{0.947}$ \\
\hline & GHS Frezeze 145 Exome & $\frac{\mathrm{ARK}}{\mathrm{EUR}}$ & $\frac{80}{170}$ & $\frac{84932}{109292}$ & $\frac{2812015}{2899753}$ & 0.930 & $\frac{0.208}{0.042}$ & 889226 & 0.033 & $\frac{0.003}{0.23}$ & $\frac{380222}{172227}$ & $\frac{0.120}{0.046}$ & 0.997 \\
\hline & UKB Freze 450 & $\begin{array}{c}\text { EUR } \\
A H\end{array}$ & 1703 & 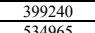 & 6411484 & 0.849 & 0.126 & 2074846 & 0.622 & 0.555 & $\frac{166323}{25216}$ & 0.000 & 1.004 \\
\hline \multirow{4}{*}{ COVID19_positive_hospitalized_vs_COVID19_positive_not_hospitalized_combined } & $\begin{array}{l}\text { Meta-analysis } \\
\text { UPENN-PMBB Freze One }\end{array}$ & $\frac{\text { ALL }}{\text { AFR }}$ & $\frac{2085}{67}$ & $\frac{534965}{99}$ & $\frac{8053662}{\mathrm{NA}}$ & $\frac{0.832}{\mathrm{NA}}$ & $\frac{0.126}{\mathrm{NA}}$ & $\frac{2833904}{\mathrm{NA}}$ & $\frac{0.599}{\mathrm{NA}}$ & $\frac{0.554}{\mathrm{NA}}$ & $\frac{352116}{330315}$ & $\frac{0.043}{0.012}$ & $\frac{1.02}{0.183}$ \\
\hline & & EUR & 170 & 664 & 209299 & 0.549 & 0.866 & $\mathrm{NA}$ & $\frac{\mathrm{NA}}{\mathrm{NA}}$ & $\mathrm{NA}$ & 173449 & 0.035 & \\
\hline & UKB Freeze 450 & EUR & & 5030 & 424564 & 0.072 & 1.099 & 112045 & 0.000 & 1.043 & $\frac{166403}{16603}$ & 0.000 & $\frac{1.013}{1.037}$ \\
\hline & Meta-analysis & ALL & 1940 & 5793 & 462977 & 0.126 & 1.017 & 128932 & 0.000 & $\frac{1.021}{1.021}$ & $\frac{198264}{39864}$ & 0.009 & $\frac{1.037}{0.388}$ \\
\hline \multirow{5}{*}{ COVID19_positive_not_hospitalized_vs_COVID19_negative_or_unknown_combined } & 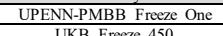 & AFR & 99 & 8738 & 893407 & 0.796 & 0.338 & $\frac{280294}{25076}$ & $\frac{0.596}{0.492}$ & $\frac{0.992}{0.928}$ & $\frac{487296}{3.7943}$ & $\frac{0.076}{0.050}$ & $\frac{0.961}{0.098}$ \\
\hline & UKB Freze 450 & $\begin{array}{ll}\text { AFR } \\
\text { SAS }\end{array}$ & 134 & 8495 & $\begin{array}{ll}816964 \\
80557\end{array}$ & $\begin{array}{ll}0.736 \\
0.55\end{array}$ & 0.48 & 250786 & 0.492 & 1.218 & $\frac{379423}{207147}$ & 0.050 & $\begin{array}{ll}0.998 \\
\end{array}$ \\
\hline & $\begin{array}{l}\text { UKB Freeze 450 } \\
\text { GHS Freze } 145 \text { Exome }\end{array}$ & $\frac{\text { SAS }}{\text { EUR }}$ & 236 & $\frac{9200}{109292}$ & $\frac{808557}{209752}$ & $\frac{0.652}{0.024}$ & $\frac{0.622}{0.167}$ & $\frac{226850}{89254}$ & $\frac{0.325}{0.559}$ & $\frac{1.326}{0.731}$ & $\frac{227147}{17221}$ & 0.016 & $\frac{1.016}{1.016}$ \\
\hline & UKB Freeze 450 & 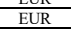 & $\frac{003}{5030}$ & 399240 & 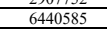 & 0.024 & 0.145 & $\frac{8925094}{208694}$ & 0.387 & $\frac{1.101}{1.074}$ & $\frac{12241}{166350}$ & 0.000 & $\frac{1.019}{1.019}$ \\
\hline & 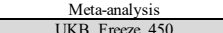 & $\frac{\text { ALL }}{S A S}$ & 6163 & 534965 & $\frac{8091286}{796240}$ & 0.710 & 0.345 & 2849393 & $\frac{0.385}{0.910}$ & $\frac{1.059}{0.13}$ & $\frac{251738}{301780}$ & 0.020 & 0.982 \\
\hline \multirow{3}{*}{ COVID19_positive_severe_vs_COVID19_negative_or_unknown_combined } & $\begin{array}{l}\text { UKB Freeze e } 50 \\
\text { UKB Freze } 450\end{array}$ & $\frac{\text { SAS }}{\text { AFR }}$ & $\frac{18}{33}$ & $\frac{9200}{8495}$ & $\frac{796240}{811241}$ & $\frac{0.961}{0.919}$ & $\frac{0.04}{0.132}$ & $\frac{2228161}{24076}$ & $\frac{0.910}{0.831}$ & $\frac{0.163}{0.346}$ & $\frac{226990}{379346}$ & $\frac{0.496}{0.302}$ & 0.821 \\
\hline & GHS Freeze 145 Exome & $\frac{A T n}{E U R}$ & 49 & $\frac{109292}{10929}$ & $\frac{28114149}{289569}$ & 0.976 & $\frac{0.013}{0.013}$ & 888545 & 0.932 & $\frac{.030}{0.08}$ & 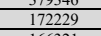 & $\frac{0.246}{0.246}$ & $\frac{0.075}{0.785}$ \\
\hline & $\begin{array}{c}\text { UKB F reeze } 450 \\
\text { Meta-analysis }\end{array}$ & EUR & $\frac{490}{590}$ & $\frac{399240}{55227}$ & $\frac{6400400}{787642}$ & 0.931 & 0.034 & $\frac{2070233}{272152}$ & 0.812 & $\frac{0.176}{0.214}$ & $\frac{166321}{22598}$ & 0.001 & $\frac{1.02}{0.899}$ \\
\hline \multirow{3}{*}{ COVID19_positive_severe_vs_COVID19_positive_not__hospitalized_combined } & UKB Freeze 450 & $\frac{\mathrm{ALL}}{\mathrm{AFR}}$ & 33 & $\frac{30221}{134}$ & $\mathrm{NA}$ & $\frac{0.917}{\mathrm{NA}}$ & NA & $\frac{212102}{\mathrm{NA}}$ & $\frac{\mathrm{N} .103}{\mathrm{NA}}$ & $\frac{0.214}{\mathrm{NA}}$ & $\frac{25350}{235941}$ & 0.090 & $\frac{0.289}{0.234}$ \\
\hline & $\begin{array}{ll}\text { GHS Freeze } 145 \text { Exome } \\
\end{array}$ & $\frac{\text { EUR }}{E \text { EUP }}$ & 49 & $\frac{664}{5030}$ & $\begin{array}{lll}194798 \\
337290\end{array}$ & 0.818 & 0.273 & $\frac{\mathrm{NA}}{87117}$ & $\frac{\mathrm{NA}}{0.043}$ & $\frac{\mathrm{NA}}{1003}$ & $\frac{170209}{1.619}$ & 0.228 & $\frac{1.141}{0.998}$ \\
\hline & $\begin{array}{c}\text { UKB Freeze 450 } \\
\text { Metatanalysis }\end{array}$ & $\frac{E U R}{A L L}$ & $\frac{400}{572}$ & $\frac{530}{5828}$ & $\frac{37369}{410271}$ & $\frac{0.327}{0.365}$ & $\frac{1.078}{0.912}$ & $\frac{87177}{101899}$ & $\frac{0.043}{0.035}$ & $\frac{1.003}{0.968}$ & $\frac{16164}{301689}$ & $\frac{0.001}{0.056}$ & 0.998 \\
\hline \multirow{4}{*}{ COVID19_positive_vs_COVID19_negative_combined } & UPENN-PMBB Freze One & AFR & 166 & 959 & 195274 & 0.331 & 1.345 & $\mathrm{NA}$ & $\mathrm{NA}$ & $\mathrm{NA}$ & 484596 & 0.023 & 0.974 \\
\hline & $\begin{array}{lll}\text { UKB Frezeze } 450 \\
\end{array}$ & $\frac{\text { AFR }}{\text { SAS }}$ & 214 & 766 & $\frac{141313}{149617}$ & 0.206 & 1.071 & $\frac{\mathrm{NA}}{\mathrm{NA}}$ & $\frac{\mathrm{NA}}{\mathrm{NA}}$ & $\frac{\mathrm{NA}}{\mathrm{N}}$ & 387132 & 0.013 & 0.938 \\
\hline & $\begin{array}{l}\text { UKB H reeze } 450 \\
\text { GHS Freeze } 145 \text { Exome } \\
\end{array}$ & $\frac{S A S}{E U R}$ & 834 & $\frac{844}{15574}$ & $\frac{149617}{896282}$ & 0.1295 & $\frac{1.1110}{0.889}$ & $\frac{\mathrm{NA}}{239671}$ & $\frac{\mathrm{NA}}{0.091}$ & $\frac{\mathrm{NA}}{1.024}$ & $\frac{28243}{172248}$ & 0.004 & $\frac{1.01}{1.019}$ \\
\hline & $\begin{array}{ll}\text { UKB Freeze } 450 \\
\text { Meta-analysis }\end{array}$ & $\begin{array}{llll}\text { EUR } \\
U I\end{array}$ & $\frac{6733}{828}$ & 31257 & 1361423 & 0.143 & $\frac{1.15}{103}$ & 417941 & 0.001 & $\frac{1.015}{1.05}$ & $\frac{166646}{47907}$ & 0.000 & $\frac{1}{0.994}$ \\
\hline \multirow{5}{*}{ COVID19_positive_vs_COVID19_negative_or_unknown_combined } & UPENN-PMBB Freatseze One & $\frac{\text { ALL }}{\text { AFR }}$ & $\frac{848}{166}$ & $\frac{4940}{8738}$ & $\frac{174710}{897805}$ & 0.203 & $\frac{1.023}{0.519}$ & 282679 & 0.434 & $\frac{1.023}{1.219}$ & 486918 & 0.0029 & $\begin{array}{ll}0.974 \\
0.972\end{array}$ \\
\hline & UKB Freze 450 & AFR & 214 & 8495 & 821371 & 0.636 & 0.666 & 253263 & 0.335 & 1.356 & 379070 & 0.015 & 1.02 \\
\hline & $\begin{array}{l}\text { UKB Freeze } 450 \\
\text { GHS Freece } 145 \text { Fome }\end{array}$ & $\frac{\text { SAS }}{\text { FUP }}$ & $\frac{301}{834}$ & $\frac{9200}{10292}$ & 812263 & 0.595 & 0.735 & 228572 & $\frac{0.246}{0.509}-x-3$ & $\frac{1.267}{0.44}$ & 2268601 & $\frac{0.007}{0.01}$ & $\frac{1.012}{1026}$ \\
\hline & UKB Freeze 450 & EUR & 6733 & 399240 & 6455895 & 0.675 & 0.446 & 2093385 & 0.315 & $\frac{1.047}{1.175}$ & $\frac{121729}{166339}$ & 0.000 & $\frac{1.060}{1.017}$ \\
\hline & Meta-analysis & ALL & 8248 & 534965 & 8111082 & 0.663 & 0.443 & 2857926 & 0.315 & 1.161 & 351576 & $\overline{0.009}$ & 0.996 \\
\hline
\end{tabular}




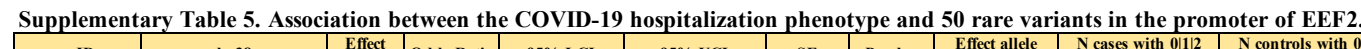

\begin{tabular}{|c|c|c|c|c|c|c|c|c|c|c|c|}
\hline rs ID & hg38 & $\begin{array}{l}\text { Effiect } \\
\text { allele }\end{array}$ & Odds Ratio & $95 \%$ LCI & $95 \%$ UCI & SE & P-value & $\begin{array}{l}\text { Effect allele } \\
\text { frequencty }\end{array}$ & $\begin{array}{l}\mathrm{N}_{\mathrm{N} \text { cases with }} 0|1| 1 \mid 2 \\
\text { copies of effect allele }\end{array}$ & $\begin{array}{l}\mathrm{N} \text { controls with } 00|1| 2 \\
\text { copies of effect allele }\end{array}$ & $\begin{array}{c}\text { Studies analyzed } \\
\end{array}$ \\
\hline $\mathrm{rr5} 332051930$ & 19:3985461:G:A & $\mathrm{A}$ & 93.9065 & 20.2954 & 434.505 & 0.7816 & $6.18 \mathrm{E}-09$ & & & & GHS Freeze 145 Megar Feeze EUR UKB Frezeze 450 EUR Meta \\
\hline$\frac{15374797871}{15.02513}$ & 19:3985414:A:G & $\mathrm{G}$ & 24.2157 & $\frac{1.84809}{1.7015}$ & 317.299 & $\frac{1.3127}{1.1209}$ & 0.0152 & & $146110^{0}$ & & $\begin{array}{l}\text { UKB Freeze } 450 \text { AFR UPENN-PMBB Freeze One AFR Meta } \\
\end{array}$ \\
\hline rs754033543 & & $\mathrm{C}$ & $\frac{18.9215}{18.659}$ & 1.73245 & $\frac{206.658}{202014}$ & $\frac{1.2198}{1.2155}$ & 0.0159 & 0.000027 & $\frac{1702110}{11769110}$ & $\begin{array}{llll}3992192110 \\
407747700\end{array}$ & $\begin{array}{c}\text { UKB Freeze 450 EUR Meta } \\
\text { SKR Frege } 40 \text { FUR }\end{array}$ \\
\hline 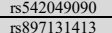 & $\frac{19: 39854377 \mathrm{~A}: \mathrm{G}}{19 \cdot 39557 \mathrm{G} \cdot \mathrm{C}}$ & $\frac{\mathrm{G}}{\mathrm{C}}$ & $\frac{18.6529}{177994}$ & $\frac{1.72231}{1.63807}$ & $\frac{202.014}{193191}$ & $\frac{1.2155}{1.2169}$ & $\frac{0.0161}{0.0180}$ & $\frac{0.000026}{0.000047}$ & $\frac{1769110}{187210}$ & $\begin{array}{l}4079477200 \\
509477470\end{array}$ & $\begin{array}{l}\text { UKB Freeze } 450 \text { EUR UPENN-PMBB Freeze One AFR } \\
\text { Geta } \\
\text { GHS Freeze } 145 \text { Megafreezez EUR UKB Freeze } 450 \text { EUR Meta }\end{array}$ \\
\hline 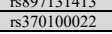 & $\begin{array}{l}\text { 19:3985354:G: } \\
\text { 19:3985421:G:A } \\
\end{array}$ & $\frac{C}{A}$ & $\frac{17.1894}{5.21063}$ & 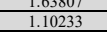 & $\frac{193.191}{24.6302}$ & $\frac{1.2169}{0.7925}$ & 0.0100 & 0.00004140 & $\frac{1982110}{1936210}$ & $50847 / 47100$ & 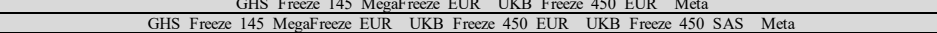 \\
\hline$\frac{15301002}{\mathrm{r} 554648032}$ & 19:3985433:G:A & & $\frac{5.2105}{6.19102}$ & 0.776398 & 49.3674 & $\frac{0.1753}{1.0593}$ & 0.0852 & 0.000057 & $\frac{195010}{1937110}$ & 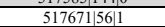 & 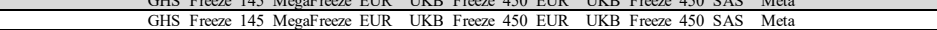 \\
\hline Is 201347619 & 19:3985401:T:A & A & 0.364401 & 0.0678296 & 1.95767 & 0.8578 & 0.2393 & 0.004028 & $\frac{197100}{14700}$ & $17094|138| 1$ & UKB Freze 450 AFR UPENN-PMBB Freeze One AFR Meta \\
\hline rs369523513 & 19:3985436:G:A & $\mathrm{A}$ & & & & & & 0.000116 & & & GHS Freeze 145 Megaf Frezeze EUR UKB Freeze 450 AFR UKB Freeze 450 EUR UPENN-PMBB Frezeze One AFR Meta \\
\hline 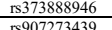 & 19:3985451:G:T & $\mathrm{T}_{\mathrm{T}}$ & 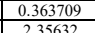 & 0.0429819 & $\frac{3.07768}{15.6831}$ & 1.0896 & 0.3533 & 0.000204 & 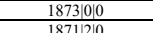 & 50831920810 & 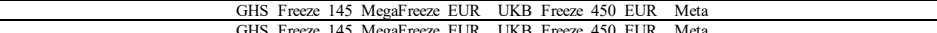 \\
\hline 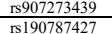 & 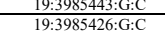 & $\frac{\mathrm{C}}{\mathrm{C}}$ & $\frac{2.35632}{0.361534}$ & $\frac{0.354027}{0.0260517}$ & $\frac{15.6831}{5.0172}$ & $\frac{0.9671}{1.342}$ & $\frac{0.3755}{0.484}$ & $\frac{0.00234}{0.000117}$ & 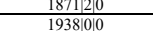 & $\frac{58227023730}{5176551220}$ & 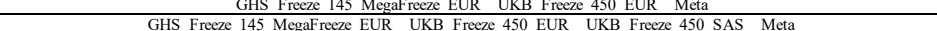 \\
\hline 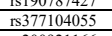 & 19:39855429:T:C & $\frac{\mathrm{C}}{\mathrm{C}}$ & 0.0361136 & $\frac{0.020317}{0.023969}$ & $\frac{5.05049}{5.5504}$ & $\frac{1.342}{1.3941}$ & 0.4650 & 0.000087 & $\frac{183800000}{18500}$ & $\frac{516505012730}{4160}$ & UKB Freeze 450 AFR UKB Freeze 450 EUR UPENN-PMBB Freeze One AFR Meta \\
\hline 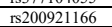 & 19:3985402:C:T & $\frac{T}{T}$ & $\frac{0.360523}{0.3053}$ & 0.00840259 & $\frac{15.4686}{1586}$ & $\frac{1.0 \% 1}{1.9179}$ & 0.5948 & 0.000064 & 17030100 & 3991871510 & 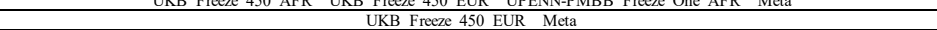 \\
\hline $\begin{array}{lll}57774095261 \\
\end{array}$ & 19:3985425:C:A & $\mathrm{A}$ & 0.352361 & 0.00521284 & 23.8177 & 2.1498 & 0.6275 & 0.000020 & 1850000 & 41643711770 & UKB Freeze $450 \mathrm{AFR}$ UKB Freze 450 EUR UPENN-PMBB Freeze One AFR Meta \\
\hline rs 529755390 & 19:3985441:T:C & $\mathrm{C}$ & 0.361172 & 0.00447913 & 29.123 & 2.2398 & & 0.000049 & $187330 \mid 00$ & $508368 \mid 5000$ & GHS Freze 145 Megafreeze EUR UKB Freeze 450 EUR Meta \\
\hline 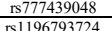 & $\frac{19: 3985423: \mathrm{A}: \mathrm{C}}{10 \cdot 398543 \cdot \mathrm{G}}$ & $\frac{\mathrm{C}}{\mathrm{G}}$ & 0.377494 & $\frac{0.00480048}{0.0023872}$ & $\frac{29.6849}{40.3162}$ & $\frac{2.227}{2.4015}$ & $\frac{0.6618}{0.670}$ & $\frac{0.000062}{0.00004}$ & 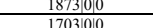 & 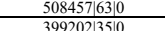 & $\begin{array}{l}\text { GHS Freeze } 145 \text { Megaf reeze EUR URB Freeze } \\
\text { UKB Frezez } 450 \text { EUR Meta }\end{array}$ \\
\hline 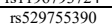 & $\frac{19.9985344 \mathrm{C}: \mathrm{U}}{19: 3985441 \mathrm{~T}: \mathrm{A}}$ & & 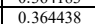 & 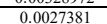 & & & & & 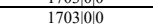 & 3991193810 & UKB Freeze 450 EUR Meta \\
\hline & 55441:T:TGGCGGCGA & $\overline{\mathrm{GGCGA}}$ & & & & & & & $\frac{187300}{18700}$ & 503368450 & GHS Freeze 145 Megafreeze EUR UKB Freeze 450 EUR Meta \\
\hline ris 190787427 & 19:39955426:G:A & $\frac{\mathrm{A}}{\mathrm{A}}$ & $\frac{0.365669}{0.3659}$ & 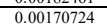 & $\frac{78.278}{78.278}$ & $\frac{2.7381}{2.738}$ & 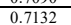 & 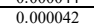 & 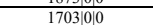 & 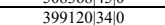 & UKB Freze 450 EUR Meta \\
\hline ris 1280637004 & 19:3985563:G:A & $\mathrm{A}$ & 0.364255 & 0.000412394 & 321.736 & 3.4611 & 0.7704 & 0.000024 & $\frac{1703000}{170300}$ & 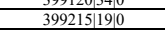 & UKB Freeze 450 EUR Meta \\
\hline rs563082396 & 19:3985435:C:A & $\mathrm{A}$ & 0.364183 & 0.000353722 & 374.953 & 3.5393 & 0.7753 & 0.000034 & 18730100 & 50846833500 & GHS Freeze 145 Megaf reeze EUR UKB Freeze 450 EUR Meta \\
\hline$\frac{\mathrm{NA}}{7374912847}$ & 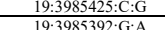 & $\mathrm{G}$ & 0.36411 & 0.000282174 & 469.838 & $\frac{3.6545}{3.8163}$ & 0.7822 & 0.000021 & 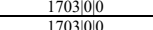 & $\frac{399217|17| 0}{3929291110}$ & $\begin{array}{l}\text { UKB Freeze } 450 \text { EUR } \quad \text { Meta } \\
\text { UKB Freece } 450 \text { FUR Meta }\end{array}$ \\
\hline$\frac{15354942847}{\mathrm{NA}}$ & 19:39850592L:G:A & & 0.3625845 & 0.000020429 & $\frac{642.444}{754.22}$ & $\frac{3.8103}{3.8969}$ & $\frac{0.7904}{0.7951}$ & $\frac{0.0000014}{0.000016}$ & $\frac{1773000}{1170300}$ & $\frac{39922991110}{399227130}$ & $\begin{array}{l}\text { UKB Freeceze } 400 \text { EUR Meta } \\
\text { UKB Freze } 450 \text { EUR Meta }\end{array}$ \\
\hline$\frac{104}{157567552}$ & 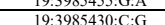 & $\frac{\mathrm{A}}{\mathrm{G}}$ & 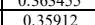 & 0.0000113146 & $\frac{73.22}{1135}$ & 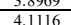 & D. 0.0013 & 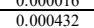 & $\frac{100300}{6500}$ & 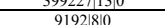 & $\begin{array}{l}\text { UKB Freece } 450 \mathrm{EUR} \text { Meta } \\
\text { UKB Freze } 450 \text { SAS Metan }\end{array}$ \\
\hline 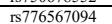 & $\frac{19: 3985428: G: A}{10}$ & $\frac{\mathrm{A}}{\mathrm{A}}$ & 0.365423 & 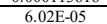 & 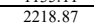 & $\begin{array}{l}4.4447 \\
4.47\end{array}$ & $\frac{1.8208}{0.820}$ & & 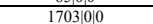 & 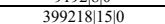 & $\begin{array}{l}\text { UNB Freze } 450 \text { SAS Meta } \\
\text { UKB Freze } 450 \text { EUR Meta } \\
\end{array}$ \\
\hline rs 3699523513 & 19:39854366:G:C & $\begin{array}{ccc}\mathrm{C} \\
\mathrm{C}\end{array}$ & 0.366851 & $\begin{array}{l}5.09 \mathrm{E}-05 \\
\end{array}$ & 2645.82 & 4.5325 & 0.8249 & ס0018 & 1873010 & $\frac{4621180}{260}$ & GHS Freeze 145 Megafreeze EUR UKB Freeze 450 EUR Meta \\
\hline $\mathrm{NA}$ & 19:3985417:G:C & $\mathrm{C}$ & 0.363855 & $2.93 \mathrm{E}-05$ & 4517.18 & 4.8096 & 0.8335 & 0.000014 & $\frac{17030100}{17000}$ & 39922441110 & UKB Freeze 450 EUR Meta \\
\hline rs1 10272742860 & $\begin{array}{ll}\text { 19:3985460:A:C } \\
10.395548 \cdot \mathrm{C} \cdot \mathrm{A}\end{array}$ & $\mathrm{C}$ & 0.36092 & $\frac{1.49 \mathrm{E}-05}{3.05}$ & 8736.83 & $\frac{5.1503}{48172}$ & 0.8431 & 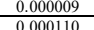 & $\frac{17030100}{170000}$ & 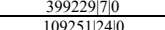 & 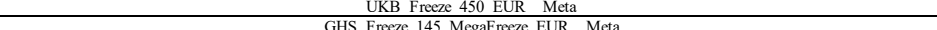 \\
\hline$\frac{157959857}{\mathrm{NA}}$ & $\frac{1 \text { 19:99855348:U:A }}{\text { 19:3985444:C:T }}$ & $\frac{\mathrm{A}}{\mathrm{T}}$ & 0.391097 & $\frac{3.10 E-03}{1.81 E-05}$ & 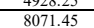 & $\frac{4.8122}{5.0807}$ & 0.84998 & 0.0000022 & $\begin{array}{l}1000 \\
187300\end{array}$ & $\frac{109331240}{5084520}$ & $\frac{\text { GHS Freeze } 145 \text { Megarireze EUR MMeta }}{145 \text { Megafreze EUR UKB Freze } 4501}$ \\
\hline$\frac{\mathrm{NA}}{\mathrm{ri} 776029459}$ & 19:3038954405:C:G & $\frac{\mathrm{T}}{\mathrm{G}}$ & $\frac{0.30160}{0.3748}$ & $\frac{1.81 \mathrm{E}-03}{1.16 \mathrm{E}-05}$ & $\frac{8071.43}{12130.2}$ & $\frac{3.0807}{5.2989}$ & 0.84530 & & & 5085131317100 & GHS Freze 145 Megaf reeze EUR UKB Freze 450 EUR \\
\hline$\frac{157170029499}{\mathrm{NA}}$ & 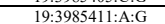 & $\frac{G}{G}$ & $\begin{array}{l}0.544480 \\
0.364948\end{array}$ & 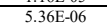 & $\frac{12190.2}{24871}$ & 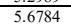 & 0.85501 & 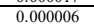 & $\frac{170300}{110300}$ & 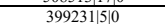 & UKB Freze 450 EUR Meta \\
\hline rs 9995814367 & 19:3985458:G:A & A & 0.365204 & $3.21 \mathrm{E}-06$ & 41519 & 5.9395 & 0.8653 & 0.000012 & 17030100 & 39922911000 & UKB Freeze 450 EUR Meta \\
\hline Is77641944249 & 19:39854408:G:A & $\mathrm{A}_{\mathrm{A}}$ & 0.365204 & & 65358.2 & 6.171 & & & & & UKB Freeze 450 EUR Meta \\
\hline 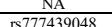 & $\frac{19: 3985542: G: A}{10 \cdot 398523: A \cdot G}$ & $\frac{\mathrm{A}}{\mathrm{G}}$ & $\begin{array}{l}0.36028 \\
0.3667\end{array}$ & $\frac{1.12 E-06}{6.02 E-07}$ & $\frac{119957}{223245}$ & 6.47957 & 0.8086 & 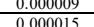 & & 23120 & $\begin{array}{l}\text { UKB Freeze } 450 \text { EUR Meta } \\
\text { UKB Freece } 450 \text { EUR Metan }\end{array}$ \\
\hline $\begin{array}{l}25866610889 \\
\text { res }\end{array}$ & 19:39955452:A:ACGG & 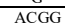 & $\frac{2.383391}{0.3831}$ & & $\frac{250305}{11505}$ & 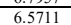 & 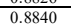 & & & & GHS \\
\hline 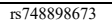 & 19:3985399:A:C & $\mathrm{C}$ & 0.366228 & $4.01 \mathrm{E}-07$ & 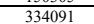 & 7.002 & $\frac{0.8859}{0.885}>0$ & & 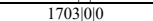 & $\frac{39933170}{399230}$ & cace 450 EUR \\
\hline & 19:3985439:G:A & $\mathrm{A}$ & 0.92441 & 0.310456 & 2.75251 & 0.5567 & 0.8877 & & & & 145 Megaf reeze EUR UKB Freze $450 \mathrm{EL}$ \\
\hline ris776567094 & 19:3985428:G:C & C & 0.365825 & $2.96 \mathrm{E}$ & & 7.1563 & 0.8882 & & & 3992187700 & UKB Freeze 450 EUR Meta \\
\hline Is 101039385884 & 19:39855467:G:A & $\mathrm{A}$ & 0.366008 & $2.35 \mathrm{E}-07 \mathrm{C}$ & 569136 & 7.2741 & 0.8901 & & & & UKB Freze 450 EUR Meta \\
\hline$\frac{1510510248170}{\mathrm{si7} 754780163}$ & $\frac{19: 3985542: A: G}{10 \cdot 398531 \cdot G \cdot A}$ & $u_{A}$ & $\frac{0.34548}{0.3688}$ & $\frac{5.19 E-08}{1.38-07}$ & $\frac{2.26706}{903791}$ & 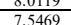 & 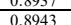 & & & $\frac{1092735150}{399227100}$ & 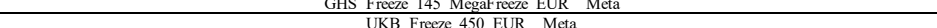 \\
\hline vos & $\frac{19 \cdot 3095432 \cdot \mathrm{C} \cdot \mathrm{G} \cdot \mathrm{G}}{19}$ & $\frac{\pi}{G}$ & 0.3676 & 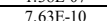 & $1,775+08$ & 102002 & 0.09217 & & & $\frac{393927150}{39925150}$ & 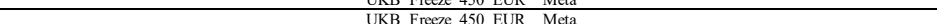 \\
\hline $\mathrm{NA}$ & 19:3985449:A:G & $\mathrm{G}$ & 0.375987 & $7.77 \mathrm{E}-10$ & $1.82 \mathrm{E}+08$ & 10.2028 & 0.9236 & 0.000027 & 170100 & 1092822600 & IFreeze EUR Meta \\
\hline$\frac{\mathrm{NA}}{\mathrm{Na}}$ & 19:3985446:G:A & $\mathrm{A}$ & 0.367402 & $2.56 \mathrm{E}-13$ & $\frac{5.28 \mathrm{E}+11}{8.07673}$ & $\frac{14.2826}{1.0244}$ & 0.9441 & & 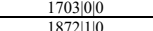 & & 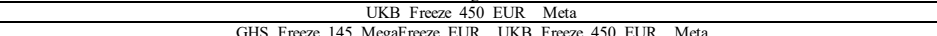 \\
\hline & & & & & & & & & & & \\
\hline
\end{tabular}


Supplementary Table 6. Evidence for association between the COVID-19 hospitalization phenotype and rs532051930 across different association tests.

\begin{tabular}{|c|c|c|c|c|c|c|c|c|c|c|c|}
\hline \multirow{2}{*}{ Approach } & \multirow{2}{*}{ Association test in individual studies } & \multirow{2}{*}{$\begin{array}{l}\text { Approach used to combine results across } \\
\text { studies }\end{array}$} & \multicolumn{3}{|c|}{ Association in UKB Europeans } & \multicolumn{3}{|c|}{ Association in GHS Europeans } & \multicolumn{3}{|c|}{ Association in UKB+GHS Europeans } \\
\hline & & & OR (95\% CI) & $\mathbf{S E}^{*}$ & P-value & OR (95\% CI) & $\mathbf{S E}^{*}$ & P-value & OR (95\% CI) & SE* $^{*}$ & P-value \\
\hline 1 (default) & \multirow{3}{*}{$\begin{array}{l}\text { REGENIE Firth exact test, with covariates and } \\
\text { LOCO }\end{array}$} & Inverse-variance fixed-effects meta-analysis & \multirow{3}{*}{$80.9(13.1-499.5)$} & \multirow{3}{*}{0.93} & \multirow{3}{*}{$2.20 \mathrm{E}-06$} & \multirow{3}{*}{$134.8(7.9-2301.3)$} & \multirow{3}{*}{1.45} & \multirow{3}{*}{ 7.07E-04 } & $93.9(20.3-434.5)$ & 0.78 & $6.17 \mathrm{E}-09$ \\
\hline 2 & & Sample size weighted meta-analysis & & & & & & & NA & & $3.14 \mathrm{E}-08$ \\
\hline 3 & & Meta-analysis of log-likelihood curves & & & & & & & $85.6(17.2-425.8)$ & 0.82 & $5.51 \mathrm{E}-08$ \\
\hline 4 & Firth exact test, no covariates & \multirow{4}{*}{ Inverse-variance fixed-effects meta-analysis } & $65.7(16.9-195.3)$ & 0.90 & $3.49 \mathrm{E}-06$ & $92.1(9.9-395.0)$ & 1.4 & 0.00127 & $72.5(16.4-321.0)$ & 0.76 & $1.64 \mathrm{E}-08$ \\
\hline 5 & Fisher's exact test (no covariates) & & $58.7(10.6-218.5)$ & 0.98 & $3.35 \mathrm{E}-05$ & $64.6(1.48-456.8)$ & 1.75 & 0.017 & $60.1(11.2-321.6)$ & 0.86 & $1.70 \mathrm{E}-06$ \\
\hline 6 & Logistic regression, with covariates & & $71.6(15.6-241.7)$ & 0.99 & $1.55 \mathrm{E}-05$ & $106.5(5.61-648.2)$ & 1.74 & 0.00733 & $78.9(14.6-425.0)$ & 0.86 & $3.73 \mathrm{E}-07$ \\
\hline 7 & Logistic regression, no covariates & & $58.7(13.4-185.0)$ & 0.96 & $2.37 \mathrm{E}-05$ & $64.7(3.51-340.4)$ & 1.67 & 0.0123 & $60.2(11.7-308.4)$ & 0.83 & $9.00 \mathrm{E}-07$ \\
\hline 8 & BinomiRare test, with covariates & Meta-analysis & NA & & $1.19 \mathrm{E}-05$ & NA & & $5.53 \mathrm{E}-05$ & NA & & $2.96 \mathrm{E}-07$ \\
\hline 9 & Firth exact test, with covariates & \multirow{5}{*}{ Mega-analysis (UKB+GHS combined) } & \multirow{5}{*}{\multicolumn{3}{|c|}{ NA }} & \multirow{5}{*}{\multicolumn{3}{|c|}{$\mathrm{NA}$}} & $85.8(17.2-427.2)$ & 0.82 & $5.48 \mathrm{E}-08$ \\
\hline 10 & Firth exact test, no covariates & & & & & & & & $54.4(11.8-250.5)$ & 0.78 & $2.91 \mathrm{E}-07$ \\
\hline 11 & Fisher's exact test (no covariates) & & & & & & & & $49.4(9.7-251.0)$ & 0.83 & $2.53 \mathrm{E}-06$ \\
\hline 12 & Logistic regression, with covariates & & & & & & & & $78.7(14.6-424.9)$ & 0.86 & $3.88 \mathrm{E}-07$ \\
\hline 13 & Logistic regression, no covariates & & & & & & & & $49.5(9.9-246.2)$ & 0.82 & $1.89 \mathrm{E}-06$ \\
\hline
\end{tabular}


Supplementary Table 7. No carriers of the rare variant rs532051930 in the promoter of EEF2 were observed in an additional 4,341 individuals with COVID-19.

\begin{tabular}{|c|c|c|c|c|c|c|}
\hline \multirow[b]{2}{*}{ Study } & \multirow[b]{2}{*}{ Reference } & \multicolumn{5}{|c|}{ N COVID-19 cases } \\
\hline & & Total & Hospitalized & Severe & $\begin{array}{l}\text { Of European|African|Asian|Hispanic|other ancestry } \\
\end{array}$ & Heterozygote for rs532051930:A \\
\hline GenOMICC & PMID 33307546 & 2969 & 2969 & 2969 & \begin{tabular}{|l|l|l|l|l|l|l|}
2110 & 145 & 375 & NA & 339 \\
\end{tabular} & 0 \\
\hline Columbia University COVID-19 Biobank & https://www.medrxiv.org/content/10.1101/2020.12.18.20248226v2 & 1152 & 1082 & 479 & \begin{tabular}{ll|l|l|l|l|l|}
67 & 463 & 33 & 506 & 83 \\
\end{tabular} & 0 \\
\hline Biobanque Québec Covid-19 & https://www.medrxiv.org/content/10.1101/2020.12.18.20248226v2 & 220 & 128 & 62 & \begin{tabular}{ll|l|l|l|l|}
154 & 30 & 29 & 7 & 0 \\
\end{tabular} & 0 \\
\hline
\end{tabular}


Supplementary Table 8. Results from burden association tests for 167 genes located in eight loci described by Horowitz et al. (2021).

\begin{tabular}{|c|c|c|c|c|c|c|c|c|c|c|c|}
\hline Trait & Gene & Burden test & MAF & Odds Ratio $95 \% \mathrm{Cl}$ & P-value & \begin{tabular}{|l}
$\mathrm{N}$ cases with RRRAR/AA \\
genotype*
\end{tabular} & $\begin{array}{l}\text { N controls with } \\
\text { RRRAAA genotype* }\end{array}$ & AAF & GWAS SNP & Distance to GWAS SNP, bp & Distance to GWAS SNP, rank \\
\hline COVID19 positive hospitalized vs COVID19 negative or unknown & CHAFIA & M1 & $<1 \%$ & $25.216[4.947 ; 128.539]$ & $1.00 \mathrm{E}-04$ & & & 0.00005 & 19:4719431:G:A & 316669 & 16 \\
\hline 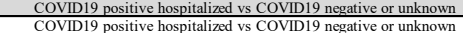 & $\frac{\text { CHAFIA }}{\text { SLC22A3I }}$ & $\frac{\mathrm{M} 3}{\mathrm{M} 1}$ & $\frac{1 \%}{<1 \%}$ & 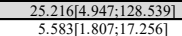 & $\frac{1.00 \mathrm{E}-04}{2.03 \mathrm{E}-03}$ & $\begin{array}{ll}19353130 \\
184460\end{array}$ & $\begin{array}{ll}5176877450 \\
4100714020\end{array}$ & $\frac{0.0005}{0.00049}$ & 19:4719431:G:A & $\frac{316669}{77271}$ & \\
\hline & $\frac{S L 222 A 1}{S L C 22 A 31}$ & $\frac{\mathrm{M} 1}{\mathrm{M} 3}$ & & $\frac{5.53311 .87771 .7 .256]}{5.583(1.807717 .256]}$ & $\frac{2.80 \mathrm{E}-03}{2.80 \mathrm{E}-03}$ & & & & & $\frac{78271}{78271}$ & \\
\hline 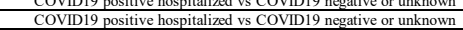 & $\frac{S L C 2 A B T}{\text { SARDH }}$ & $\frac{\mathrm{M} 3}{\mathrm{M} 1}$ & $\frac{1 \%}{<1 \%}$ & 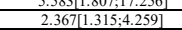 & $\begin{aligned} 2.80 \mathrm{E}-03 \\
4.00 \mathrm{E}-03\end{aligned}$ & $\frac{184460}{2072 \mid 1211}$ & $\begin{aligned} 41001 / 4020 \\
533477|1487| 1 \\
\end{aligned}$ & $\frac{0.0049}{0.0014}$ & $\frac{16.8911727: \mathrm{C}}{9: 133270015: \mathrm{A}: \mathrm{C}}$ & $\frac{18271}{393873}$ & \\
\hline $\begin{array}{ll}\text { COVID19 positive hospitalized vs COVID19 negative or unknown } \\
\text { CODID19 }\end{array}$ & $\frac{S H D}{C T B .51710}$ & & $\begin{array}{c}<\% \\
5<\%\end{array}$ & 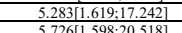 & \begin{tabular}{|l|l|l|l}
$5.80 \mathrm{E}-03$ \\
700.03
\end{tabular} & $\frac{186940}{18640}$ & 508290124210 & $\frac{0.00024}{0.0024}$ & 19:47194311:G:A & 439368 & \\
\hline 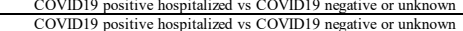 & 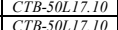 & & $\frac{1 \%}{51 \%}$ & 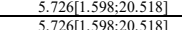 & 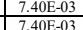 & $\frac{2017730}{201730}$ & $\begin{array}{r}525625[14000 \\
5252551400\end{array}$ & $\frac{0.00014}{0.00014}$ & 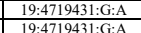 & 247081 & \\
\hline 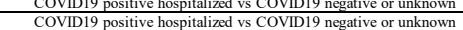 & $\frac{C T B-50 L H 7.10}{D B H}$ & & & 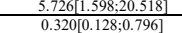 & 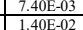 & $\frac{20173130}{208320}$ & $\begin{aligned} 5252625 \mid 14000 \\
5227122040\end{aligned}$ & 0.00014 & 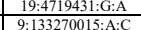 & $\frac{247081}{360356}$ & \\
\hline 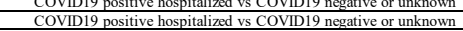 & DIGLECI4 & $\frac{\mathrm{M} 1}{\mathrm{M} 1}$ & $<1 \%$ & $\begin{array}{l}0.320[0.182,0.796] \\
6.544[1.434 ; 29.868] \\
\end{array}$ & 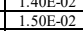 & $\frac{28053210}{193620}$ & $\frac{35271212040}{51762595112}$ & 0.000012 & 19:132/5173901:A97 & $\frac{365050}{96143}$ & \\
\hline COVII19 positive hospitalized vs COVID19 negative or unknown & OLIG2 & M1 & $<1 \%$ & $\frac{12.046[1.255 ; 115.574]}{100612515.571}$ & $3.10 \mathrm{E}-02$ & 1872110 & 50845617600 & 0.00008 & 21:33252612:A:G & 225750 & \\
\hline 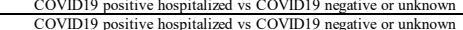 & $\frac{O L I I 2}{P S O R S I C 2}$ & $\frac{M}{M}$ & $\frac{<\%}{<1 \%}$ & $\frac{12.046[1.255 ; 115.574]}{5.176611 .1512 .23 .275]}$ & $\frac{3.10 \mathrm{E}-02}{3.20 \mathrm{E}-22}$ & $\frac{1872110}{187120}$ & $\frac{50845667160}{50835010}$ & $\frac{0.00008}{0.00018}$ & $\frac{\text { 21:33252612:A:G }}{6 \text { 6:31153649:GA }}$ & 225750 & \\
\hline & & & & & & & & & 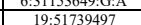 & & \\
\hline 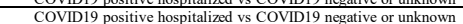 & 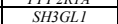 & $\frac{1}{\mathrm{Mi}}$ & $\frac{1 \%}{<<\%},{ }_{1}$ & 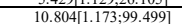 & 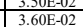 & $\frac{187120}{187210}$ & $\frac{50835179930}{508459730}$ & 0.000007 & 19:471943131:G:A & 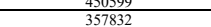 & \\
\hline 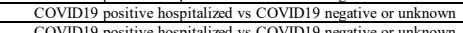 & $M I C B$ & $\mathrm{M1}$ & $<1 \%$ & $2.106[1.007 ; 4.401]$ & $4.80 \mathrm{E}-022$ & 207780 & $\frac{5339211104311}{532010421}$ & 0.00098 & 6:31153649:G:A & 344544 & \\
\hline 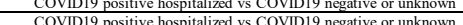 & $\frac{M I C B}{A^{A T P G V I G 2}}$ & & & $\frac{2.166[1.0077 .4 .401]}{8.5960 .96766022}$ & 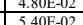 & 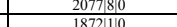 & $\frac{5339211104331}{5084756770}$ & & $6: 31153649: \mathrm{G}: \mathrm{A}$ & & \\
\hline 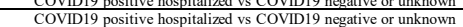 & $\frac{A A P O V I T 2}{A T P 6 V I G 2}$ & $\frac{N}{N}$ & $<1 \%$ & $\begin{array}{l}8.99060 .909 ; 0.0 .002 \\
8.5960 .965 ; 76.602\end{array}$ & $\begin{array}{lll}5.40 \mathrm{E}-0.2 \\
5.40-02\end{array}$ & $\frac{1882110}{1872110}$ & $\frac{508445151570}{5087570}$ & 0.000006 & 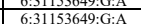 & $\frac{391778}{391758}$ & \\
\hline COVID19 positive hospitalized vs COVID19 negative or unknown & SURFG & & & $5.02550 .971: 25.993$ & 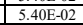 & 2016210 & 5259751525200 & 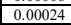 & 9:133270015:A:C & $\frac{18533}{6183}$ & \\
\hline COVVII19 positive hospitalized vs COVIII9 negative or unknown & $M Y D G F$ & $\mathrm{M}$ & $<1 \%$ & $0.343[0.115 ; 1.024]$ & $5.50 \mathrm{E}-022$ & 2085000 & 53446949660 & 0.00046 & 19:47719431:G:A & 61427 & \\
\hline 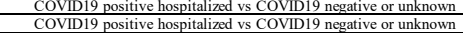 & $\frac{X C R 1}{C 60 r 15}$ & $\frac{\mathrm{M} 1}{\mathrm{M} 3}$ & $\frac{1 \% \%}{<1 \%}$ & $\begin{array}{l}3.068[0.9677 .9733]] \\
3.003[0.965 ; 9351]\end{array}$ & 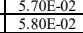 & 20171300 & $\frac{525342133330}{52546529911}$ & 0.000329 & $\begin{array}{l}\text { 3:445859597:C:T } \\
\text { 6:31153649:G:A }\end{array}$ & $\frac{161348}{42269}$ & \\
\hline $\begin{array}{l}\text { COVIDI } 19 \text { positive hospitalized vs COVDII } 19 \text { negative or unknown } \\
\end{array}$ & $\begin{array}{lll}\text { LARS2 } \\
\text { PRC24 } \\
\end{array}$ & $\frac{\mathrm{M}_{3}}{\mathrm{M}^{2}}$ & $\frac{<1 \%}{<1 \%}$ & $\begin{array}{ll}.355[0.987 ; 1.861] \\
07165051019\end{array}$ & $6.00 \mathrm{E}-02$ & 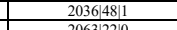 & 52494599823138 & 0.00941 & 3:45859597:C:T & $\frac{465144}{46910}$ & \\
\hline 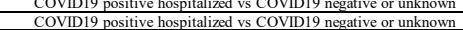 & & & & $\frac{0.716[16.005 ; 1,016]}{2.202[0.962 ; 5.038]}$ & $\frac{6.10 \mathrm{E}-0.2}{6.20 \mathrm{E}-\mathrm{C}^{2}}$ & $\frac{20653220}{207960}$ & $\frac{524933511002527}{5340539120}$ & 0.000975 & $\begin{array}{l}\text { 6.:311536699::A A } \\
3: 45859597: \mathrm{T}\end{array}$ & $\frac{469140}{264718}$ & \\
\hline COVID19 positive hospitalized vs COVID19 negative or unknown & 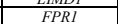 & & & $\frac{9.25210 .902,0.0503}{9.521[0.887 ; 102.209]}$ & 6.30E-02 & 20191100 & $\frac{5+5911140}{5257311340}$ & $\frac{0.00003}{0.0003}$ & 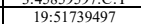 & 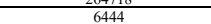 & \\
\hline COVID19 positive hospitalized vs COVID19 negative or unknown & SIGLECI4 & & $<1 \%$ & $3.535[0.936 ; 13.349]$ & $6.30 \mathrm{E}-0.0$ & 2003220 & $526273 \mid 117918$ & 0.00021 & 19:51739497 & 96143 & \\
\hline $\begin{array}{l}\text { COVII19 positive hospitalized vs COVID19 negative or unknown } \\
\text { and }\end{array}$ & $C_{C Y B A}$ & & & 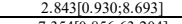 & & 2080550 & 5344005566000 & 0.00053 & $\frac{16: 89117727}{2}$ & & \\
\hline 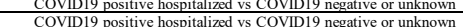 & $\frac{O L I I G I}{O L I G I}$ & $\frac{\mathrm{M}}{\mathrm{M}}$ & $\frac{<1 \%}{<1 \%}$ & 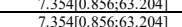 & 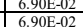 & $\frac{1872110}{1872110}$ & $\frac{5084547780}{508454780}$ & 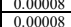 & $\begin{array}{l}21: 3325252612: \mathrm{A}: \mathrm{G} \\
21 \cdot 33252612 \mathrm{~A} \cdot \mathrm{G}\end{array}$ & 183666 & \\
\hline COVID19 positive hospitalizized vs COVID19 negative or unknown & $\frac{O L W 15}{Z N F 615}$ & & $\frac{1 \%}{<1 \%}$ & $\frac{1.3470 .000,03.204}{0.368[0.121 ; 1.117]}$ & 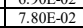 & $\frac{1082110}{208500}$ & $\frac{5005441501}{53415481011}$ & $\frac{2.00006}{0.00076}$ & $19: 51739497$ & 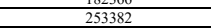 & \\
\hline tive hospitalizizd vs COVID19 negative or unknown & ZNFGIS & $\overline{\mathrm{N}}$ & $<1 \%$ & $0.368[0.121 ; 1.1177]$ & $7.80 \mathrm{E}-022$ & 2085000 & 5344154810111 & 0.00076 & 19:517394977 & 253382 & \\
\hline COVID19 positive hospitalized vs COVID19 negative or unknown & KDMAB & 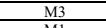 & $<1 \%$ & $2.146[0.916 ; 5.028]$ & $7.90 \mathrm{E}-02 \mathrm{2}$ & 20778180 & $533186 \mid 177811$ & 0.00166 & 19:4719431:G:A & 313459 & \\
\hline 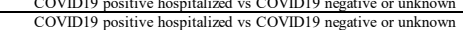 & $\frac{C P N E 7}{D B H}$ & & $\frac{<1 \%}{<1 \%}$ & $\frac{2.5090 .08717 .72221}{0.824[0.657 .1033]}$ & 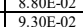 & $\frac{207960}{2021640}$ & $\frac{53422317420}{514043208873}$ & $\frac{0.0007}{0.01957}$ & $\frac{16: 89917727}{9 \cdot 133270015 \cdot \mathrm{A} \cdot \mathrm{C}}$ & 年358170 & \\
\hline 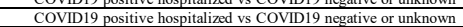 & 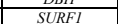 & $\frac{\mathrm{M}}{\mathrm{M}}$ & $<1 \%$ & $\frac{0.0240 .0037,1.03)}{1.734[0.905 ; 3.321]}$ & $\frac{9.30 \mathrm{E}-0}{9.70 \mathrm{E}-0}$ & $\frac{20217+10}{2075100}$ & 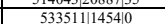 & $\frac{2.09036}{0.00136}$ & 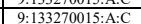 & $\begin{array}{l}3013907 \\
81897\end{array}$ & \\
\hline COVID19 positive hospitalized vs COVID19 negative or unknown & CTU2 & $\mathrm{M}$ & $<1 \%$ & $2.046[0.868 ; 4.422]$ & $\frac{1.00 \mathrm{E}-01}{1}+\mathrm{C}$ & 207690 & 53371616124722 & 0.00117 & 16:89117727 & 411197 & \\
\hline COVIII9 positive hospitallized vs COVID19 negative or unknown & & & & & $1.30 \mathrm{E}-011$ & & 5259143131300 & 0.0003 & & & \\
\hline 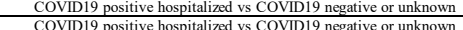 & $\frac{F E M I A}{E Z T T E I}$ & $\frac{\mathrm{M}}{\mathrm{M}}$ & $\frac{<1 \%}{<1 \%}$ & $\frac{3.778[0.670 ; 21.285]}{25870.7568 .8000]}$ & $\frac{1.30 \mathrm{E}-01}{130 \mathrm{E}-1}$ & $\frac{2015310}{200230}$ & 525914313100 & $\frac{0.0003}{0.00043}$ & $\begin{array}{c}\text { 19:4719431:G:A } \\
\text { 3:5889597:CT } \\
\end{array}$ & $\frac{72423}{33284}$ & \\
\hline 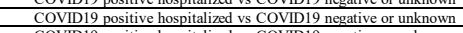 & SURF 2 & $\mathrm{M}$ & $<1 \%$ & $0.471[0.176 ; 1.262]$ & $\frac{1.30 \mathrm{E}-01}{1.30}$ & 2084110 & 534038992710 & 0.00086 & 9:133270015:A:C & 86577 & \\
\hline 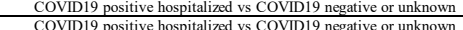 & $\frac{A R R D C 5}{F L O T}$ & $\frac{M}{M}$ & $\frac{<1 \%}{<<\%}$ & $\frac{2.513[0.744: 8.487]}{1.960[0.80 .4836]}$ & $\frac{1.40 \mathrm{E}-0.1}{1.40 \mathrm{E}-0.0}$ & $\frac{20805150}{200780}$ & $\frac{53426377020}{53232701120121}$ & 0.00066 & 19:4719431:G:A & 171614 & \\
\hline 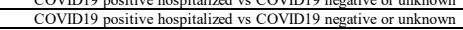 & FLLONS & $\frac{M}{M}$ & $\frac{11 \%}{<1 \%}$ & $\frac{1.99010 .820 .4 .8301}{19.0790 .389: 936.241]}$ & $\frac{1.40 \mathrm{E}-0.0}{1.40 \mathrm{E}-0}$ & $\frac{207180}{18721100}$ & $\frac{533221124211}{508445 \mid 870}$ & 0.000009 & $\begin{array}{ll}0.31153049 .0 . \mathrm{A} \\
19: 51739497 \\
\end{array}$ & 4276560 & \\
\hline COVID19 positive hospitalized vs COVID19 negative or unknown & SLC6A20 & M1 & $<1 \%$ & $\begin{array}{ll}0.462[0.161 ; 1,1.328] \\
\end{array}$ & $1.50 \mathrm{E}-01 \mathrm{1}$ & & 5340619040 & 0.00084 & 3:45859597:C:T & 101161 & \\
\hline sitive hospitatizizd vs COVID19 negative or unknown & $\frac{M A T 2 B}{M}$ & & & $0.473[0.168: 1.1330]$ & $1.60 \mathrm{E}-011$ & 20841100 & $\frac{53407888870}{-53012}$ & 0.00083 & $5: 163300447$ & 202947 & \\
\hline 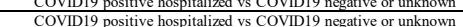 & $\frac{S A R S C I}{T S C I}$ & $\frac{M}{M}$ & $\frac{1 \%}{<1 \%}$ & $\frac{1.299[0.905 ; 1.848]}{0.741[0.490 ; 1.121]}$ & 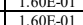 & 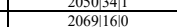 & $\begin{array}{lll}528071689933 \\
52819067687\end{array}$ & 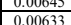 & 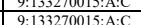 & 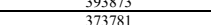 & \\
\hline COVID19 positive hospitalizized vs COVID19 negative or unknown & $M U C 211$ & $\mathrm{M1}$ & $<1 \%$ & $0.367[0.086 ; 1.1555]$ & $\frac{1.70 \mathrm{E}-01}{1.70-1}$ & 2020000 & $\frac{525263530111}{52532011}$ & 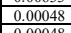 & 6:31153649:G:A & 169691 & $\frac{0}{0}$ \\
\hline 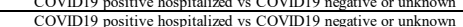 & MUC21 & $\frac{\mathrm{M} 3}{\mathrm{M} 1}$ & $\frac{1 \%}{<1 \%}$ & 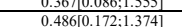 & $\frac{1.70 \mathrm{E}-01}{1.70 \mathrm{E}-01}$ & $\frac{202000}{2084110}$ & 5252635301112 & $\frac{0.00048}{0.00087}$ & 6:311536499:G:A & $\frac{169991}{195904}$ & \\
\hline COVID19 positive hospitalized vs COVIII19 negative or unknown & PLINS & $\frac{\mathrm{M} 1}{\mathrm{M} 3}$ & $<1 \%$ & $\frac{0.4601 .112,1.374)}{0.486[0.172 ; 1.374]}$ & $\frac{1.70 \mathrm{E}-01}{1.70 \mathrm{E}-01}$ & 20844110 & $534032|931| 2$ & 0.00087 & 19:4719431:G:A & 195904 & \\
\hline COVID19 positive hospitalized vs COVID19 negative or unknown & LIMDI & $\bar{M}$ & $<1 \%$ & 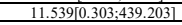 & 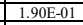 & 1872110 & $508431|101| 0$ & 0.0001 & 3:45859597:C:T & 264718 & \\
\hline COVID19 positive hospitalized vs COVID19 negative or unknown & 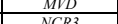 & 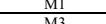 & $\frac{1 \%}{1} 1 \%$ & $0.362[0.078 ; 1.673]$ & $\frac{1.900-01}{1.00-1}$ & 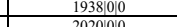 & $\frac{51733339990}{52535141440}$ & 0.00038 & 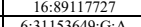 & $\frac{465203}{43517}$ & \\
\hline COVID19 positive hospitallized vs $\mathrm{C}$ & 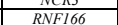 & $\frac{\mathrm{Mn} 3}{\mathrm{M} 3}$ & $\frac{1 \%}{<1 \%}$ & 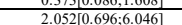 & $\frac{1.900-1}{1.90-01}$ & 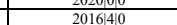 & $\frac{235371740}{525167980}$ & 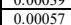 & 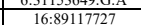 & $\frac{435417}{420160}$ & \\
\hline COVID19 positive hospitalized vs COVID19 negative or unknown & SACMIL & $\overline{\mathrm{M}} \mathrm{C}$ & $<1 \%$ & $3.293[0.554 ; 19.585]$ & $1.90 \mathrm{E}-01 \mathrm{1}$ & 1937110 & 51758411480 & 0.00014 & 3:458595977:C:T & $\frac{170132}{2}$ & \\
\hline CoVID19 positive hospitalized vs COVID19 negative or unknown & 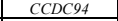 & & & $3.763[0.497 ; 28.456$ & $2.00 \mathrm{E}-0.0$ & 20191100 & 525606159900 & 0.00015 & 19:4719431:G:A & & \\
\hline 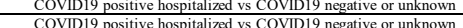 & $\frac{S A C M I L}{T R A P P C L L}$ & $\frac{\mathrm{M} 3}{\mathrm{M} 1}$ & $\frac{<\%}{<1 \%}$ & $\frac{1.982[0.690 ; 5.692]}{0.750[0.498: 1.158]}$ & $\frac{2.00 \mathrm{E}-01}{2000-1}$ & $\frac{20805150}{2060160}$ & $\frac{534178778611}{5281716783111}$ & $\frac{0.00074}{0.00635}$ & 3:45859597:C:T & $\frac{170132}{260577}$ & \\
\hline COVVIDI9 positive hospitallized vs COVIDI9 negative or unknown & ZNF616 & $\mathrm{M}$ & $<1 \%$ & $0.493[0.166 ; 1.465]$ & $2.00 \mathrm{E}-01$ & 20041100 & $525530|940| 0$ & 0.00089 & $19: 51739497$ & 375320 & \\
\hline COVII19 positive hospitalized vs COVID19 negative or unknown & & $\frac{M}{M},>C$ & & $0.493[0.166 ; 1.465]$ & $2.000-011$ & 2004110 & $\frac{52553090400}{525000}$ & 0.00089 & 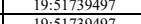 & 375320 & \\
\hline 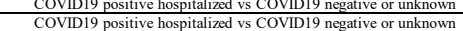 & 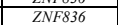 & $\frac{\mathrm{M}_{1}}{\mathrm{M}}$ & $\frac{<\%}{<1 \%},{ }_{0}$ & $\frac{0.56310 .066 .1 .72]}{0.363[0.076 ; 1.725]}$ & 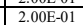 & 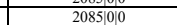 & $\begin{aligned} 534615153000 \\
534615350 \mid 0\end{aligned}$ & 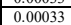 & $\frac{19: 5113949 / 1}{19: 51739497}$ & 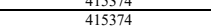 & \\
\hline 19 positive hospitalized vs COVID19 negative or unknown & CEACAMI8 & $\begin{array}{l}\mathrm{Ml} \\
\mathrm{Ml}\end{array}$ & $<1 \%$ & & 2.10 & 2005000 & 526042424280 & 0.06 & $\frac{19}{19}$ & 2608555 & \\
\hline COVVID19 positive hospitallized vs COVID19 negative or unknown & CEACAMI8 & $\mathrm{M}^{\mathrm{M}}$ & $\leq 1 \%$ & 7075;1.7773] & $2.10 \mathrm{E}-01$ & 2005000 & 5260424428000 & 0.0004 & 19:517394947 & 200855 & \\
\hline 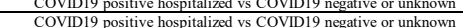 & 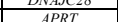 & $\frac{M}{M}$ & $\frac{1}{410} 6$ & & $\begin{array}{l}2.10 \mathrm{E}-0.0 \\
2.0 \mathrm{E}-0\end{array}$ & $\frac{20832120}{2084110}$ & $\frac{6361118340}{53440}$ & 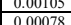 & 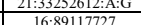 & 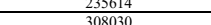 & \\
\hline Dig native or unknown & ${ }_{B A G G}$ & & & & & & 5316251337373 & & 6:3111536499:G:A & & \\
\hline COVID19 positive hospitalized vs COVID19 negative or unknown & HMMR & $\mathrm{M}^{3}$ & $<1 \%$ & 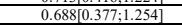 & $\frac{1.20 \mathrm{E}-01}{2.01}$ & 2007870 & $532229 \mid 273016$ & 0.00256 & $5: 163300447$ & $\left.\frac{160245}{164}+2\right)$ & 年 \\
\hline COVIII9 positive hospitatized vs COV & $\frac{S L C 6 A 20}{S P C 40}$ & $\frac{\mathrm{M} 3}{\mathrm{M} 1}$ & $<1 \%$ & $0.721[0.428: 1.216]$ & $\frac{2,20 \mathrm{E}-01}{20}, \mathrm{~F}$ & 2076900 & $\frac{531236 \mid 3727 / 2}{5352534402}$ & 0.00348 & 3:45859597:C:T & $\frac{101161}{386068}$ & \\
\hline 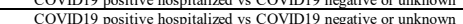 & 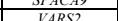 & $\frac{14}{\mathrm{M} 1}$ & $\frac{1 \%}{51 \%}$ & & & & & 0.00041 0.037 & 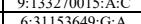 & 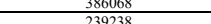 & \\
\hline Dingegative or unknown & 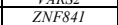 & 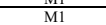 & $\frac{1 \%}{<1 \%}<-2$ & 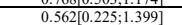 & $\frac{2.201}{2.201}-20$ & 208320 & $\frac{15369412710}{5336910}$ & $\frac{0.0019}{0.0019}$ & 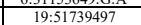 & 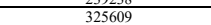 & \\
\hline COVII19 positive hospitalized vs $\mathrm{G}$ & ZNFF41 & $\overline{\mathrm{M}}$ & $<1 \%$ & & $2.201 \mathrm{r}$ & & 5336941127100 & 0.00119 & & & \\
\hline sitive hos & $\frac{D D R I}{D D I}$ & $\mathrm{M} 1 \mathrm{C}^{2}$ & $\leq 1 \%$ & & $2.30 \mathrm{E}-01 \mathrm{1}$ & 1933 & 5177314414800 & 0.0004 & 6:311536499:G:A & 2084300 & \\
\hline 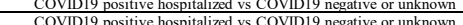 & 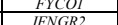 & $\frac{M_{3}}{M 1}+\mathrm{C}_{2}$ & $\frac{1 \%}{4}<\%$ & & 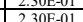 & & & 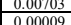 & & 年1606 & \\
\hline 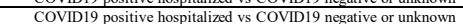 & 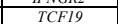 & $\frac{\mathrm{M} 1}{\mathrm{M} 3}$ & $<<1 \%$ & 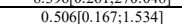 & $\frac{2.30 \mathrm{E}-0 \mid}{2.0}$ & 20844110 & 534099866511 & 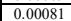 & 6:311153649:G:A & 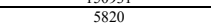 & \\
\hline COVID19 positive hospitalized vs COVID19 negative or unknown & VARS2 & $\mathrm{M} 3^{\mathrm{N}} \mathrm{C}$ & $<<1 \%$ & & $2.30 \mathrm{E}-0.10$ & 20553300 & $525693|9261| 11$ & 0.00867 & 6:31153649:G:A & 239238 & \\
\hline COVID19 positive hospitalized vs COVID19 negative or u & IFNAR2 2 & & $1 \% \%$ & $2.077[0.620 ; 6.961]]$ & $2.40 \mathrm{E}-01 \mathrm{1}$ & 2082/3] & 53427768880 & 0.00064 & $21: 33252612: \mathrm{A}: \mathrm{G}$ & 10690 & \\
\hline
\end{tabular}




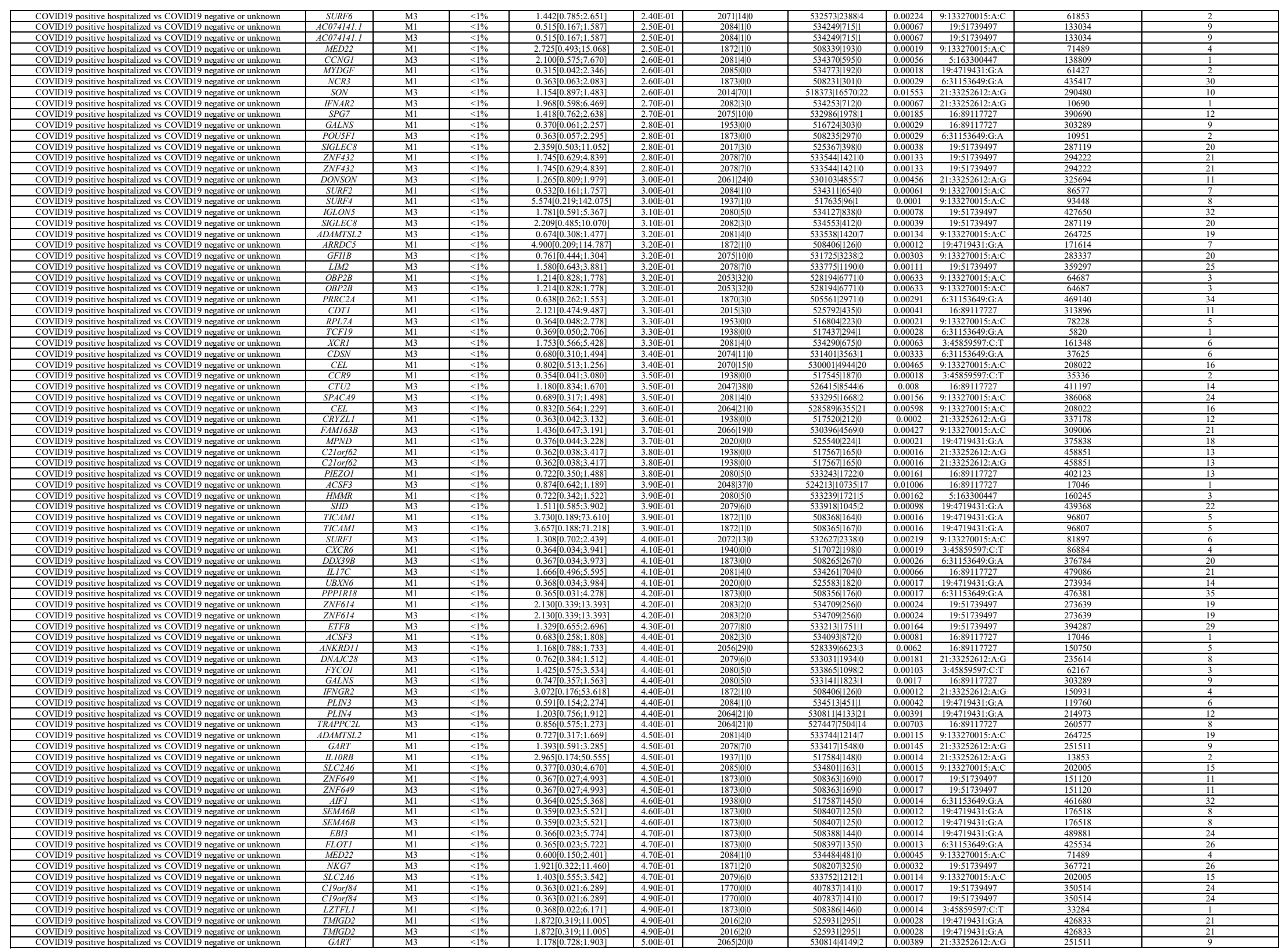









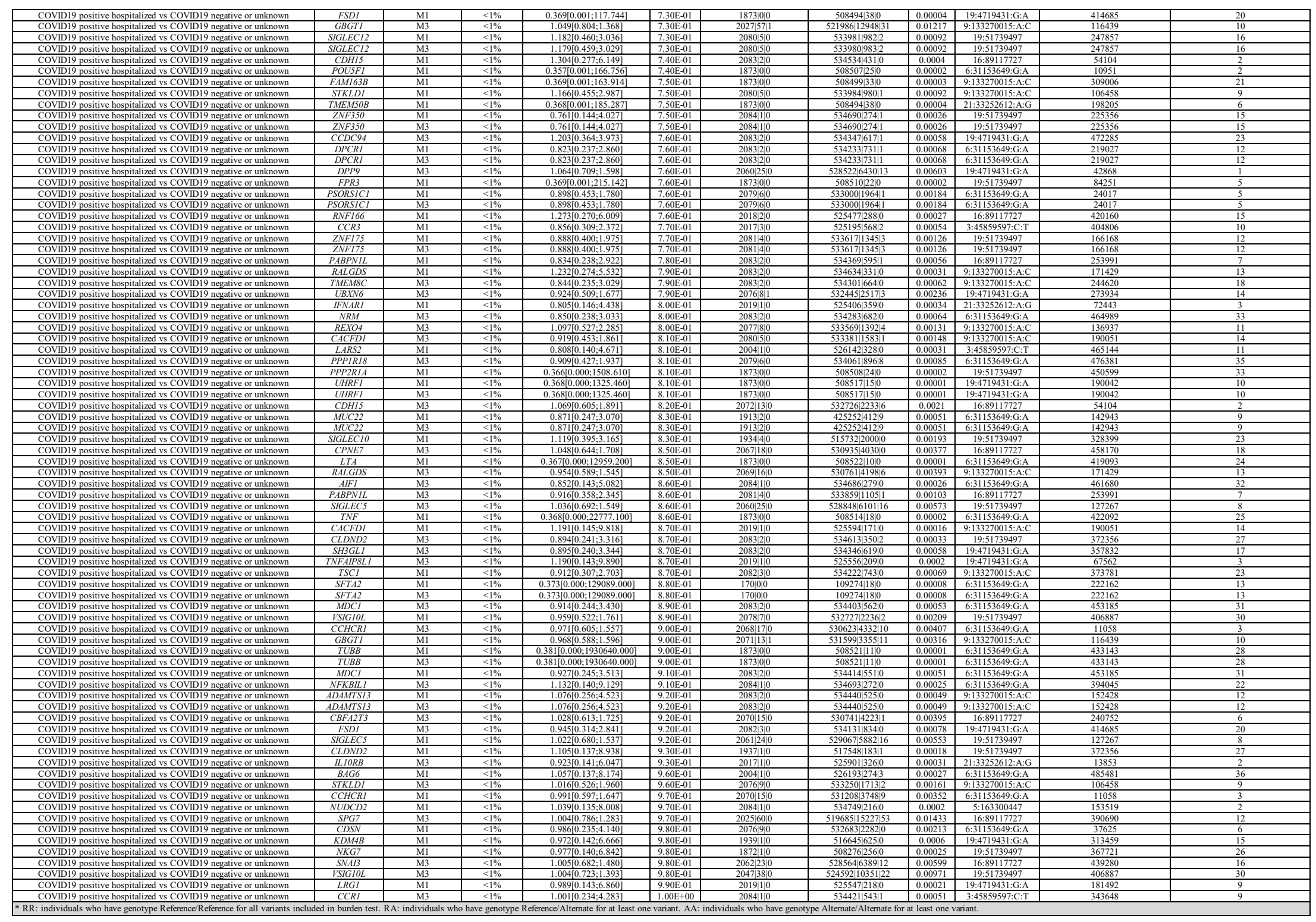


Supplementary Table 9. Results from burden association tests for 14 genes related to interferon signaling.

\begin{tabular}{|c|c|c|c|c|c|c|c|c|}
\hline Trait & Gene & Burden test & MAF & Odds Ratio $[95 \%$ CI] & P-value & $\begin{array}{c}\text { N cases with } \\
\text { RR|RA|AA genotype* }\end{array}$ & $\begin{array}{c}\text { N controls with } \\
\text { RR|RA|AA genotype* }\end{array}$ & AAF \\
\hline COVID19 positive hospitalized vs COVID19 negative or unknown & IFNARI & M1 & $<0.1 \%$ & $0.8(0.15,4.44)$ & 0.8033 & $2019|1| 0$ & $525406|359| 0$ & $3.41 \mathrm{E}-04$ \\
\hline COVID19 positive hospitalized vs COVID19 negative or unknown & IFNAR2 & M1 & $<0.1 \%$ & $2.08(0.62,6.96)$ & 0.2361 & $2082|3| 0$ & $534277|688| 0$ & $6.43 \mathrm{E}-04$ \\
\hline COVID19 positive hospitalized vs COVID19 negative or unknown & $I K B K G$ & M1 & $<0.1 \%$ & $0.49(0.0,50.22)$ & 0.7634 & $1873|0| 0$ & $508491|31| 10$ & $5.00 \mathrm{E}-05$ \\
\hline COVID19 positive hospitalized vs COVID19 negative or unknown & $I R F 3$ & M1 & $<0.1 \%$ & $0.96(0.25,3.64)$ & 0.9476 & $2083|2| 0$ & $534559|406| 0$ & $3.80 \mathrm{E}-04$ \\
\hline COVID19 positive hospitalized vs COVID19 negative or unknown & IRF7 & M1 & $<0.1 \%$ & $1.16(0.43,3.18)$ & 0.766 & $2082|3| 0$ & $534124|841| 0$ & 7.86E-04 \\
\hline COVID19 positive hospitalized vs COVID19 negative or unknown & $I R F 9$ & M1 & $<0.1 \%$ & $0.37(0.0,53.77)$ & 0.696 & $1873|0| 0$ & $508479|53| 0$ & $5.19 \mathrm{E}-05$ \\
\hline COVID19 positive hospitalized vs COVID19 negative or unknown & STATI & M1 & $<0.1 \%$ & $0.37(0.0,126.71)$ & 0.7357 & $1873|0| 0$ & $508490|42| 0$ & 4.11E-05 \\
\hline COVID19 positive hospitalized vs COVID19 negative or unknown & STAT2 & M1 & $<0.1 \%$ & $0.35(0.03,4.44)$ & 0.4215 & $1873|0| 0$ & $508405|127| 0$ & $1.24 \mathrm{E}-04$ \\
\hline COVID19 positive hospitalized vs COVID19 negative or unknown & TBK1 & M1 & $<0.1 \%$ & $0.37(0.01,11.96)$ & 0.5714 & $1873|0| 0$ & $508445|87| 0$ & $8.52 \mathrm{E}-05$ \\
\hline COVID19 positive hospitalized vs COVID19 negative or unknown & TICAMI & M1 & $<0.1 \%$ & $3.73(0.19,73.61)$ & 0.387 & $1872|1| 0$ & $508368|164| 0$ & $1.62 \mathrm{E}-04$ \\
\hline COVID19 positive hospitalized vs COVID19 negative or unknown & $T L R 3$ & M1 & $<0.1 \%$ & $1.13(0.14,8.83)$ & 0.909 & $2084|1| 0$ & $534674|291| 0$ & $2.72 \mathrm{E}-04$ \\
\hline COVID19 positive hospitalized vs COVID19 negative or unknown & $T L R 7$ & M1 & $<0.1 \%$ & $7.63(1.87,31.08)$ & 0.004584 & $1872|0| 1$ & $508503|25| 4$ & 3.43E-05 \\
\hline COVID19 positive hospitalized vs COVID19 negative or unknown & TRAF3 & M1 & $<0.1 \%$ & $0.37(0.0,733.64)$ & 0.7966 & $1873|0| 0$ & $508504|28| 0$ & $2.74 \mathrm{E}-05$ \\
\hline COVID19 positive hospitalized vs COVID19 negative or unknown & UNC93B1 & M1 & $<0.1 \%$ & $1.3(0.27,6.24)$ & 0.741 & $1938|2| 0$ & $516861|409| 0$ & 3.96E-04 \\
\hline COVID19 positive hospitalized vs COVID19 negative or unknown & IFNARI & M1 & $<1 \%$ & $0.8(0.15,4.44)$ & 0.8033 & $2019|1| 0$ & $525406|359| 0$ & $3.41 \mathrm{E}-04$ \\
\hline COVID19 positive hospitalized vs COVID19 negative or unknown & IFNAR2 & M1 & $<1 \%$ & $2.08(0.62,6.96)$ & 0.2361 & $2082|3| 0$ & $534277|688| 0$ & $6.43 \mathrm{E}-04$ \\
\hline COVID19 positive hospitalized vs COVID19 negative or unknown & $I K B K G$ & M1 & $<1 \%$ & $0.49(0.0,50.22)$ & 0.7634 & $1873|0| 0$ & $508491|31| 10$ & $5.00 \mathrm{E}-05$ \\
\hline COVID19 positive hospitalized vs COVID19 negative or unknown & $I R F 3$ & M1 & $<1 \%$ & $1.82(0.54,6.13)$ & 0.3334 & $2082|2| 1$ & $534509|455| 1$ & 4.29E-04 \\
\hline COVID19 positive hospitalized vs COVID19 negative or unknown & IRF7 & M1 & $<1 \%$ & $1.16(0.43,3.18)$ & 0.766 & $2082|3| 0$ & $534124|841| 0$ & $7.86 \mathrm{E}-04$ \\
\hline COVID19 positive hospitalized vs COVID19 negative or unknown & IRF9 & M1 & $<1 \%$ & $0.37(0.0,53.77)$ & 0.696 & $1873|0| 0$ & $508479|53| 0$ & $5.19 \mathrm{E}-05$ \\
\hline COVID19 positive hospitalized vs COVID19 negative or unknown & STAT1 & M1 & $<1 \%$ & $0.37(0.0,126.71)$ & 0.7357 & $1873|0| 0$ & $508490|42| 0$ & $4.11 \mathrm{E}-05$ \\
\hline COVID19 positive hospitalized vs COVID19 negative or unknown & STAT2 & M1 & $<1 \%$ & $0.35(0.03,4.44)$ & 0.4215 & $1873|0| 0$ & $508405|127| 0$ & $1.24 \mathrm{E}-04$ \\
\hline COVID19 positive hospitalized vs COVID19 negative or unknown & $T B K 1$ & M1 & $<1 \%$ & $0.37(0.01,11.96)$ & 0.5714 & $1873|0| 0$ & $508445|87| 0$ & $8.52 \mathrm{E}-05$ \\
\hline COVID19 positive hospitalized vs COVID19 negative or unknown & TICAMI & M1 & $<1 \%$ & $3.73(0.19,73.61)$ & 0.387 & $1872|1| 0$ & $508368|164| 0$ & $1.62 \mathrm{E}-04$ \\
\hline COVID19 positive hospitalized vs COVID19 negative or unknown & $T L R 3$ & M1 & $<1 \%$ & $1.13(0.14,8.83)$ & 0.909 & $2084|1| 0$ & $534674|291| 0$ & $2.72 \mathrm{E}-04$ \\
\hline COVID19 positive hospitalized vs COVID19 negative or unknown & $T L R 7$ & M1 & $<1 \%$ & $7.63(1.87,31.08)$ & 0.004584 & $1872|0| 1$ & $508503|25| 4$ & 3.43E-05 \\
\hline COVID19 positive hospitalized vs COVID19 negative or unknown & TRAF3 & M1 & $<1 \%$ & $0.37(0.0,733.64)$ & 0.7966 & $1873|0| 0$ & $508504|28| 0$ & $2.74 \mathrm{E}-05$ \\
\hline COVID19 positive hospitalized vs COVID19 negative or unknown & UNC93B1 & M1 & $<1 \%$ & $1.3(0.27,6.24)$ & 0.741 & $1938|2| 0$ & $516861|409| 0$ & $3.96 \mathrm{E}-04$ \\
\hline COVID19 positive hospitalized vs COVID19 negative or unknown & IFNARI & M1 & singleton & $0.37(0.0,44.0)$ & 0.6857 & $1873|0| 0$ & $508477|55| 0$ & $5.39 \mathrm{E}-05$ \\
\hline COVID19 positive hospitalized vs COVID19 negative or unknown & IFNAR2 & M1 & singleton & $0.36(0.0,179.42)$ & 0.7463 & $1873|0| 0$ & $508500|32| 0$ & 3.13E-05 \\
\hline COVID19 positive hospitalized vs COVID19 negative or unknown & $I K B K G$ & M1 & singleton & $0.55(0.0,2706.13)$ & 0.8906 & $1873|0| 0$ & $508523|7| 2$ & $1.08 \mathrm{E}-05$ \\
\hline COVID19 positive hospitalized vs COVID19 negative or unknown & $I R F 3$ & M1 & singleton & $0.37(0.0,113.18)$ & 0.7313 & $1873|0| 0$ & $508495|37| 0$ & 3.62E-05 \\
\hline COVID19 positive hospitalized vs COVID19 negative or unknown & IRF7 & M1 & singleton & $0.37(0.0,64.55)$ & 0.7071 & $1873|0| 0$ & $508481|51| 0$ & $5.00 \mathrm{E}-05$ \\
\hline COVID19 positive hospitalized vs COVID19 negative or unknown & IRF9 & M1 & singleton & $0.37(0.0,249.69)$ & 0.7666 & $1873|0| 0$ & $508505|27| 0$ & $2.64 \mathrm{E}-05$ \\
\hline COVID19 positive hospitalized vs COVID19 negative or unknown & STAT1 & M1 & singleton & $0.37(0.0,301.54)$ & 0.7688 & $1873|0| 0$ & $508502|30| 0$ & $2.94 \mathrm{E}-05$ \\
\hline COVID19 positive hospitalized vs COVID19 negative or unknown & STAT2 & M1 & singleton & $0.37(0.0,37.61)$ & 0.6705 & $1873|0| 0$ & $508487|45| 0$ & 4.41E-05 \\
\hline COVID19 positive hospitalized vs COVID19 negative or unknown & $T B K 1$ & M1 & singleton & $0.36(0.0,86.69)$ & 0.7179 & $1873|0| 0$ & $508501|31| 0$ & $3.04 \mathrm{E}-05$ \\
\hline COVID19 positive hospitalized vs COVID19 negative or unknown & TICAMI & M1 & singleton & $18.3(1.71,196.34)$ & 0.01636 & $1872|1| 0$ & $508489|43| 0$ & 4.31E-05 \\
\hline COVID19 positive hospitalized vs COVID19 negative or unknown & $T L R 3$ & M1 & singleton & $15.34(1.46,161.33)$ & 0.02294 & $1939|1| 0$ & $517242|28| 0$ & $2.79 \mathrm{E}-05$ \\
\hline COVID19 positive hospitalized vs COVID19 negative or unknown & TLR7 & M1 & singleton & $12.49(2.71,57.56)$ & 0.001198 & $1872|0| 1$ & $508520|10| 2$ & $1.57 \mathrm{E}-05$ \\
\hline COVID19 positive hospitalized vs COVID19 negative or unknown & TRAF3 & M1 & singleton & $0.37(0.0,8930.06)$ & 0.8463 & $1873|0| 0$ & $508514|18| 0$ & $1.76 \mathrm{E}-05$ \\
\hline COVID19 positive hospitalized vs COVID19 negative or unknown & UNC93B1 & M1 & singleton & $0.37(0.0,186.54)$ & 0.7539 & $1873|0| 0$ & $508489|43| 0$ & 4.21E-05 \\
\hline COVID19 positive hospitalized vs COVID19 negative or unknown & IFNARI & M3 & $<0.1 \%$ & $0.76(0.23,2.44)$ & 0.64 & $2083|2| 0$ & $534219|746| 0$ & $6.96 \mathrm{E}-04$ \\
\hline COVID19 positive hospitalized vs COVID19 negative or unknown & IFNAR2 & M3 & $<0.1 \%$ & $1.97(0.6,6.47)$ & 0.2651 & $2082|3| 0$ & $534253|712| 0$ & $6.66 \mathrm{E}-04$ \\
\hline COVID19 positive hospitalized vs COVID19 negative or unknown & $I K B K G$ & M3 & $<0.1 \%$ & $0.45(0.01,19.74)$ & 0.6761 & $1873|0| 0$ & $508452|70| 10$ & $8.82 \mathrm{E}-05$ \\
\hline COVID19 positive hospitalized vs COVID19 negative or unknown & $I R F 3$ & M3 & $<0.1 \%$ & $0.79(0.24,2.59)$ & 0.692 & $2083|2| 0$ & $534413|552| 0$ & $5.16 \mathrm{E}-04$ \\
\hline COVID19 positive hospitalized vs COVID19 negative or unknown & IRF7 & M3 & $<0.1 \%$ & $1.14(0.52,2.49)$ & 0.7481 & $2080|5| 0$ & $533486|1479| 0$ & $1.38 \mathrm{E}-03$ \\
\hline COVID19 positive hospitalized vs COVID19 negative or unknown & $I R F 9$ & M3 & $<0.1 \%$ & $0.37(0.0,53.77)$ & 0.696 & $1873|0| 0$ & $508479|53| 0$ & $5.19 \mathrm{E}-05$ \\
\hline
\end{tabular}




\begin{tabular}{|c|c|c|c|c|c|c|c|c|}
\hline COVID19 positive hospitalized vs COVID19 negative or unknown & STAT1 & M3 & $<0.1 \%$ & $0.37(0.04,3.49)$ & 0.3816 & $2018|0| 0$ & $526009|218| 0$ & $2.06 \mathrm{E}-04$ \\
\hline COVID19 positive hospitalized vs COVID19 negative or unknown & STAT2 & M3 & $<0.1 \%$ & $2.6(1.27,5.31)$ & 0.008795 & $2073|12| 0$ & $533405|1559| 1$ & $1.46 \mathrm{E}-03$ \\
\hline COVID19 positive hospitalized vs COVID19 negative or unknown & $T B K 1$ & M3 & $<0.1 \%$ & $1.11(0.45,2.79)$ & 0.8171 & $2081|4| 0$ & $533861|1103| 1$ & $1.03 \mathrm{E}-03$ \\
\hline COVID19 positive hospitalized vs COVID19 negative or unknown & TICAMI & M3 & $<0.1 \%$ & $3.66(0.19,71.22)$ & 0.392 & $1872|1| 0$ & $508365|167| 0$ & $1.65 \mathrm{E}-04$ \\
\hline COVID19 positive hospitalized vs COVID19 negative or unknown & TLR3 & M3 & $<0.1 \%$ & $0.81(0.43,1.49)$ & 0.4921 & $2077|8| 0$ & $532355|2609| 1$ & $2.44 \mathrm{E}-03$ \\
\hline COVID19 positive hospitalized vs COVID19 negative or unknown & $T L R 7$ & M3 & $<0.1 \%$ & $1.58(0.63,3.98)$ & 0.3321 & $2001|3| 1$ & $525830|477| 163$ & 7.64E-04 \\
\hline COVID19 positive hospitalized vs COVID19 negative or unknown & TRAF3 & M3 & $<0.1 \%$ & $3.01(0.53,17.22)$ & 0.2148 & $2019|1| 0$ & $525523|242| 0$ & $2.30 \mathrm{E}-04$ \\
\hline COVID19 positive hospitalized vs COVID19 negative or unknown & UNC93B1 & M3 & $<0.1 \%$ & $1.66(0.77,3.58)$ & 0.1922 & $2075|10| 0$ & $533331|1634| 0$ & $1.53 \mathrm{E}-03$ \\
\hline COVID19 positive hospitalized vs COVID19 negative or unknown & IFNARI & M3 & $<1 \%$ & $0.76(0.23,2.44)$ & 0.64 & $2083|2| 0$ & $534219|746| 0$ & $6.96 \mathrm{E}-04$ \\
\hline COVID19 positive hospitalized vs COVID19 negative or unknown & IFNAR2 & M3 & $<1 \%$ & $1.97(0.6,6.47)$ & 0.2651 & $2082|3| 0$ & $534253|712| 0$ & $6.66 \mathrm{E}-04$ \\
\hline COVID19 positive hospitalized vs COVID19 negative or unknown & $I K B K G$ & M3 & $<1 \%$ & $1.04(0.54,2.01)$ & 0.9101 & $1935|0| 3$ & $516444|949| 339$ & $1.57 \mathrm{E}-03$ \\
\hline COVID19 positive hospitalized vs COVID19 negative or unknown & $I R F 3$ & M3 & $<1 \%$ & $1.38(0.46,4.15)$ & 0.5704 & $2082|2| 1$ & $534363|601| 1$ & $5.65 \mathrm{E}-04$ \\
\hline COVID19 positive hospitalized vs COVID19 negative or unknown & IRF7 & M3 & $<1 \%$ & $1.14(0.52,2.49)$ & 0.7481 & $2080|5| 0$ & $533486|1479| 0$ & $1.38 \mathrm{E}-03$ \\
\hline COVID19 positive hospitalized vs COVID19 negative or unknown & IRF9 & M3 & $<1 \%$ & $0.37(0.0,53.77)$ & 0.696 & $1873|0| 0$ & $508479|53| 0$ & $5.19 \mathrm{E}-05$ \\
\hline COVID19 positive hospitalized vs COVID19 negative or unknown & STAT1 & M3 & $<1 \%$ & $0.37(0.04,3.49)$ & 0.3816 & $2018|0| 0$ & $526009|218| 0$ & $2.06 \mathrm{E}-04$ \\
\hline COVID19 positive hospitalized vs COVID19 negative or unknown & STAT2 & M3 & $<1 \%$ & $2.6(1.27,5.31)$ & 0.008795 & $2073|12| 0$ & $533405|1559| 1$ & $1.46 \mathrm{E}-03$ \\
\hline COVID19 positive hospitalized vs COVID19 negative or unknown & $T B K 1$ & M3 & $<1 \%$ & $1.11(0.45,2.79)$ & 0.8171 & $2081|4| 0$ & $533861|1103| 1$ & $1.03 \mathrm{E}-03$ \\
\hline COVID19 positive hospitalized vs COVID19 negative or unknown & TICAMI & M3 & $<1 \%$ & $3.66(0.19,71.22)$ & 0.392 & $1872|1| 0$ & $508365|167| 0$ & $1.65 \mathrm{E}-04$ \\
\hline COVID19 positive hospitalized vs COVID19 negative or unknown & $T L R 3$ & M3 & $<1 \%$ & $0.83(0.52,1.32)$ & 0.4285 & $2070|15| 0$ & $530068|4895| 2$ & $4.57 \mathrm{E}-03$ \\
\hline COVID19 positive hospitalized vs COVID19 negative or unknown & TLR7 & M3 & $<1 \%$ & $1.58(0.63,3.98)$ & 0.3321 & $2001|3| 1$ & $525830|477| 163$ & 7.64E-04 \\
\hline COVID19 positive hospitalized vs COVID19 negative or unknown & TRAF3 & M3 & $<1 \%$ & $0.89(0.48,1.65)$ & 0.711 & $2076|9| 0$ & $532255|2706| 4$ & $2.54 \mathrm{E}-03$ \\
\hline COVID19 positive hospitalized vs COVID19 negative or unknown & UNC93BI & M3 & $<1 \%$ & $1.66(0.77,3.58)$ & 0.1922 & $2075|10| 0$ & $533331|1634| 0$ & $1.53 \mathrm{E}-03$ \\
\hline COVID19 positive hospitalized vs COVID19 negative or unknown & IFNARI & M3 & singleton & $0.37(0.01,20.63)$ & 0.6273 & $1873|0| 0$ & $508465|67| 0$ & $6.56 \mathrm{E}-05$ \\
\hline COVID19 positive hospitalized vs COVID19 negative or unknown & IFNAR2 & M3 & singleton & $0.36(0.0,138.92)$ & 0.7352 & $1873|0| 0$ & $508498|34| 0$ & 3.33E-05 \\
\hline COVID19 positive hospitalized vs COVID19 negative or unknown & $I K B K G$ & M3 & singleton & $0.55(0.0,2553.85)$ & 0.889 & $1873|0| 0$ & $508522|8| 2$ & $1.18 \mathrm{E}-05$ \\
\hline COVID19 positive hospitalized vs COVID19 negative or unknown & $I R F 3$ & M3 & singleton & $0.37(0.0,46.47)$ & 0.687 & $1940|0| 0$ & $517212|58| 0$ & $5.59 \mathrm{E}-05$ \\
\hline COVID19 positive hospitalized vs COVID19 negative or unknown & IRF7 & M3 & singleton & $2.94(0.17,51.0)$ & 0.4591 & $2004|1| 0$ & $526371|99| 0$ & $9.46 \mathrm{E}-05$ \\
\hline COVID19 positive hospitalized vs COVID19 negative or unknown & IRF9 & M3 & singleton & $0.37(0.0,249.69)$ & 0.7666 & $1873|0| 0$ & $508505|27| 0$ & $2.64 \mathrm{E}-05$ \\
\hline COVID19 positive hospitalized vs COVID19 negative or unknown & STAT1 & M3 & singleton & $0.37(0.01,19.67)$ & 0.6207 & $1873|0| 0$ & $508458|74| 0$ & $7.25 \mathrm{E}-05$ \\
\hline COVID19 positive hospitalized vs COVID19 negative or unknown & STAT2 & M3 & singleton & $35.11(4.02,306.33)$ & 0.001283 & $2018|2| 0$ & $525651|114| 0$ & $1.10 \mathrm{E}-04$ \\
\hline COVID19 positive hospitalized vs COVID19 negative or unknown & TBK1 & M3 & singleton & $0.37(0.02,8.91)$ & 0.5401 & $2005|0| 0$ & $526361|109| 0$ & $1.03 \mathrm{E}-04$ \\
\hline COVID19 positive hospitalized vs COVID19 negative or unknown & TICAMI & M3 & singleton & $17.91(1.68,190.85)$ & 0.01686 & $1872|1| 0$ & $508486|46| 0$ & $4.60 \mathrm{E}-05$ \\
\hline COVID19 positive hospitalized vs COVID19 negative or unknown & TLR3 & M3 & singleton & $0.93(0.14,6.19)$ & 0.943 & $2084|1| 0$ & $534786|178| 1$ & $1.69 \mathrm{E}-04$ \\
\hline COVID19 positive hospitalized vs COVID19 negative or unknown & TLR7 & M3 & singleton & $4.02(1.16,13.91)$ & 0.02818 & $1939|0| 1$ & $517197|55| 18$ & $8.96 \mathrm{E}-05$ \\
\hline COVID19 positive hospitalized vs COVID19 negative or unknown & TRAF3 & M3 & singleton & $0.37(0.01,21.93)$ & 0.6308 & $1873|0| 0$ & $508461|71| 0$ & $6.96 \mathrm{E}-05$ \\
\hline COVID19 positive hospitalized vs COVID19 negative or unknown & UNC93B1 & M3 & singleton & $0.38(0.01,12.45)$ & 0.5832 & $1953|0| 0$ & $516939|88| 0$ & $8.48 \mathrm{E}-05$ \\
\hline COVID19 positive severe vs COVID19 negative or unknown & IFNARI & M1 & $<0.1 \%$ & $2.62(0.18,38.8)$ & 0.4837 & $571|1| 0$ & $516685|342| 0$ & $3.31 \mathrm{E}-04$ \\
\hline COVID19 positive severe vs COVID19 negative or unknown & IFNAR2 & M1 & $<0.1 \%$ & $1.97(0.17,22.68)$ & 0.5855 & $589|1| 0$ & $525553|674| 0$ & $6.41 \mathrm{E}-04$ \\
\hline COVID19 positive severe vs COVID19 negative or unknown & $I K B K G$ & M1 & $<0.1 \%$ & $14.74(1.12,193.22)$ & 0.04042 & $539|0| 0$ & $508491|31| 10$ & $5.01 \mathrm{E}-05$ \\
\hline COVID19 positive severe vs COVID19 negative or unknown & IRF3 & M1 & $<0.1 \%$ & $3.02(0.6,15.18)$ & 0.1793 & $589|1| 0$ & $525854|373| 0$ & $3.55 \mathrm{E}-04$ \\
\hline COVID19 positive severe vs COVID19 negative or unknown & IRF7 & M1 & $<0.1 \%$ & $2.68(0.39,18.58)$ & 0.3189 & $588|2| 0$ & $525395|832| 0$ & $7.92 \mathrm{E}-04$ \\
\hline COVID19 positive severe vs COVID19 negative or unknown & IRF9 & M1 & $<0.1 \%$ & $0.42(0.0,5297.95)$ & 0.8575 & $539|0| 0$ & $508479|53| 0$ & $5.21 \mathrm{E}-05$ \\
\hline COVID19 positive severe vs COVID19 negative or unknown & STAT1 & M1 & $<0.1 \%$ & $0.38(0.0,3004.31)$ & 0.8315 & $539|0| 0$ & $508490|42| 0$ & 4.13E-05 \\
\hline COVID19 positive severe vs COVID19 negative or unknown & STAT2 & M1 & $<0.1 \%$ & $0.37(0.0,38.82)$ & 0.6778 & $539|0| 0$ & $508405|127| 0$ & $1.25 \mathrm{E}-04$ \\
\hline COVID19 positive severe vs COVID19 negative or unknown & $T B K 1$ & M1 & $<0.1 \%$ & $0.38(0.0,211.44)$ & 0.7619 & $539|0| 0$ & $508445|87| 0$ & $8.54 \mathrm{E}-05$ \\
\hline COVID19 positive severe vs COVID19 negative or unknown & TICAMI & M1 & $<0.1 \%$ & $0.89(0.05,15.25)$ & 0.9349 & $539|0| 0$ & $508368|164| 0$ & $1.61 \mathrm{E}-04$ \\
\hline COVID19 positive severe vs COVID19 negative or unknown & $T L R 3$ & M1 & $<0.1 \%$ & $0.41(0.01,21.61)$ & 0.6594 & $590|0| 0$ & $525950|277| 0$ & $2.63 \mathrm{E}-04$ \\
\hline COVID19 positive severe vs COVID19 negative or unknown & $T L R 7$ & M1 & $<0.1 \%$ & $42.12(0.51,3486.63)$ & 0.0969 & $539|0| 0$ & $508503|25| 4$ & $3.24 \mathrm{E}-05$ \\
\hline COVID19 positive severe vs COVID19 negative or unknown & TRAF3 & M1 & $<0.1 \%$ & $0.43(0.0,281622.0)$ & 0.9011 & $539|0| 0$ & $508504|28| 0$ & $2.75 \mathrm{E}-05$ \\
\hline COVID19 positive severe vs COVID19 negative or unknown & UNC93B1 & M1 & $<0.1 \%$ & $3.35(0.18,61.63)$ & 0.4157 & $538|1| 0$ & $508128|404| 0$ & $3.98 \mathrm{E}-04$ \\
\hline COVID19 positive severe vs COVID19 negative or unknown & IFNARI & M1 & $<1 \%$ & $2.62(0.18,38.8)$ & 0.4837 & $571|1| 0$ & $516685|342| 0$ & $3.31 \mathrm{E}-04$ \\
\hline
\end{tabular}




\begin{tabular}{|c|}
\hline COVID19 positive severe vs COVID19 negative or unknown \\
\hline COVID19 positive severe vs COVID19 negative or unknown \\
\hline COVID19 positive severe vs COVID19 negative or unknown \\
\hline COVID19 positive severe vs COVID19 negative or unknown \\
\hline COVID19 positive severe vs COVID19 negative or unknown \\
\hline COVID19 positive severe vs COVID19 negative or unknown \\
\hline COVID19 positive severe vs COVID19 negative or unknown \\
\hline COVID19 positive severe vs COVID19 negative or unknown \\
\hline COVID19 positive severe vs COVID19 negative or unknown \\
\hline COVID19 positive severe vs COVID19 negative or unknown \\
\hline COVID19 positive severe vs COVID19 negative or unknown \\
\hline COVID19 positive severe vs COVID19 negative or unknown \\
\hline COVID19 positive severe vs COVID19 negative or unknown \\
\hline COVID19 positive severe vs COVID19 negative or unknown \\
\hline COVID19 positive severe vs COVID19 negative or unknown \\
\hline COVID19 positive severe vs COVID19 negative or unknown \\
\hline COVID19 positive severe vs COVID19 negative or unknown \\
\hline COVID19 positive severe vs COVID19 negative or unknown \\
\hline COVID19 positive severe vs COVID19 negative or unknown \\
\hline COVID19 positive severe vs COVID19 negative or unknown \\
\hline COVID19 positive severe vs COVID19 negative or unknown \\
\hline COVID19 positive severe vs COVID19 negative or unknown \\
\hline COVID19 positive severe vs COVID19 negative or unknown \\
\hline COVID19 positive severe vs COVID19 negative or unknown \\
\hline COVID19 positive severe vs COVID19 negative or unknown \\
\hline COVID19 positive severe vs COVID19 negative or unknown \\
\hline COVID19 positive severe vs COVID19 negative or unknown \\
\hline COVID19 positive severe vs COVID19 negative or unknown \\
\hline COVID19 positive severe vs COVID19 negative or unknown \\
\hline COVID19 positive severe vs COVID19 negative or unknown \\
\hline COVID19 positive severe vs COVID19 negative or unknown \\
\hline COVID19 positive severe vs COVID19 negative or unknown \\
\hline COVID19 positive severe vs COVID19 negative or unknown \\
\hline COVID19 positive severe vs COVID19 negative or unknown \\
\hline COVID19 positive severe vs COVID19 negative or unknown \\
\hline COVID19 positive severe vs COVID19 negative or unknown \\
\hline COVID19 positive severe vs COVID19 negative or unknown \\
\hline COVID19 positive severe vs COVID19 negative or unknown \\
\hline COVID19 positive severe vs COVID19 negative or unknown \\
\hline COVID19 positive severe vs COVID19 negative or unknown \\
\hline COVID19 positive severe vs COVID19 negative or unknown \\
\hline COVID19 positive severe vs COVID19 negative or unknown \\
\hline COVID19 positive severe vs COVID19 negative or unknown \\
\hline COVID19 positive severe vs COVID19 negative or unknown \\
\hline COVID19 positive severe vs COVID19 negative or unknown \\
\hline COVID19 positive severe vs COVID19 negative or unknown \\
\hline COVID19 positive severe vs COVID19 negative or unknown \\
\hline COVID19 positive severe vs COVID19 negative or unknown \\
\hline COVID19 positive severe vs COVID19 negative or unknown \\
\hline COVID19 positive severe vs COVID19 negative or unknown \\
\hline COVID19 positive severe vs COVID19 negative or unknown \\
\hline
\end{tabular}

\begin{tabular}{|c|c|c|c|c|c|c|c|}
\hline IFNAR2 & M1 & $<1 \%$ & $1.97(0.17,22.68)$ & 0.5855 & $589|1| 0$ & $525553|674| 0$ & $6.41 \mathrm{E}-04$ \\
\hline$I K B K G$ & M1 & $<1 \%$ & $14.74(1.12,193.22)$ & 0.04042 & $539|0| 0$ & $508491|31| 10$ & $5.01 \mathrm{E}-05$ \\
\hline$I R F 3$ & M1 & $<1 \%$ & $3.02(0.6,15.18)$ & 0.1793 & $589|1| 0$ & $525854|373| 0$ & $3.55 \mathrm{E}-04$ \\
\hline IRF7 & M1 & $<1 \%$ & $2.68(0.39,18.58)$ & 0.3189 & $588|2| 0$ & $525395|832| 0$ & $7.92 \mathrm{E}-04$ \\
\hline IRF9 & M1 & $<1 \%$ & $0.42(0.0,5297.95)$ & 0.8575 & $539|0| 0$ & $508479|53| 0$ & $5.21 \mathrm{E}-05$ \\
\hline STATI & M1 & $<1 \%$ & $0.38(0.0,3004.31)$ & 0.8315 & $539|0| 0$ & $508490|42| 0$ & 4.13E-05 \\
\hline STAT2 & M1 & $<1 \%$ & $0.37(0.0,38.82)$ & 0.6778 & $539|0| 0$ & $508405|127| 0$ & $1.25 \mathrm{E}-04$ \\
\hline TBK1 & M1 & $<1 \%$ & $0.38(0.0,211.44)$ & 0.7619 & $539|0| 0$ & $508445|87| 0$ & $8.54 \mathrm{E}-05$ \\
\hline ТICAMI & M1 & $<1 \%$ & $0.89(0.05,15.25)$ & 0.9349 & $539|0| 0$ & $508368|164| 0$ & $1.61 \mathrm{E}-04$ \\
\hline$T L R 3$ & M1 & $<1 \%$ & $0.41(0.01,21.61)$ & 0.6594 & $590|0| 0$ & $525950|277| 0$ & $2.63 \mathrm{E}-04$ \\
\hline TLR7 & M1 & $<1 \%$ & $42.12(0.51,3486.63)$ & 0.0969 & $539|0| 0$ & $508503|25| 4$ & $3.24 \mathrm{E}-05$ \\
\hline TRAF3 & M1 & $<1 \%$ & $0.43(0.0,281622.0)$ & 0.9011 & $539|0| 0$ & $508504|28| 0$ & $2.75 \mathrm{E}-05$ \\
\hline UNC93B1 & M1 & $<1 \%$ & $3.35(0.18,61.63)$ & 0.4157 & $538|1| 0$ & $508128|404| 0$ & $3.98 \mathrm{E}-04$ \\
\hline IFNARI & M1 & singleton & $0.37(0.0,165.53)$ & 0.7518 & $539|0| 0$ & $508477|55| 0$ & $5.40 \mathrm{E}-05$ \\
\hline IFNAR2 & M1 & singleton & $0.48(0.0,901579.0)$ & 0.9216 & $539|0| 0$ & $508500|32| 0$ & $3.14 \mathrm{E}-05$ \\
\hline$I K B K G$ & M1 & singleton & $0.58(0.0,711727.0)$ & 0.939 & $490|0| 0$ & $399233|6| 1$ & $1.00 \mathrm{E}-05$ \\
\hline$I R F 3$ & M1 & singleton & $24.01(0.35,1669.95)$ & 0.1419 & $539|0| 0$ & $508495|37| 0$ & 3.63E-05 \\
\hline IRF7 & M1 & singleton & $0.45(0.0,19828.4)$ & 0.8843 & $539|0| 0$ & $508481|51| 0$ & $5.01 \mathrm{E}-05$ \\
\hline IRF9 & M1 & singleton & $0.45(0.0,564343.0)$ & 0.9115 & $539|0| 0$ & $508505|27| 0$ & $2.65 \mathrm{E}-05$ \\
\hline STAT1 & M1 & singleton & $0.38(0.0,9818.87)$ & 0.8505 & $539|0| 0$ & $508502|30| 0$ & $2.95 \mathrm{E}-05$ \\
\hline STAT2 & M1 & singleton & $0.39(0.0,13826.4)$ & 0.861 & $539|0| 0$ & $508487|45| 0$ & $4.42 \mathrm{E}-05$ \\
\hline TBK1 & M1 & singleton & $0.38(0.0,28255.6)$ & 0.8649 & $539|0| 0$ & $508501|31| 0$ & 3.04E-05 \\
\hline TICAMI & M1 & singleton & $15.49(0.28,860.18)$ & 0.1812 & $539|0| 0$ & $508489|43| 0$ & 4.22E- 05 \\
\hline$T L R 3$ & M1 & singleton & $0.38(0.0,18335.2)$ & 0.8602 & $539|0| 0$ & $508509|23| 0$ & $2.26 \mathrm{E}-05$ \\
\hline$T L R 7$ & M1 & singleton & $0.4(0.0,3891300000.0)$ & 0.9371 & $490|0| 0$ & $399229|9| 2$ & $1.63 \mathrm{E}-05$ \\
\hline TRAF3 & M1 & singleton & $0.42(0.0,1871470.0)$ & 0.9114 & $539|0| 0$ & $508514|18| 0$ & $1.77 \mathrm{E}-05$ \\
\hline UNC93B1 & M1 & singleton & $0.42(0.0,20393.0)$ & 0.8758 & $539|0| 0$ & $508489|43| 0$ & $4.22 \mathrm{E}-05$ \\
\hline IFNARI & M3 & $<0.1 \%$ & $1.07(0.15,7.68)$ & 0.9458 & $589|1| 0$ & $525500|727| 0$ & $6.91 \mathrm{E}-04$ \\
\hline IFNAR2 & M3 & $<0.1 \%$ & $1.88(0.17,20.82)$ & 0.6068 & $589|1| 0$ & $525529|698| 0$ & $6.63 \mathrm{E}-04$ \\
\hline$I K B K G$ & M3 & $<0.1 \%$ & $12.55(0.99,159.28)$ & 0.051 & $539|0| 0$ & $508452|70| 10$ & $8.84 \mathrm{E}-05$ \\
\hline$I R F 3$ & M3 & $<0.1 \%$ & $2.53(0.54,11.8)$ & 0.2388 & $589|1| 0$ & $525713|514| 0$ & $4.89 \mathrm{E}-04$ \\
\hline IRF7 & M3 & $<0.1 \%$ & $3.07(0.81,11.64)$ & 0.09817 & $587|3| 0$ & $524764|1463| 0$ & $1.39 \mathrm{E}-03$ \\
\hline IRF9 & M3 & $<0.1 \%$ & $0.42(0.0,5297.95)$ & 0.8575 & $539|0| 0$ & $508479|53| 0$ & $5.21 \mathrm{E}-05$ \\
\hline STAT1 & M3 & $<0.1 \%$ & $0.38(0.01,14.6)$ & 0.6027 & $590|0| 0$ & $526009|218| 0$ & $2.07 \mathrm{E}-04$ \\
\hline STAT2 & M3 & $<0.1 \%$ & $1.64(0.36,7.55)$ & 0.5246 & $587|3| 0$ & $524718|1508| 1$ & $1.44 \mathrm{E}-03$ \\
\hline TBK1 & M3 & $<0.1 \%$ & $1.96(0.33,11.47)$ & 0.456 & $588|2| 0$ & $525137|1089| 1$ & $1.04 \mathrm{E}-03$ \\
\hline ТICАMI & M3 & $<0.1 \%$ & $0.89(0.05,15.22)$ & 0.9349 & $539|0| 0$ & $508365|167| 0$ & $1.64 \mathrm{E}-04$ \\
\hline$T L R 3$ & M3 & $<0.1 \%$ & $0.74(0.24,2.26)$ & 0.5951 & $588|2| 0$ & $523680|2546| 1$ & $2.42 \mathrm{E}-03$ \\
\hline$T L R 7$ & M3 & $<0.1 \%$ & $1.22(0.29,5.15)$ & 0.7855 & $557|0| 0$ & $517105|467| 160$ & $7.59 \mathrm{E}-04$ \\
\hline TRAF3 & M3 & $<0.1 \%$ & $14.61(1.54,138.27)$ & 0.01935 & $571|1| 0$ & $516792|235| 0$ & $2.28 \mathrm{E}-04$ \\
\hline UNC93B1 & M3 & $<0.1 \%$ & $3.13(1.26,7.77)$ & 0.01414 & $584|6| 0$ & $524612|1615| 0$ & $1.54 \mathrm{E}-03$ \\
\hline IFNARI & M3 & $<1 \%$ & $1.07(0.15,7.68)$ & 0.9458 & $589|1| 0$ & $525500|727| 0$ & $6.91 \mathrm{E}-04$ \\
\hline IFNAR2 & M3 & $<1 \%$ & $1.88(0.17,20.82)$ & 0.6068 & $589|1| 0$ & $525529|698| 0$ & $6.63 \mathrm{E}-04$ \\
\hline$I K B K G$ & M3 & $<1 \%$ & $1.41(0.48,4.17)$ & 0.5303 & $556|0| 1$ & $516444|949| 339$ & $1.57 \mathrm{E}-03$ \\
\hline$I R F 3$ & M3 & $<1 \%$ & $2.53(0.54,11.8)$ & 0.2388 & $589|1| 0$ & $525713|514| 0$ & $4.89 \mathrm{E}-04$ \\
\hline IRF7 & M3 & $<1 \%$ & $3.07(0.81,11.64)$ & 0.09817 & $587|3| 0$ & $524764|1463| 0$ & $1.39 \mathrm{E}-03$ \\
\hline IRF9 & M3 & $<1 \%$ & $0.42(0.0,5297.95)$ & 0.8575 & $539|0| 0$ & $508479|53| 0$ & $5.21 \mathrm{E}-05$ \\
\hline STATI & M3 & $<1 \%$ & $0.38(0.01,14.6)$ & 0.6027 & $590|0| 0$ & $526009|218| 0$ & $2.07 \mathrm{E}-04$ \\
\hline STAT2 & M3 & $<1 \%$ & $1.64(0.36,7.55)$ & 0.5246 & $587|3| 0$ & $524718|1508| 1$ & $1.44 \mathrm{E}-03$ \\
\hline TBK1 & M3 & $<1 \%$ & $1.96(0.33,11.47)$ & 0.456 & $588|2| 0$ & $525137|1089| 1$ & $1.04 \mathrm{E}-03$ \\
\hline TICAMI & M3 & $<1 \%$ & $0.89(0.05,15.22)$ & 0.9349 & $539|0| 0$ & $508365|167| 0$ & $1.64 \mathrm{E}-04$ \\
\hline
\end{tabular}




\begin{tabular}{|c|c|c|c|c|c|c|c|c|}
\hline COVID19 positive severe vs COVID19 negative or unknown & $T L R 3$ & M3 & $<1 \%$ & $0.97(0.41,2.26)$ & 0.9396 & $585|5| 0$ & $521403|4822| 2$ & $4.59 \mathrm{E}-03$ \\
\hline COVID19 positive severe vs COVID19 negative or unknown & TLR7 & M3 & $<1 \%$ & $1.22(0.29,5.15)$ & 0.7855 & $557|0| 0$ & $517105|467| 160$ & $7.59 \mathrm{E}-04$ \\
\hline COVID19 positive severe vs COVID19 negative or unknown & TRAF3 & M3 & $<1 \%$ & $1.27(0.49,3.25)$ & 0.6217 & $587|3| 0$ & $523530|2693| 4$ & $2.57 \mathrm{E}-03$ \\
\hline COVID19 positive severe vs COVID19 negative or unknown & UNC93B1 & M3 & $<1 \%$ & $3.13(1.26,7.77)$ & 0.01414 & $584|6| 0$ & $524612|1615| 0$ & $1.54 \mathrm{E}-03$ \\
\hline COVID19 positive severe vs COVID19 negative or unknown & IFNARI & M3 & singleton & $0.37(0.0,119.72)$ & 0.738 & $539|0| 0$ & $508465|67| 0$ & $6.58 \mathrm{E}-05$ \\
\hline COVID19 positive severe vs COVID19 negative or unknown & IFNAR2 & M3 & singleton & $0.47(0.0,448932.0)$ & 0.9144 & $539|0| 0$ & $508498|34| 0$ & $3.34 \mathrm{E}-05$ \\
\hline COVID19 positive severe vs COVID19 negative or unknown & $I K B K G$ & M3 & singleton & $0.57(0.0,614503.0)$ & 0.9374 & $490|0| 0$ & $399232|7| 1$ & $1.13 \mathrm{E}-05$ \\
\hline COVID19 positive severe vs COVID19 negative or unknown & IRF3 & M3 & singleton & $20.95(0.32,1352.58)$ & 0.1525 & $539|0| 0$ & $508480|52| 0$ & $5.11 \mathrm{E}-05$ \\
\hline COVID19 positive severe vs COVID19 negative or unknown & IRF7 & M3 & singleton & $0.42(0.0,600.62)$ & 0.8166 & $557|0| 0$ & $517640|92| 0$ & $8.88 \mathrm{E}-05$ \\
\hline COVID19 positive severe vs COVID19 negative or unknown & IRF9 & M3 & singleton & $0.45(0.0,564343.0)$ & 0.9115 & $539|0| 0$ & $508505|27| 0$ & $2.65 \mathrm{E}-05$ \\
\hline COVID19 positive severe vs COVID19 negative or unknown & STAT1 & M3 & singleton & $0.38(0.0,269.14)$ & 0.7735 & $539|0| 0$ & $508458|74| 0$ & 7.27E-05 \\
\hline COVID19 positive severe vs COVID19 negative or unknown & STAT2 & M3 & singleton & $0.4(0.0,128.93)$ & 0.7543 & $572|0| 0$ & $516919|108| 0$ & $1.04 \mathrm{E}-04$ \\
\hline COVID19 positive severe vs COVID19 negative or unknown & TBK1 & M3 & singleton & $0.38(0.0,184.6)$ & 0.7614 & $557|0| 0$ & $517628|104| 0$ & $1.00 \mathrm{E}-04$ \\
\hline COVID19 positive severe vs COVID19 negative or unknown & TICAMI & M3 & singleton & $15.0(0.27,819.65)$ & 0.1846 & $539|0| 0$ & $508486|46| 0$ & 4.52E-05 \\
\hline COVID19 positive severe vs COVID19 negative or unknown & TLR3 & M3 & singleton & $0.41(0.01,15.67)$ & 0.6287 & $590|0| 0$ & $526065|161| 1$ & $1.55 \mathrm{E}-04$ \\
\hline COVID19 positive severe vs COVID19 negative or unknown & $T L R 7$ & M3 & singleton & $11.63(0.84,161.65)$ & 0.06761 & $539|0| 0$ & $508468|49| 15$ & 7.76E-05 \\
\hline COVID19 positive severe vs COVID19 negative or unknown & TRAF3 & M3 & singleton & $0.4(0.0,689.93)$ & 0.8098 & $539|0| 0$ & $508461|71| 0$ & $6.97 \mathrm{E}-05$ \\
\hline COVID19 positive severe vs COVID19 negative or unknown & UNC93B1 & M3 & singleton & $0.42(0.0,250.75)$ & 0.7916 & $572|0| 0$ & $516939|88| 0$ & $8.50 \mathrm{E}-05$ \\
\hline
\end{tabular}


Supplementary Table 10. Results from burden association tests for 32 additional genes of biological or therapeutic interest.

\begin{tabular}{|c|c|c|c|c|c|c|c|c|}
\hline Trait & Gene & Burden test & MAF & Odds Ratio $[95 \% \mathrm{CI}]$ & P-value & $\begin{array}{c}\mathrm{N} \text { cases with } \\
\text { RR|RA|AA genotype* }\end{array}$ & $\begin{array}{c}\text { N controls with } \\
\text { RR|RA|AA genotype* }\end{array}$ & AAF \\
\hline COVID19 positive hospitalized vs COVID19 negative or unknown & IL23R & M1 & $<1 \%$ & $3.849[0.853 ; 17.373]$ & $8.00 \mathrm{E}-02$ & $1871|2| 0$ & $508324|208| 0$ & 0.00021 \\
\hline COVID19 positive hospitalized vs COVID19 negative or unknown & IL1A & M3 & $<1 \%$ & $2.350[0.835 ; 6.611]$ & $1.10 \mathrm{E}-01$ & $2016|4| 0$ & $525349|415| 1$ & 0.0004 \\
\hline COVID19 positive hospitalized vs COVID19 negative or unknown & IFNL3 & M1 & $<1 \%$ & $14.959[0.345 ; 647.891]$ & $1.60 \mathrm{E}-01$ & $1872|1| 0$ & $508438|94| 0$ & 0.00009 \\
\hline COVID19 positive hospitalized vs COVID19 negative or unknown & IL1A & M1 & $<1 \%$ & $4.218[0.574 ; 31.008]$ & $1.60 \mathrm{E}-01$ & $2019|1| 0$ & $525641|124| 0$ & 0.00012 \\
\hline COVID19 positive hospitalized vs COVID19 negative or unknown & IFNL1 & M3 & $<1 \%$ & $0.369[0.086 ; 1.585]$ & $1.80 \mathrm{E}-01$ & $2085|0| 0$ & $534569|395| 1$ & 0.00037 \\
\hline COVID19 positive hospitalized vs COVID19 negative or unknown & TMPRSS2 & M1 & $<1 \%$ & $2.526[0.646,9.876]$ & $1.80 \mathrm{E}-01$ & $1936|4| 0$ & $516764|506| 0$ & 0.00049 \\
\hline COVID19 positive hospitalized vs COVID19 negative or unknown & $\mathrm{C} 5$ & M1 & $<1 \%$ & $2.077[0.702 ; 6.144]$ & $1.90 \mathrm{E}-01$ & $2081|4| 0$ & $534324|640| 1$ & 0.0006 \\
\hline COVID19 positive hospitalized vs COVID19 negative or unknown & IFNL1 & M1 & $<1 \%$ & $0.369[0.081 ; 1.687]$ & $2.00 \mathrm{E}-01$ & $2085|0| 0$ & $534607|357| 1$ & 0.00033 \\
\hline COVID19 positive hospitalized vs COVID19 negative or unknown & IL17RC & M3 & $<1 \%$ & $1.643[0.749 ; 3.604]$ & $2.20 \mathrm{E}-01$ & $2080|5| 0$ & $533824|1140| 1$ & 0.00107 \\
\hline COVID19 positive hospitalized vs COVID19 negative or unknown & VEGFA & M3 & $<1 \%$ & $0.558[0.219 ; 1.418]$ & $2.20 \mathrm{E}-01$ & $2083|2| 0$ & $533873|1091| 1$ & 0.00102 \\
\hline COVID19 positive hospitalized vs COVID19 negative or unknown & IL7R & M1 & $<1 \%$ & $1.668[0.692 ; 4.019]$ & $2.50 \mathrm{E}-01$ & $2079|6| 0$ & $533848|1117| 0$ & 0.00105 \\
\hline COVID19 positive hospitalized vs COVID19 negative or unknown & IL12B & M3 & $<1 \%$ & $2.200[0.438 ; 11.048]$ & $3.40 \mathrm{E}-01$ & $2017|1| 0$ & $526033|194| 0$ & 0.00018 \\
\hline COVID19 positive hospitalized vs COVID19 negative or unknown & IL23A & M3 & $<1 \%$ & $0.366[0.046 ; 2.919]$ & $3.40 \mathrm{E}-01$ & $1938|0| 0$ & $517449|282| 1$ & 0.00027 \\
\hline COVID19 positive hospitalized vs COVID19 negative or unknown & IL17RA & M1 & $<1 \%$ & $0.359[0.040 ; 3.220]$ & $3.60 \mathrm{E}-01$ & $2020|0| 0$ & $525537|228| 0$ & 0.00022 \\
\hline COVID19 positive hospitalized vs COVID19 negative or unknown & IFNLR1 & M3 & $<1 \%$ & $0.366[0.040 ; 3.321]$ & $3.70 \mathrm{E}-01$ & $1938|0| 0$ & $517531|201| 0$ & 0.00019 \\
\hline COVID19 positive hospitalized vs COVID19 negative or unknown & IL1B & M3 & $<1 \%$ & $0.369[0.039 ; 3.491]$ & $3.80 \mathrm{E}-01$ & $2005|0| 0$ & $526208|262| 0$ & 0.00025 \\
\hline COVID19 positive hospitalized vs COVID19 negative or unknown & IFNL3 & M3 & $<1 \%$ & $3.464[0.185 ; 64.982]$ & $4.10 \mathrm{E}-01$ & $1939|1| 0$ & $517141|129| 0$ & 0.00013 \\
\hline COVID19 positive hospitalized vs COVID19 negative or unknown & JAK1 & M1 & $<1 \%$ & $1.942[0.398 ; 9.474]$ & $4.10 \mathrm{E}-01$ & $1937|1| 0$ & $517541|189| 2$ & 0.00019 \\
\hline COVID19 positive hospitalized vs COVID19 negative or unknown & JAK1 & M3 & $<1 \%$ & $1.942[0.398 ; 9.474]$ & $4.10 \mathrm{E}-01$ & $1937|1| 0$ & $517541|189| 2$ & 0.00019 \\
\hline COVID19 positive hospitalized vs COVID19 negative or unknown & IFNLR1 & M1 & $<1 \%$ & $0.365[0.030 ; 4.527]$ & $4.30 \mathrm{E}-01$ & $1938|0| 0$ & $517571|161| 0$ & 0.00015 \\
\hline COVID19 positive hospitalized vs COVID19 negative or unknown & IL1B & M1 & $<1 \%$ & $0.368[0.030 ; 4.481]$ & $4.30 \mathrm{E}-01$ & $1873|0| 0$ & $508320|212| 0$ & 0.00021 \\
\hline COVID19 positive hospitalized vs COVID19 negative or unknown & JAK2 & M1 & $<1 \%$ & $0.366[0.029 ; 4.555]$ & $4.30 \mathrm{E}-01$ & $1938|0| 0$ & $517530|202| 0$ & 0.00019 \\
\hline COVID19 positive hospitalized vs COVID19 negative or unknown & IL23R & M3 & $<1 \%$ & $0.847[0.554 ; 1.296]$ & $4.40 \mathrm{E}-01$ & $2067|18| 0$ & $529085|5861| 19$ & 0.00551 \\
\hline COVID19 positive hospitalized vs COVID19 negative or unknown & VEGFA & M1 & $<1 \%$ & $0.661[0.218 ; 2.002]$ & $4.60 \mathrm{E}-01$ & $2083|2| 0$ & $534217|747| 1$ & 0.0007 \\
\hline COVID19 positive hospitalized vs COVID19 negative or unknown & IL1R1 & M1 & $<1 \%$ & $0.666[0.222 ; 1.995]$ & $4.70 \mathrm{E}-01$ & $1936|2| 0$ & $517281|444| 7$ & 0.00044 \\
\hline COVID19 positive hospitalized vs COVID19 negative or unknown & IL7R & M3 & $<1 \%$ & $1.269[0.666 ; 2.419]$ & $4.70 \mathrm{E}-01$ & $2075|10| 0$ & $532768|2197| 0$ & 0.00205 \\
\hline COVID19 positive hospitalized vs COVID19 negative or unknown & TMPRSS2 & M3 & $<1 \%$ & $1.341[0.606,2.967]$ & $4.70 \mathrm{E}-01$ & $2077|8| 0$ & $533498|1467| 0$ & 0.00137 \\
\hline COVID19 positive hospitalized vs COVID19 negative or unknown & IFNG & M3 & $<1 \%$ & $0.366[0.020 ; 6.537]$ & $4.90 \mathrm{E}-01$ & $1873|0| 0$ & $508402|130| 0$ & 0.00013 \\
\hline COVID19 positive hospitalized vs COVID19 negative or unknown & BTK & M3 & $<1 \%$ & $0.497[0.061 ; 4.077]$ & $5.10 \mathrm{E}-01$ & $2020|0| 0$ & $525622|114| 29$ & 0.00016 \\
\hline COVID19 positive hospitalized vs COVID19 negative or unknown & IL6 & M3 & $<1 \%$ & $0.369[0.019 ; 7.067]$ & $5.10 \mathrm{E}-01$ & $1953|0| 0$ & $516905|122| 0$ & 0.00012 \\
\hline COVID19 positive hospitalized vs COVID19 negative or unknown & IL6R & M1 & $<1 \%$ & $0.377[0.020 ; 7.210]$ & $5.20 \mathrm{E}-01$ & $1940|0| 0$ & $517152|118| 0$ & 0.00011 \\
\hline COVID19 positive hospitalized vs COVID19 negative or unknown & IL12B & M1 & $<1 \%$ & $0.365[0.016 ; 8.562]$ & $5.30 \mathrm{E}-01$ & $1873|0| 0$ & $508442|90| 0$ & 0.00009 \\
\hline COVID19 positive hospitalized vs COVID19 negative or unknown & IL1R1 & M3 & $<1 \%$ & $0.739[0.283 ; 1.931]$ & $5.40 \mathrm{E}-01$ & $2082|3| 0$ & $534274|684| 7$ & 0.00065 \\
\hline COVID19 positive hospitalized vs COVID19 negative or unknown & IL6 & M1 & $<1 \%$ & $0.367[0.014 ; 9.615]$ & $5.50 \mathrm{E}-01$ & $1873|0| 0$ & $508423|109| 0$ & 0.00011 \\
\hline COVID19 positive hospitalized vs COVID19 negative or unknown & IFNGR1 & M3 & $<1 \%$ & $0.651[0.149 ; 2.841]$ & $5.70 \mathrm{E}-01$ & $2084|1| 0$ & $534532|433| 0$ & 0.0004 \\
\hline COVID19 positive hospitalized vs COVID19 negative or unknown & IFNL2 & M3 & $<1 \%$ & $1.481[0.380 ; 5.766]$ & $5.70 \mathrm{E}-01$ & $2082|3| 0$ & $534408|557| 0$ & 0.00052 \\
\hline COVID19 positive hospitalized vs COVID19 negative or unknown & IFNB1 & M3 & $<1 \%$ & $0.828[0.423 ; 1.623]$ & $5.80 \mathrm{E}-01$ & $2011|7| 0$ & $524038|2186| 3$ & 0.00208 \\
\hline COVID19 positive hospitalized vs COVID19 negative or unknown & IFNG & M1 & $<1 \%$ & $0.364[0.011 ; 12.464]$ & $5.80 \mathrm{E}-01$ & $1873|0| 0$ & $508453|79| 0$ & 0.00008 \\
\hline COVID19 positive hospitalized vs COVID19 negative or unknown & JAK2 & M3 & $<1 \%$ & $0.850[0.481 ; 1.503]$ & $5.80 \mathrm{E}-01$ & $2075|10| 0$ & $532245|2714| 6$ & 0.00255 \\
\hline COVID19 positive hospitalized vs COVID19 negative or unknown & IL4R & M1 & $<1 \%$ & $1.931[0.154 ; 24.219]$ & $6.10 \mathrm{E}-01$ & $1937|1| 0$ & $517553|179| 0$ & 0.00017 \\
\hline COVID19 positive hospitalized vs COVID19 negative or unknown & PDCD1 & M3 & $<1 \%$ & $0.367[0.005 ; 29.373]$ & $6.50 \mathrm{E}-01$ & $1873|0| 0$ & $508473|59| 0$ & 0.00006 \\
\hline COVID19 positive hospitalized vs COVID19 negative or unknown & IL17A & M1 & $<1 \%$ & $0.364[0.004 ; 35.613]$ & $6.70 \mathrm{E}-01$ & $1873|0| 0$ & $508492|40| 0$ & 0.00004 \\
\hline COVID19 positive hospitalized vs COVID19 negative or unknown & IL23A & M1 & $<1 \%$ & $0.365[0.002 ; 57.511]$ & $7.00 \mathrm{E}-01$ & $1873|0| 0$ & $508494|38| 0$ & 0.00004 \\
\hline COVID19 positive hospitalized vs COVID19 negative or unknown & ACE2 & M1 & $<1 \%$ & $0.392[0.002 ; 61.868]$ & $7.20 \mathrm{E}-01$ & $1873|0| 0$ & $508485|44| 3$ & 0.00005 \\
\hline COVID19 positive hospitalized vs COVID19 negative or unknown & IL1RAP & M3 & $<1 \%$ & $1.272[0.349 ; 4.641]$ & $7.20 \mathrm{E}-01$ & $2083|2| 0$ & $534386|579| 0$ & 0.00054 \\
\hline COVID19 positive hospitalized vs COVID19 negative or unknown & IL4R & M3 & $<1 \%$ & $1.534[0.147 ; 16.057]$ & $7.20 \mathrm{E}-01$ & $2017|1| 0$ & $526039|188| 0$ & 0.00018 \\
\hline COVID19 positive hospitalized vs COVID19 negative or unknown & PDCD1 & M1 & $<1 \%$ & $0.367[0.002 ; 83.673]$ & $7.20 \mathrm{E}-01$ & $1873|0| 0$ & $508492|40| 0$ & 0.00004 \\
\hline COVID19 positive hospitalized vs COVID19 negative or unknown & CSF2 & M3 & $<1 \%$ & $0.368[0.001 ; 136.635]$ & 7.40E-01 & $1873|0| 0$ & $508491|41| 0$ & 0.00004 \\
\hline COVID19 positive hospitalized vs COVID19 negative or unknown & BTK & M1 & $<1 \%$ & $0.363[0.001 ; 230.098]$ & $7.60 \mathrm{E}-01$ & $1873|0| 0$ & $508505|27| 0$ & 0.00003 \\
\hline COVID19 positive hospitalized vs COVID19 negative or unknown & IFNGR1 & M1 & $<1 \%$ & $0.807[0.145 ; 4.481]$ & $8.10 \mathrm{E}-01$ & $2084|1| 0$ & $534629|336| 0$ & 0.00031 \\
\hline
\end{tabular}




\begin{tabular}{|c|c|c|c|c|c|c|c|c|}
\hline COVID19 positive hospitalized vs COVID19 negative or unknown & ACE2 & $\mathrm{M} 3$ & $<1 \%$ & $0.944[0.582 ; 1.533]$ & $8.20 \mathrm{E}-01$ & $2079|2| 4$ & $532861|1626| 478$ & 0.00241 \\
\hline COVID19 positive hospitalized vs COVID19 negative or unknown & CCR5 & M1 & $<1 \%$ & $0.939[0.521 ; 1.690]$ & $8.30 \mathrm{E}-01$ & $2077|8| 0$ & $532508|2453| 4$ & 0.0023 \\
\hline COVID19 positive hospitalized vs COVID19 negative or unknown & CCR5 & $\mathrm{M} 3$ & $<1 \%$ & $0.939[0.521 ; 1.690]$ & $8.30 \mathrm{E}-01$ & $2077|8| 0$ & $532508|2453| 4$ & 0.0023 \\
\hline COVID19 positive hospitalized vs COVID19 negative or unknown & IL1RAP & M1 & $<1 \%$ & $1.281[0.142 ; 11.540]$ & $8.30 \mathrm{E}-01$ & $1872|1| 0$ & $508333|199| 0$ & 0.0002 \\
\hline COVID19 positive hospitalized vs COVID19 negative or unknown & CSF2 & M1 & $<1 \%$ & $0.370[0.000 ; 6631.170]$ & $8.40 \mathrm{E}-01$ & $1873|0| 0$ & $508515|17| 0$ & 0.00002 \\
\hline COVID19 positive hospitalized vs COVID19 negative or unknown & IL17RC & M1 & $<1 \%$ & $1.113[0.317 ; 3.899]$ & $8.70 \mathrm{E}-01$ & $2083|2| 0$ & $534378|587| 0$ & 0.00055 \\
\hline COVID19 positive hospitalized vs COVID19 negative or unknown & IL17A & $\mathrm{M} 3$ & $<1 \%$ & $0.885[0.140 ; 5.608]$ & $9.00 \mathrm{E}-01$ & $1872|1| 0$ & $508249|283| 0$ & 0.00028 \\
\hline COVID19 positive hospitalized vs COVID19 negative or unknown & $\mathrm{C} 5$ & $\mathrm{M} 3$ & $<1 \%$ & $0.984[0.670 ; 1.445]$ & $9.30 \mathrm{E}-01$ & $2059|26| 0$ & $529016|5928| 21$ & 0.00558 \\
\hline COVID19 positive hospitalized vs COVID19 negative or unknown & IL6R & M3 & $<1 \%$ & $1.089[0.143 ; 8.291]$ & $9.30 \mathrm{E}-01$ & $2084|1| 0$ & $534746|219| 0$ & 0.0002 \\
\hline COVID19 positive hospitalized vs COVID19 negative or unknown & IL17RA & $\mathrm{M} 3$ & $<1 \%$ & $1.009[0.713 ; 1.429]$ & $9.60 \mathrm{E}-01$ & $2052|33| 0$ & $527528|7417| 20$ & 0.00697 \\
\hline COVID19 positive hospitalized vs COVID19 negative or unknown & IL33 & $\mathrm{M} 3$ & $<1 \%$ & $0.988[0.649 ; 1.505]$ & $9.60 \mathrm{E}-01$ & $2063|22| 0$ & $529239|5720| 6$ & 0.00536 \\
\hline COVID19 positive hospitalized vs COVID19 negative or unknown & IFNB1 & M1 & $<1 \%$ & $0.987[0.470 ; 2.070]$ & $9.70 \mathrm{E}-01$ & $1946|7| 0$ & $515284|1741| 2$ & 0.00169 \\
\hline COVID19 positive hospitalized vs COVID19 negative or unknown & IL33 & M1 & $<1 \%$ & $0.993[0.652 ; 1.513]$ & $9.70 \mathrm{E}-01$ & $2063|22| 0$ & $529265|5694| 6$ & 0.00533 \\
\hline COVID19 positive hospitalized vs COVID19 negative or unknown & IFNL2 & M1 & $<1 \%$ & $0.992[0.240 ; 4.100]$ & $9.90 \mathrm{E}-01$ & $2083|2| 0$ & $534469|496| 0$ & 0.00046 \\
\hline
\end{tabular}

